A Voice without a Veto: Consensus-Building through Inclusion of Stakeholders

by

\title{
Kira Pronin
}

Master of Economics, University of Bergen, 2008

Submitted to the Graduate Faculty of the Dietrich School of Arts and Sciences in partial fulfillment of the requirements for the degree of

\section{Doctor of Philosophy}

University of Pittsburgh 


\section{UNIVERSITY OF PITTSBURGH \\ DIETRICH SCHOOL OF ARTS AND SCIENCES}

This dissertation was presented

by

Kira Pronin

It was defended on

November 24, 2020

and approved by

B. Guy Peters, Ph.D., Department of Political Science

Jonathan Woon, Ph.D., Department of Political Science

Jae-Jae Spoon, Ph.D., Department of Political Science

Michael MacKenzie, Ph.D., Department of Political Science

Jennifer Murtazashvili, Ph.D., GSPIA 
Copyright (C) by Kira Pronin

2020 


\title{
A Voice without a Veto: Consensus-Building through Inclusion of Stakeholders
}

\author{
Kira Pronin, $\mathrm{PhD}$ \\ University of Pittsburgh, 2020
}

This thesis studies whether including a broad group of stakeholders in policy advisory commissions helps build consensus. It may seem that including interested parties with conflicting preferences would increase conflict, but advisory commissions reach unanimity with a surprisingly high frequency. I propose two reasons why diversity can increase agreement. First, ideologically diverse parties from a variety of backgrounds can produce a greater variety of policy-relevant knowledge, increasing the valence of a proposal. Second, in a diverse commission, a proposal without broad appeal will lead some commission members to issue dissenting opinions, which reduce the government's willingness to follow the majority recommendation. I show in a formal model that both of these factors help increase consensus by incentivizing commission members to coordinate on a policy recommendation that all actors weakly prefer to the government's outside option. To test the model's predictions, I use a novel, hand-collected data set of 2,705 Swedish commissions of inquiry that completed their inquiries between 1990 and 2018. Swedish governments appoint commissions for all significant legislative initiatives, so the data minimize selection bias. As the theory predicts, I find that increasing stakeholder representation in broadly representative commissions increases consensus. The last chapter of this thesis studies the preconditions that make it possible for this institution to flourish. These may explain variation in the appointment of broadly representative commissions under different governments. 


\section{Table of Contents}

Preface ...............................

1.0 Introduction . . . . . . . . . . . . . . . . . . . 1

1.1 Research Questions . . . . . . . . . . . . . . . . . . . . . 1

1.2 Research Methodology and Main Claims . . . . . . . . . . . . . 5

1.3 Main Contributions and Organization of Study . . . . . . . . . . . . 6

2.0 Scope of Inquiry and Literature Review . . . . . . . . . . . . . 8

2.1 Scope of Inquiry: Policy Advisory Commissions . . . . . . . . . . . . 8

2.2 Literature Review . . . . . . . . . . . . . . . . . . . . . . . 10

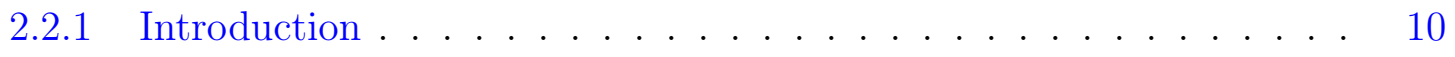

2.2.2 Prior literature on advisory commissions . . . . . . . . . . 11

2.2.3 Prior literature on informational theories of legislative committees . 16

2.2.4 Contribution to other literatures . . . . . . . . . . . . . 18

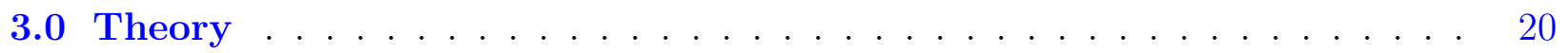

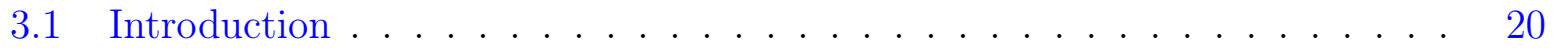

3.2 Theoretical Framework: Principal-Agent Models of Delegation . . . . . . . 23

3.3 Description of the Model; Behavioral and Informational Assumptions . . . 26

3.3.1 Description of the model . . . . . . . . . . . . . . . 26

3.3 .2 What the model does not include . . . . . . . . . . . . . 31

3.4 Collective Choice Mechanism . . . . . . . . . . . . . . . . . . 32

3.5 Behavioral Outcomes . . . . . . . . . . . . . . . . . . 33

3.6 Summary of the Theoretical Framework . . . . . . . . . . . . 35

4.0 Formal Model . . . . . . . . . . . . . . . . . . . . . . . . . 37

4.1 Setup: Players, General Sequence of Play, and Preferences _ . . . . . . . 37

4.2 Uncertainty . . . . . . . . . . . . . . . . . . . . . . . . . 39

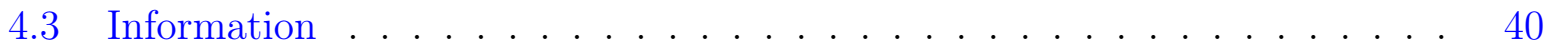

4.3 .1 Generalizable information . . . . . . . . . . . . 40 
4.3 .2 Policy-specific information . . . . . . . . . . . . . . . . . 41

4.4 Sequence of Events . . . . . . . . . . . . . . . . . . . . 41

4.5 Solving the Game . . . . . . . . . . . . . . . . . . . . 42

4.5.1 Last stage: the government's policy decision . . . . . . . . . . 43

4.5.2 Commission's recommendation and the decision to support or dissent 47

4.5.3 Decision on policy to research . . . . . . . . . . . 48

4.5.4 Government's appointment decision . . . . . . . . . . . . . . 49

4.6 Empirical Predictions . . . . . . . . . . . . . . . . . . . . . . . . . 49

5.0 Empirical Design and Results . . . . . . . . . . . . . . . . 52

5.1 Case Selection, Sampling, and Data Collection . . . . . . . . . . . . 52

5.2 Case Context . . . . . . . . . . . . . . . . . . . . . 56

5.3 Variables . . . . . . . . . . . . . . . . . . . . . 61

5.3 .1 Dependent variables $\ldots \ldots \ldots \ldots \ldots \ldots$

5.3 .2 Independent variables $\ldots \ldots \ldots \ldots \ldots \ldots$

5.3 .3 Control and selection variables . . . . . . . . . . . . . 63

5.3 .4 Descriptive statistics . . . . . . . . . . . . . . . . . . 68

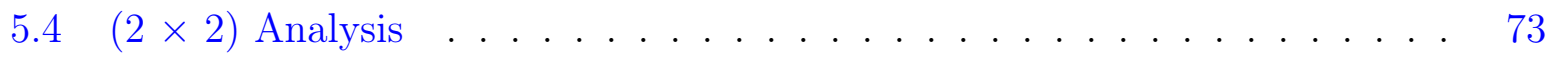

$5.5 \quad$ Empirical Models . . . . . . . . . . . . . . . . . . . 74

5.5 .1 Empirical challenges . . . . . . . . . . . . . . . . 74

5.5.2 Adjusting for nesting: a multilevel probit model . . . . . . . . 75

5.5.3 Adjusting for selection and commission size: a bivariate probit with a correction for commission size . . . . . . . . . . . 76

5.6 Results from the Multilevel Probit . . . . . . . . . . . . . . . . . . . 79

5.7 Results from the Bivariate Probit . . . . . . . . . . . . . . 84

5.8 Discussion and Conclusions . . . . . . . . . . . . . . . . 86

6.0 The Decline of Parliamentary Commissions and the Role of Politicians 89

6.1 Introduction and Sample Selection _ . . . . . . . . . . . . . . . 89

6.2 Trends in Appointments, Membership, Report Volumes, and Dissent . . . . 92

6.2.1 New commission appointments and report volumes . . . . . . . 92

6.2 .2 Membership composition . . . . . . . . . . . . . . 96 
6.2 .3 Policy areas . . . . . . . . . . . . . . . . . . . . . 103

6.3 Theory: Factors Affecting the Government's Appointment Decision . . . 105

6.4 Consequences: No Decline in Latent Dissent but Less Dissent in Reports . 108

7.0 Conclusions, Policy Implications, and Future Work . . . . . . . . . . 115

Appendix A. Proofs . . . . . . . . . . . . . . . . . . . . . . . 118

Appendix B. Description of Data and Codebook . . . . . . . . . . . . . 120

B.1 Membership Data File . . . . . . . . . . . . . . . . . . . . . 120

B.1.1 Population . . . . . . . . . . . . . . . . . . . . 120

B.1.2 Members . . . . . . . . . . . . . . . . . . . . . 121

B.1.3 Variables . . . . . . . . . . . . . . . . . . . . . . 122

B.1.4 Codebook . . . . . . . . . . . . . . . . . 123

B.2 Inquiry Data File . . . . . . . . . . . . . . . . . . . . . 126

B.2.1 Population; inclusion and exclusion criteria . . . . . . . . 127

B.2.2 Variables. . . . . . . . . . . . . . . . . . . 127

Bibliography . . . . . . . . . . . . . . . . . . . . . . 129 


\section{List of Tables}

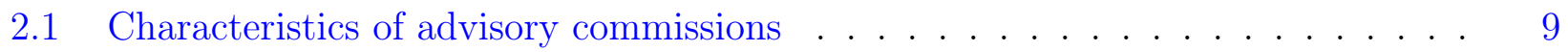

3.1 Member types . . . . . . . . . . . . . . . . . . . . . . . . . . . 29

3.2 Generalizable and policy-specific information . . . . . . . . . . . 31

5.1 Sample selection . . . . . . . . . . . . . . . . . . . . 54

5.2 Governments . . . . . . . . . . . . . . . . . . . 54

5.3 Member categories . . . . . . . . . . . . . . . . . 56

5.4 Commissions of inquiry vs. special investigator inquiries . . . . . . . . . . 60

5.5 Dependent variables . . . . . . . . . . . . . . . . . . . . . 62

5.6 Independent variables $\ldots \ldots \ldots \ldots \ldots \ldots \ldots$

5.7 Control $/$ selection variables . . . . . . . . . . . . . . . . . . 65

5.8 Summary statistics for representative commissions _ . . . . . . . . . . . . 69

5.9 Summary statistics for expert inquiries (expert commissions) _ . . . . . . . 69

5.10 Shares of types of interest groups, commissions and spec. inv. . . . . . . . . . 72

5.11 Ten most frequent interest groups . . . . . . . . . . . . . . . . . . . . 72

5.12 Policy areas by type of inquiry $\ldots \ldots \ldots \ldots$

5.13 Individual dissent by inclusivity and inquiry type . . . . . . . . . . . . . 74

5.14 Predicted signs of coefficients for Model $(5.1) \ldots \ldots \ldots \ldots$

5.15 Predicted sign of coefficient for Model $(5.2) \ldots \ldots \ldots \ldots$. . . . . . 77

5.16 Predicted signs of coefficients for Model $(5.3) \ldots \ldots \ldots \ldots$

5.17 Multilevel probit model; DV: presence of dissent, cluster robust SE . . . . . . 80

5.18 Multilevel probit; DV: presence of dissent, cluster robust SE . . . . . . . . . 81

5.19 Group variables . . . . . . . . . . . . . . . . . . . . . . . 82

5.20 Probit model, DV: Repr. commission(=1), cluster robust SE . . . . . . . . 85

5.21 Probit by inquiry type, cluster robust $\mathrm{SE} \ldots \ldots \ldots \ldots$. . . . . . . 87

5.22 Correlation with estimated probability of an individual dissent . . . . . . . 88

5.23 Summary of results . . . . . . . . . . . . . . . 88 
6.1 Sample selection . . . . . . . . . . . . . . . . . . . . . . . . . . . 91

6.2 Governments . . . . . . . . . . . . . . . . . . . . . . . . . . . 92

6.3 Types of policy advisory inquiries, $1990-2016 \ldots \ldots \ldots$

6.4 Types of commissions and special investigator inquiries, 1990-2016. Sample: 2,088 new policy advisory commissions and special investigator inquiries ap-

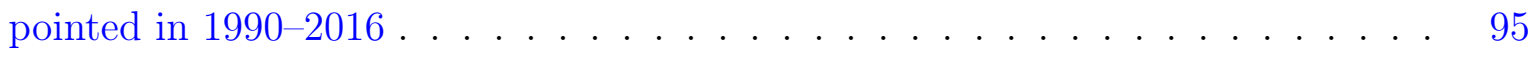

6.5 Shares of experts, stakeholders, politicians, and judges in new commissions and special investigator inquiries, $1990-2016 \ldots \ldots \ldots \ldots$

6.6 Shares of bureaucrats, interest groups, politicians, academics, and judges in new appointed commissions and special investigator inquiries, 1990-2016 _. . . . . 101

6.7 Policy areas by government, Carlsson II-Löfven I cabinets (includes all policy inquiries appointed in 1990-2016) . . . . . . . . . . . . . . . . . . 104

6.8 Presence and shares of reservations and dissenting opinions, 1990-2016 _ . . . 110

6.9 Nr reservations and dissenting opinions by member type . . . . . . . . . . . 111

B.1 Commission and inquiry-level variables . . . . . . . . . . . . . . . . . . 122

B.2 Member-level variables . . . . . . . . . . . . . . . . . . . . . . . . . . . . 122

B.3 Ministries . . . . . . . . . . . . . . . . . . . . . . . . . . 123

B.4 Membership classification . . . . . . . . . . . . . . . . . . . 125

B.5 Inquiry-, commission-, and government-level variables . . . . . . . . . . . 127

B.6 Policy areas . . . . . . . . . . . . . . . . . . . . . . . . . 127 


\section{List of Figures}

3.1 Policy conflicts among the commission members and the government . . . . . . 27

3.2 Policy conflict and shared valence benefit . . . . . . . . . . . . . 28

3.3 Theoretical framework . . . . . . . . . . . . . . . . . 36

6.1 Shares of types of policy inquiries, 1990-2016. From Dahlström, Lundberg and

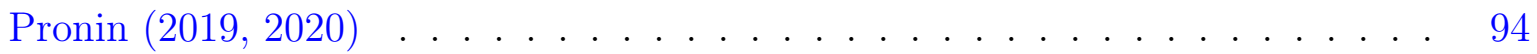

6.2 Number of published SOUs, 1990-2018. Population sample $(N=3,516)$ of all published SOUs in 1990-2018, with long-term economic forecasts (Långtidsutredningen) and five SOU reports missing from all archives excluded . . . . . . . 97

6.3 Shares of experts, stakeholders, politicians, and judges in new commissions and

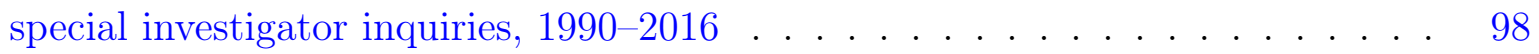

6.4 Shares of bureaucrats, interest groups, politicians, academics, and judges in new commissions and special investigator inquiries, 1990-2016 . . . . . . . . . 99

6.5 Presence and share of reservations and special comments in inquiry reports, 19902018. Sample includes SOUs in 1990-2018 $(N=2,705)$. . . . . . . . . . 109 


\section{Preface}

I thank my supervisor, B. Guy Peters, and committee members Michael MacKenzie, Jennifer Murtazashvili, Jae-Jae Spoon, and Jonathan Woon, for their advice and support. I also thank the following people for offering helpful comments or for assistance in coding the data: Despina Alexiadou, Love Christensen, Carl Dahlström, Ove Knekt, Anne-Kathrin Kreft, Erik Lundberg, David McCoy, Patrik Marier, Garen Markarian, Morgan Medvedz, PerOla Öberg, Laura Paler, Aníbal Pérez-Liñán, Jon Pierre, Yuriy Podvysotskiy, G.S. Prasser, Oskar Rydén, Jordan Tama, and the members of the Comparative Political Science Reading Group. I also received valuable suggestions from participants at the EITM 2019 Summer Institute at the University of Houston, and especially from the following faculty members: Gail Buttorff, Francisco Cantú, Doug Dion, Jim Granato, Sebastian Saiegh, and M. C. Sunny Wong. I also received valuable feedback from the EUREX group in Oslo. I am grateful for external financial support from the American Scandinavian Foundation and from the National Science Foundation EITM Program and for the internal financial support at the University of Pittsburgh from European Studies Center (ESC), the University Center for International Studies, and the Office of the Provost. I am also indebted to the University of Gothenburg and Uppsala University, which provided me with office space and resources during my fieldwork stay. 


\subsection{Introduction}

\section{$1.1 \quad$ Research Questions}

Reaching broad agreement on collective decisions is essential to democratic rule yet difficult to achieve. This is true about forming a government, getting a bill through a polarized legislature, making decisions at faculty meetings, and even choosing a restaurant between a group of friends.

Governments seeking broad agreement on particularly important or controversial policy initiatives sometimes appoint ad hoc, independent commissions to provide policy formulation advice. ${ }^{1}$ Such commissions are usually broadly representative and include both third-party experts and interested parties, often in a deliberately bipartisan or counterbalanced fashion (Cartwright, 1975, 62-63,102-103). In many consensus democracies, they are used routinely for large-scale reforms or otherwise significant policy initiatives. They are purely advisory, and their output is a consensus report with research findings and policy recommendations. The report may also contain reservations and dissenting opinions if the commission fails to come to consensus.

This dissertation investigates whether receiving advice from such commissions helps governments develop policies with widespread support and, if so, through what mechanism. In addition, I present conditions under which governments are more likely to appoint broadly representative advisory commissions. Variation in these conditions may explain why such commissions are more common in some countries and time periods and rare in others.

It may be surprising that governments would expect a group of people representing political and societal interests from many sides of an important or controversial issue to deliver a unanimous policy recommendation. The veto player theory of Tsebelis $(1995,1999$,

\footnotetext{
${ }^{1}$ These type of advisory commissions are known by various names, such as commissions of inquiry, Royal commissions, governmental commissions, and public inquiries. In the United States, blue ribbon commissions and presidential commissions serve a similar purpose (Rowe and Mcallister, 2006). Commissions of inquiry can also be appointed to investigate political scandals or large-scale accidents, and in some countries, there are even permanent commissions dedicated to an important policy area, such as agriculture or nuclear energy. However, my focus is on ad hoc, temporary commissions providing advice to the government in the policy formulation stage of the legislative process.
} 
2002) implies that adding more players to a collective decision-making body makes it difficult to move away from the status quo. A broadly representative commission would then at best be a means of delaying a decision, a possibility that many commentators have raised (Stigler, 1963; McEachern, 1987). Even in a setting without veto players, social choice theory would suggest that increasing the number of members with different goals would lead to gridlock or internal conflict (Arrow, 1950, 1951).

Interestingly, advisory commissions have largely avoided these pitfalls. In a study of British Royal commissions from 1800 to 1969, Cartwright $(1975,181)$ reports that commissions have delivered unanimous recommendations nearly 50 percent of the time. Similarly, Swedish commissions of inquiry of have reached unanimity around 43 percent of the time (Petersson, 2016). For an eight-member commission, a 43 percent unanimity rate implies that a randomly chosen commission member would have a 90 percent chance of supporting the recommendation, an astoundingly high level of agreement. ${ }^{2}$

The incongruity of these observations with social choice and veto player theory presents a puzzle. A possible explanation could be that governments stack commissions with likeminded members. Stigler $(1963,21)$ raises this possibility and argues from personal experience that it is not unusual. On the other hand, Cartwright (1975) suggests that deck-stacking is rare and that commission members are usually selected in a deliberately counterbalanced fashion (Cartwright, 1975, 62-63 and 102-103). ${ }^{3}$

A second and opposite possibility is that advisory commissions serve as a check on special interests. McEachern (1987) discusses this possibility and contrasts it with a deck-stacking model in the tradition of Stigler (1963). However, he finds little empirical evidence for a pure public interest explanation.

In what follows, I offer a third possibility: that the institutional features of advisory commissions make them well suited for producing consensus, especially if they are sufficiently inclusive of different interests. In contrast to a deck-stacking or a public interest model, the institutional theory I present endogenously determines the circumstances under which a

\footnotetext{
${ }^{2}$ If there is a 90 percent probability that a randomly chosen commission member supports a proposal, then the probability of getting all successes on eight independent trials would be $0.9^{8}=0.43$.

${ }^{3}$ Interests will be carefully balanced: the right professional and administrative groups; Scotland and Wales; the north and the south; women and men; the left and the right, though the representatives of each generally come from the middle of the political road (Donnison $(1968,558)$, cited in Cartwright $(1975,75))$.
} 
government would appoint a broad, ideologically diverse commission. The theory predicts that, all else equal, consensus will increase in ideological diversity. This contrasts sharply with a deck-stacking model, in which ideological diversity is harmful or a sham, and with a public interest model, in which a commission's ideological composition is irrelevant.

A central feature of the theory is that commissions are purely advisory and do not make the final policy decision. This means that the government considers the commission's recommendation but also potential alternatives, including those that have come up during the inquiry. By stating reservations or dissenting opinions, minority members can try to steer the government away from the policy recommendation and toward an alternative. This (limited) ability of dissenters to influence the government incentivizes the commission members to moderate their demands. Another central feature of the theory is that commissions produce policy valence, which can serve as a basis for compromise.

Naturally, other factors, such as political culture and supporting institutions, also play an important role in whether advisory commissions reach consensus (see, e.g., Anton, 1969). However, there are good reasons to look for an institutional explanation (in the tradition of Shepsle, 1979; Shepsle and Weingast, 1987) of why advisory commissions are more consensual than social choice theory would predict. ${ }^{4}$ For example, in a study of ad hoc commissions in the United States and United Kingdom, Bulmer (1981) finds that Royal commissions and presidential commissions have produced bipartisan agreement on controversial issues more frequently than select committees of the House of Commons or U.S. congressional committees. Furthermore, the policy issues that governments assign to advisory commissions, such as health care reforms and storage of nuclear waste, are often controversial even in the most consensus-oriented societies. This suggests that the institutional features of advisory commissions may be an important determinant of their ability to bridge ideological divisions.

Before describing the theoretical and empirical setting in more detail, I first provide some background on the prevalence and structure of the advisory commissions.

Advisory commissions have a long history of use in different time periods and under various forms of government. McEachern (1987) notes that George Washington appointed

\footnotetext{
${ }^{4}$ For two general overviews of institutional theories and of theories of institutions, see Peters (1996) and Diermeier and Krehbiel (2003).
} 
the first advisory commission in the United States (in 1794) to help determine how to address the Whiskey Rebellion. In Britain, Royal commissions of inquiry date back as far as the Domesday Book (commissioned by William the Conqueror and published in 1086), and their current form was adopted in 1517 (Clokie and Robinson, 1937; Lockwood, 1967). ${ }^{5}$ They are common in other Westminster democracies and Commonwealth countries as well, dating to 1861 in Canada (Inwood and Johns, 2014) and to 1819 in Australia (Prasser, 2003, 67). However, they are also common in monarchies and consensus democracies with (neo)corporatist interest group politics (Siaroff, 1999), such as Denmark, the Netherlands, Norway, and Sweden, where their use dates to the early seventeenth century, well before modern parliamentary democracy (Hesslén, 1927). For example, Hesslén (1927) found that there were 531 commissions appointed between 1855 and 1904 in Sweden (before the transition to full democracy, with parliamentarianism arriving in 1917 and women's suffrage in 1921).

Despite the variety of government structures and time periods in which advisory commissions have been used, there are some common features. Advisory commissions are usually appointed by the government or head of state on an ad hoc basis to provide advice on formulating policies that are controversial or particularly significant in nature (see Salter, 2003; Rowe and Mcallister, 2006; Marier, 2009). Their members consist of third-party experts, civil servants, and stakeholders representing different political and societal interests and, in some countries, politicians from both the government and opposition parties (see the discussion in Christiansen et al., 2010; Tama, 2014). They are appointed for a limited time period but have a high degree of independence from the government and both the judicial and legislative branches. Their output is a report containing a policy recommendation, but dissenting members are usually allowed to express their concerns and opposition in the form of reservations and dissenting opinions.

\footnotetext{
${ }^{5}$ Royal commissions are no longer in common use; the last one delivered its report in 2000 . However, departmental committees of inquiry, which are similar, are still appointed (Prasser, 2003, 66). The main difference between the two is that Royal commissions are appointed by the Home Secretary (historically, by the Crown), while departmental commissions can be appointed by any minister (Cartwright, 1975, 7-31).
} 


\subsection{Research Methodology and Main Claims}

I incorporate these common features of advisory commissions into a theoretical model, from which I derive and test empirical implications. That is, I use the Empirical Implications of Theoretical Models (EITM) approach (Aldrich, Alt and Lupia, 2008; Granato, Lo and Wong, 2010).

The model treats advisory commissions as providing information about potential policies, with bargaining occurring within the commission. The framework builds on the models of legislative committees by Gilligan and Krehbiel (1987, 1989, 1990), with three important departures. Most crucially, because the commission delivers a report, which may contain dissenting opinions, I do not limit attention to the commission's median voter and its final recommendation. Second, I allow for information to be imperfectly substitutable across policies. This gives commission members the ability to provide research that is more relevant to some proposals than to others, resulting in different policies having different valence (Stokes, 1963; Londregan, 2000; Hirsch and Shotts, 2012). ${ }^{6}$ Third, I allow the government to choose any policy after receiving the report. That is, there is no possibility of a closed rule (as discussed in Baron and Ferejohn, 1989), because the commission is not formally part of the legislature. Instead, the setting is closer to the veto-based delegation model of Mylovanov (2008), in which a principal delegates a decision provisionally to a better-informed agent but retains its veto power.

To test the empirical implications of the model, I use a unique, hand-collected data set of 2,705 Swedish commissions of inquiry that published their reports during the years 19902018. The use of advisory commissions in Sweden is widespread, but as I discuss, there are important variations over time in the extent to which the government has included politicians and stakeholders on their commissions. Because nearly all major legislation in Sweden is prepared by an advisory commission of some kind, using Swedish data allows me to control for selection issues while holding culture and other variables fixed.

My main finding is that including policy stakeholders in commissions increases consensus. Consistent with the findings of the model, the data suggest that stakeholders can use

\footnotetext{
${ }^{6}$ As in Hirsch and Shotts (2012), valence is operationalized as reduction in policy uncertainty.
} 
their specialized knowledge to increase the valence of particular policies, and they can use their ability to dissent to incentivize other commission members to moderate their demands. Because valence is a general benefit, commission members (and governments) are willing to trade some of their ideological preferences in exchange for supporting a policy with greater valence. One can therefore say that commission members have both coalition and blackmail potential (Sartori, 2005) through their abilities to create valence and to dissent. A related finding is that governments are more likely to appoint broadly representative commissions when political polarization is high. These results presuppose that there is policy uncertainty and that none of the political actors are ideologically extreme. This suggests that advisory commissions are less useful for resolving purely ideological or distributional conflicts.

\subsection{Main Contributions and Organization of Study}

This study contributes to the literature of commissions of inquiry and similar advisory bodies by providing an integrated theory of advisory commissions and their appointment. The theory explains why ideologically diverse, broadly representative advisory commissions have often been successful in reaching consensus and when governments would appoint such commissions. Previous research has identified relative autonomy from political pressure, incorporation of nonpartisan technical expertise, publicness, and the inclusion of interested parties as common features of institutions that facilitate broad agreement (Martin, 2013; Prasser, 2003, 14). I expand this literature by presenting a potential mechanism of how the incorporation of technical expertise and the inclusion of policy stakeholders promote consensus. With the exception of a few studies (e.g., Johansson (1992); Hermansson (1993)), previous literature has provided few theoretical explanations of how the government selects commission members (McEachern, 1987) and how their membership composition affects the inquiry outcome (Prasser, 2003, 34). This study fills this gap. In addition, I analyze two features of advisory commissions, the combined effects of which have not been considered in the committee decision-making literature: the separation of policy analysis from the decisionmaking power and the ability to write dissenting opinions. Finally, I use the model to derive 
additional predictions about the government's appointment decision, which could be used in future research.

This study may also provide insight about the design of deliberative institutions (Martin, 2013) and help clarify the theoretical connection between consensus democracy and the institutionalized participation of interest groups in the governmental policy-making process, which is still not completely understood (Giuliani, 2016). Additionally, this study contributes to the political methodology literature by introducing a correction to probit estimation, providing an estimate of the probability of an individual success (or failure) from the fitted probabilities of a group success (or failure).

This study is organized as follows. Chapter 2 provides a definition of advisory commissions and a literature review. Chapter 3 presents an informal overview of the theory. Chapter 4 presents the formal model and its empirical implications. Chapter 5 describes the empirical design, variables, and formal hypotheses to be tested as well as the empirical results. Chapter 6 analyzes trends in commission membership and dissent patterns in Sweden from 1990 to 2016 in light of the theoretical predictions. Finally, Chapter 7 concludes with a discussion of implications of the results and topics for further research. 


\subsection{Scope of Inquiry and Literature Review}

\subsection{Scope of Inquiry: Policy Advisory Commissions}

This study focuses on policy advisory commissions (or advisory commissions for short), a subset of commissions of inquiry, Royal commissions, public inquiries, and blue ribbon commissions. These are special ad hoc bodies set up by a government or head of state to provide advice on specific policy problems, usually during the policy formulation stage of the legislative process.

There are also special inquiry or investigative commissions, which investigate particular events, such as political scandals, large industrial accidents, or controversial historical events. These are not strictly advisory and may have judicial powers. They have been studied elsewhere (e.g., Peachment, 2006; Sulitzeanu-Kenan, 2006; Farson and Phythian, 2010; Sulitzeanu-Kenan, 2010; Sulitzeanu-Kenan and Holzman-Gazit, 2016; Prasser, 2014) and will not be discussed further in this study.

Governments also appoint commissions for political reasons, such as shifting blame and delaying action on controversial issues (Stigler, 1963; Lockwood, 1967; McEachern, 1987; Marier, 2009). These topics are also outside the scope of this study.

Advisory commissions have several features that differentiate them from other types of committees and policy preparation bodies. These are summarized in Table 2.1.

First, advisory commissions are ad hoc, temporary bodies appointed for a specific task and cease to exist when their assignment is complete. Second, advisory commissions are established and funded by the executive government, which also defines their terms of reference. These describe what issues the commission is to examine and the date by which the inquiry should be completed. The government can usually dismantle a commission before its assignment is complete, although this may be politically costly. By contrast, investigative commissions cannot be dissolved before they have completed their inquiry. Third, although commissions are attached to a ministry, they are not formally part of a government agency, department, or a permanent advisory body but function as an independent body. Fourth, 
Table 2.1: Characteristics of advisory commissions

1. Nonpermanent, ad hoc bodies assigned for a specific task.

2. Established and funded by the executive government, which also defines the commission's terms of reference.

3. Independent organizational units, not formally part of a government agency, department, or permanent advisory body.

4. Members include representatives from outside the public service and government, such as third-party experts and policy stakeholders, generally in a bipartisan or counterbalanced pattern.

5. Advisory powers only.

6. Output is a report, instead of a majority vote.

7. Appointment, decision-making, and reports more public and open relative to other policy preparation bodies.

commissions engage a wider set of actors (e.g., third-party experts and representatives of interest groups) in the process of deliberating and formulating policy than is typical in the legislative process. Fifth, commissions have advisory powers only. Sixth, their output is a consensus report with policy recommendations, instead of a decision based on majority vote. However, this report may include reservations or dissenting opinions/minority reports if there is a dissenting minority. Seventh, commissions are generally more public than other governmental institutions: their appointment is publicly announced, their processes of inquiry are relatively open and inclusive (e.g., through public hearings or press releases), and their reports are made available to the general public. 


\section{$2.2 \quad$ Literature Review}

\subsubsection{Introduction}

In an early study on commissions of inquiry, Gosnell (1934) lays out a series of questions that have been debated for nearly a century but are still not completely resolved: what is the purpose of advisory commissions and their role in the policy-making system, how are they different from other policy preparation bodies and governmental committees, which factors drive their appointment, how is their membership selected, how do they use scientific evidence, how are their findings received by the public, do they build consensus, do their reports influence policy, and what are the effects of reservations and minority reports by dissenting minorities? Some of these questions have been more thoroughly answered, while others have received less attention.

There is broad agreement in the literature that advisory commissions are a unique institution of government, distinct from other types of governmental committees and policy preparation bodies (Cartwright, 1975, 7), and that they serve two purposes, which are the primary reasons for their appointment. The first is to provide independent expertise on a specific policy initiative for policy formulation purposes. The second is to appease interested parties and to establish a basis for compromise (Bulmer, 1983; Marier, 2009). Many studies also point out that there can be partisan reasons for appointing commissions, such as shifting blame, delaying a difficult decision, and increasing support for government policies (Bulmer, 1983; Marier, 2009). Several studies also note their remarkably high rate of unanimous recommendations (Cartwright, 1975; Tama, 2014; Petersson, 2016, 181).

However, much of the existing research is descriptive, with limited conceptual or theoretical development (Prasser, 2003, 45). In particular, the literature lacks an integrated institutional theory (Diermeier and Krehbiel, 2003) of advisory commissions, which would describe conditions under which governments are more likely to appoint advisory commissions; how their ability to provide policy-relevant information and to represent a wide variety of interests relates to their ability to reach consensus; and how consensus, or the lack of it, affects the government's decision to implement the commission's recommendation (although 
see McEachern, 1987). This study fills this gap. In addition, to my knowledge, no previous studies (with perhaps the exception of Johansson (1979)) have examined the effects of reservations and dissenting/minority opinions on the government's choice of policy.

In Subsection 2.2.2, I provide a more thorough overview of the state of the literature on advisory commissions and how this study contributes to this literature.

Several other research streams, though not primarily about advisory commissions, are also closely related. The literature on informational theories of legislative bargaining, in particular, combines the two main themes I address - that of gaining expertise and of negotiation among parties with different policy preferences. As noted above, an important institutional difference between legislative committees and advisory commissions is that legislative committees are typically majoritarian and issue a single recommendation to the parent body. This means that some of the bargaining aspects of legislative committees can be studied by focusing on their median voter, whereas advisory commissions can include minority reports with dissenting opinions or reservations. Understanding the findings from informational theories of legislative bargaining can, therefore, highlight the roles of these institutional differences between legislative committees and advisory commissions, and their similarities in purpose. I discuss this literature in Subsection 2.2.3.

There is also literature specific to consensus democracies and to the Swedish case in particular. The findings from this literature, along with some findings on interest group corporatism, are helpful in interpreting the data I use in the main empirical analyses in subsequent chapters. I discuss this literature in Subsection 2.2.4.

\subsubsection{Prior literature on advisory commissions}

The older literature on advisory commissions consists mostly of descriptive and historical studies; good summaries of these can be found in Cartwright (1975), Prasser (2003), and Rowe and Mcallister (2006). Prior literature also includes discussions of their overall role in the policy process and reasons for their appointment (Rowe and Mcallister, 2006; Marier, 2009), investigations of whether their recommendations result in policy change or are accepted by the public (Inwood and Johns, 2014, 2018), and analyses of to what extent 
they rely on academic experts or use scientific research in formulating policy (Bulmer, 1981, 1983; Sheriff, 1983; Marier, 2009; Christensen and Holst, 2017; Christensen and Hesstvedt, 2019).

In terms of the role of commissions in the policy process, Gosnell (1934) observes that commissions are used to provide expertise about policy options and to serve as a platform for bargaining among different interests. According to Hesstvedt and Christiansen (2020), most of the prior research on advisory commissions can be divided into two streams based on which one of these roles is emphasized. Thus one stream of the literature emphasizes their role as an expert body and the other their role as an arena for negotiation and compromise seeking among competing interests.

A second observation, implicit in Gosnell (1934), though not explicitly discussed, is that advisory commissions have unusually high levels of consensus. Out of the 33 British Royal commissions studied by Gosnell, ranging in size from 10 to 23 members, there were 7 in which there was at least one dissent and 5 in which there was at least one reservation. This would imply that at least 64 percent of commission recommendations had unanimous support (more if some commissions had both reservations and dissents) and an individual level of support of at least 93 percent. Similarly high levels of consensus are also reported by Cartwright (1975) and Tama (2014), who study British Royal commissions and U.S. blue ribbon commissions, respectively. There is, however, no systematic theory that explains how the dual nature of commissions is related to their ability to reach consensus, although Rustow (1955), Anton (1969), and Petersson (2016) discuss the key role of advisory commissions in Sweden's rationalistic and consensus-oriented policy-making system.

Research on the role of commissions as expert bodies ${ }^{1}$ has often focused on a single or small group of countries or on a collection of commissions addressing a given policy issue. Many of these conclude that the independent expertise provided by advisory commissions had contributed to the acceptance of their findings. For example, investigating pension commissions in France, the United Kingdom, and Sweden, Marier (2009) concludes that commissions help governments learn about policy issues, that they increase insight about the

\footnotetext{
${ }^{1}$ A general statement on the informational role of commissions is in Hogwood and Peters (1985, 6386), who describe commissions as vehicles for governments to obtain research and assistance in formulating policies.
} 
consequences of different policies, and that "their research publications - but not necessarily their recommendations - are widely accepted by all major policy actors as ... accurate and impartial." In a comparison of U.S. and U.K. experiences with commissions, Bulmer (1981) similarly observes that, despite institutional differences, the analyses of commissions are generally held in high regard.

A second major focus of prior research has been the role of commissions as negotiating bodies. Much of this research focuses on consensus democracies with neocorporatist interest group politics and the commissions' central role in this system. For example, in a much-cited study of Swedish commissions of inquiry, Anton (1969) describes them as an arena of negotiation and consensus building between the government, the opposition, and peak interest groups within a highly integrated, open, deliberative, and rationalistic policy-making system. Other studies use the number of commissions or their share of interest group members to measure decline in corporatism and its causes and consequences. For example, Binderkrantz and Christiansen (2015) compares the number of seats on Danish advisory commissions offered to interest groups in 2010 with the corresponding number in 1975 (which Öberg et al. (2011) identifies as the peak of corporatism). They find that the distribution of seats to interest groups is essentially unchanged, with the main difference being that fewer commissions were formed in 2010 than in 1975, but that more interest groups were incorporated into those commissions that did form. They conclude that the use of commissions in bargaining has adapted rather than vanished. Hermansson, Svensson and Öberg (1997) reach a similar conclusion about Sweden. Öberg (2016), however, suggests that the shifts away from involving fewer, larger organized interests have been accompanied by an increase in professional lobbying. The implications for consensus are unclear, though Petersson (2016) claims that the shift toward shorter time frames in which Swedish commissions can finish their work has resulted in a move away from a consensus-seeking system to a short-term trial-and-error approach.

Some possible connections between commissions' dual purposes and their ability to bring about consensus are discussed in Prasser (2003), who gives an in-depth analysis of several Australian cases. Prasser $(2003,14)$ concludes that commissions can be consensual, not just internally but in terms of the broad acceptance of their policy proposals, because they are 
public in nature. Their transparency makes the information commissions provide more trustworthy. This may justify the claim in Bulmer (1981) that reports from advisory commissions are held in higher regard than research from other policy advisory bodies. Prasser (2003) can therefore be read as saying that if commissions appear impartial in the information they provide, they face less political resistance. He does not provide details of the underlying mechanism of this connection or circumstances under which this pressure is likely to be stronger or weaker, however. On the other hand, being public may require incorporating comments and concerns from various stakeholders and affected parties. Cartwright (1975, 75 and 181) gives a similar interpretation of commissions, viewing their consensual nature as being tied to the trustworthiness of their information and the tendency to appoint interest group representatives who "generally come from the middle of the political road," that is, members who are not overtly ideological. Tama $(2014,2016)$ similarly states that a commission that is ideologically balanced is able to convey that its proposal is widely acceptable. If the a bipartisan commission reaches consensus, their proposal can become a focal point for policy change.

Many studies, going back to at least Gosnell (1934) and Donnison (1968), have also discussed the importance of the membership composition of advisory commissions (also see Cartwright (1975) for descriptive statistics for British Royal commissions and Hesslén (1927), Meijer (1956), Hermansson (1993), and Johansson (1992) for descriptive statistics for Swedish commissions of inquiry). However, Prasser (2003) remarks that prior research has not provided a theoretical connection between the membership characteristics of a commission and its inquiry outcomes. A notable exception is Niskanen (1971), who argues that important characteristics in developing public trust are that commission members do not have strong incentive to perpetuate their work and do not seem to be a form of interest group capture. In this way, the temporary, ad hoc nature of commissions makes them less valuable for partisan purposes than standing commissions would be, and including a heterogeneous set of interest groups would be important to gaining public support for their recommendations. In an attempt to explain the high share of consensual reports, Bulmer (1981) argues that the high regard in which commission reports are held creates internal pressure to reach consensus, as unanimous reports are more difficult to dispute. In a study of interest group representa- 
tion on the boards of government agencies, Öberg (2002) suggests a deliberative mechanism might be in play and argues that the inclusion of organized interests in the policy-making process increases trust among the parties involved and leads organized interests to moderate their demands.

Although many studies have described the circumstances under which governments appoint commissions, few quantitative studies have evaluated the political conditions that lead to commission appointments. A recent effort in this direction is Hesstvedt and Christiansen (2020), whose random effects model finds that minority and coalition governments in Denmark and Norway are more likely to appoint commissions. Older work on Swedish commissions of inquiry (Tingsten, 1940; Meijer, 1956) has similarly described the usefulness of commissions as a policy-making tool to weak minority governments.

It is difficult to determine whether commission proposals are actually implemented, because the amount of time between receiving a report and passing legislation can vary, a point that Gosnell (1934) observes. Nevertheless, Marier (2009), Inwood and Johns (2014), Inwood and Johns (2018), Tama (2014), and Tama (2016) all find evidence that commissions influence policy change. In a rare quantitative study linking membership composition and the later legislative fate of the bill, Hermansson (1993) shows that bills prepared by broadly representative commissions encounter less resistance in parliamentary committees and pass by a higher vote margin.

Last, to the best of my knowledge, there are no theoretical studies of how the minority reports with dissenting opinions and reservations affect commission outcomes and the government's likelihood of adopting their recommendations, although (Johansson, 1979) states that dissenting opinions and reservations can lead the government to abandon its plans for policy change or to order another inquiry.

To recap, there is a general understanding that advisory commissions have a dual role in providing independent expertise and serving as a platform for negotiation. The literature lacks a unified theory connecting this dual nature to the high rate of consensus found in commissions and to the government's decision to appoint broadly representative commissions. Similarly, although there are studies of commission membership characteristics, there is no general theory explaining the link of commission membership to their high rate of consen- 
sus. From an institutional viewpoint, there is also a gap in that there is, to the best of my knowledge, no work explaining how the advisory nature of commissions and the ability of dissenters to issue minority reports can affect commission outcomes (although some pieces of the puzzle are in Tama, 2014, 2016). Finally, the understanding of the connections between political context and commission appointment is still limited, as Hesstvedt and Christiansen (2020) point out.

\subsubsection{Prior literature on informational theories of legislative committees}

Although the institutional setting of advisory commissions differs from that of legislative committees, there are some important similarities. Both involve the government delegating authority, and as Rowe and Mcallister (2006) point out, this means the government surrenders some control of the policy agenda in exchange for obtaining expertise. Epstein and O'Halloran (1994) provides a principal-agent model of bureaucratic delegation and argues that if the legislature has ex post agenda control (as is certainly the case when appointing an advisory commission), it is more inclined to cede authority to a committee. Hammond and Knott (1996) approach a similar question of under what circumstances the legislature (or other branch) is willing to delegate and find that the answer depends in part on the wider political context, specifically on the interactions among the various branches of government. More recently, Mylovanov (2008) models delegation to an agent, in which the principal can veto the agent's proposal. This is similar to the problem studied here, except that in the case of delegation to an advisory commission, a government does not precommit to a default option in advance but can and does condition its proposal on what it learns from the commission's research.

Other literature on legislative committees focuses less on the decision to appoint and more on what impact the committee's work has on the legislature's decision, and how this impact may depend on the committee's makeup. This literature commonly works in a cheap-talk setting (based on Crawford and Sobel, 1982), in which important concerns are

how forthcoming committee members are with their private information and how much information committee members are willing to exert effort gathering (see Austen-Smith and 
Riker, 1987, on this point as well). Krehbiel (1991) argues that ideological diversity is a mechanism for making a committee's message credible, a point that Tama (2014) notes.

The legislative committee model of Gilligan and Krehbiel (1990), and its two predecessors (Gilligan and Krehbiel, 1987, 1989), addresses issues closely related to those in the present study. They find that legislatures may benefit from including preference outliers on committees, provided that the preference outliers are not too extreme. Importantly, the legislature and the committee members cannot reap the full benefits of committee member expertise. The reason is that legislators can use the information the committee provides to promote their own ideological ends. The need to use an open rule (which always arises with advisory commissions) limits the degree to which the government can promise ideological shifts in exchange for better-informed policies.

Hirsch and Shotts (2012) extend the Gilligan-Krehbiel model by introducing the idea of policy-specific information. Policy-specific information provides policy-relevant information about the consequences of policies. However, this information is useful only in implementing a particular policy and cannot therefore be appropriated by the legislators to implement a different policy. The model shows that when information is transferable, a closed rule can induce committee specialization, but that, when information is policy-specific, an open rule is superior for inducing specialization. In the present setting, the implication of Hirsch and Shotts (2012) is that commissions gain the ability to bargain with the government if they have members who are capable of providing information about the specific details associated with particular proposals.

The benefit from information that Gilligan and Krehbiel (1990) and Hirsch and Shotts (2012) study is a valence benefit, based on Stokes (1963). That is, it is a benefit that is not directly tied to the spatial preferences of the committee members or the government. The key difference is that policy-specific information is bundled with the policy's expected location. In both cases, the valence benefit is a public good, which is not always the case with policy valence.

Londregan (2000) studies a purely private valence benefit, which the government can receive if certain conditions are met. His focus is the democratic transition of Chile, in which the private benefit is in the form of guarantees to an authoritarian government in exchange 
for ceding power to democratic successors. In the present setting, a private valence benefit to the government may come from assurances of broad support for a policy the government is considering adopting. In this way, although both Londregan (2000) and Hirsch and Shotts (2012) introduce valence benefits into legislative bargaining, their nature as private or public goods differs. To the best of my knowledge, no prior work has separated the distinct ways in which private and public valence benefits affect the ability to reach consensus.

\subsubsection{Contribution to other literatures}

By focusing on specific features of commissions of inquiry, there are necessarily some aspects that are abstracted away. These factors can play an important role in whether commissions reach consensus, whether they influence policy, and their overall role in the political system.

In the case of Sweden, advisory commissions have a long historical legacy, which likely has important effects on how they are used and perceived today. Both Hesslén (1927) and Meijer (1956) report that commissions were in use in the seventeenth century, well before the introduction of parliamentary democracy, and that there is a long tradition of having them prepare all significant bills and policy reforms. Petersson (2016) points out that commissions are used in part because Swedish ministries have less capacity than ministries in most Western democracies. Anton (1969) discusses the central place of commissions in providing an arena for negotiation between the government, the opposition, and peak interest groups in Sweden's highly centralized and neocorporatist policy-making system. Lindvall et al. $(2017,2020)$ point out that Sweden has been governed by minority governments for nearly a century, which has made it necessary to develop ways to appease the opposition and interested parties. These considerations may indicate that the use of advisory commissions is thoroughly entrenched in the Swedish political practice and that short-term contextual factors play a lesser role in their appointment than in other countries.

These observations coincide with general remarks in Anton (1969) on Swedish political culture. Anton describes the political culture of Sweden as deliberative, rationalistic, open, and consensual. In this view, the inclusion of stakeholders and opposition party members 
may reflect the general openness, and the ability to reach unanimity may be due to an intrinsic preference for consensus that is common to the Swedish political culture. These observations present a challenge to the current study's emphasis on institutional features as creating pressure for inclusion and to its focus on consensus arising for instrumental reasons.

It should be noted, however, that even the proponents of a cultural explanation of the consensual nature of Swedish commissions also point to instrumental factors. For example, Tingsten (1940), Meijer (1956), Premfors (1983), and Lindvall et al. (2017, 2020) observe that the importance of commissions increased considerably during the 1920s. Meijer (1956) attributes this to the presence of "very weak minority governments," similar to the recent findings by Hesstvedt and Christiansen (2020) on Denmark and Norway. The Scandinavian cultures may value consensus and inclusion, but if inclusion depends heavily on a government's weakness, instrumental motives are likely to be important. The similarity in rates of consensus in Scandinavia to those that Cartwright (1975) reports for the United Kingdom further suggests that some features particular to advisory commissions, independent of the political setting, help them reach unanimity.

Öberg (2002) finds that trust among organized interests, if not between the public at large and the government, is promoted by the inclusion of stakeholders in the administrative boards in government agencies. In this interpretation, it is the inclusivity and (neo)corporatist nature of commissions that fosters the political culture Anton (1969) observes, rather than the other way around. 


\subsection{Theory}

\subsection{Introduction}

This chapter presents an informal overview of the theory developed in Chapter 4 . The theory establishes a link between three main aspects of advisory commissions and their ability to find widely acceptable policy proposals.

The first aspect I focus on is the dual nature of advisory commissions as both bargaining platforms and expert panels, which has been highlighted in many studies of advisory commissions. The important consequence of this dual nature is that each commission member evaluates potential policies on two dimensions: the fit of a policy with the member's policy preferences $^{1}$, and benefits of policies in terms of shared value (known as valence since Stokes, $1963)$.

Stokes (1963) noted that, in an election, there are two kinds of issues that voters care about. The first type includes issues on which voters and parties can organize themselves spatially on a policy space, such as the traditional left-right dimension. The second type includes valence issues on which all voters are in broad agreement, such as candidate honesty and integrity, and on which political parties cannot realistically take opposing positions. In elections where valence issues are particularly salient, voters would then evaluate a party's competence based on whether the party would most effectively bring about a goal or quality embodied by the valence issue. In practice, most policy issues likely contain elements of both, as Londregan $(2000,21)$ points out: most policy issues, no matter how consensual, contain divisive elements, and most policy issues, however divisive, contain some elements on which different parties can find agreement.

In the spirit of Londregan (2000), in the theoretical model political actors care about both positional and valence issues. That is, commission members and the government evaluate policies based on their position on an unidimesional policy space (which can be thought as the traditional left-right dimension) as well as on a valence dimension representing shared

\footnotetext{
${ }^{1}$ Or, the policy preferences of the groups that the member represents.
} 
value. On the position dimension, commission members may disagree with each other and the government about which policies are best. By contrast, on the valence dimension, all parties agree what makes a better policy.

As in the legislative committee model of Hirsch and Shotts (2012), I operationalize valence as a reduction in policy uncertainty of particular policies. In the model, therefore, the function of the valence is to reduce undesirable side effects of potential policy options. This a mathematically convenient, but not the only possible way to operationalize valence. However, alternative operationalizations of valence would result in similar conclusions. ${ }^{2}$

By evaluating policy preferences and valence jointly, the commission creates incentives for its members to find ways to move closer together. ${ }^{3}$ In this way, the theory develops insight into the design of policy-making institutions that encourage deliberative negotiation (as described in Warren and Mansbridge, 2013).

The second central aspect I focus on is that commissions are purely advisory. A commission can have its recommendation adopted only if it persuades the government that the proposed policy has high valence or is close to the government's policy preferences. This need to persuade reinforces the commission members' incentive to demonstrate valence of the proposed policy and that this valence does not carry over to other policy options. To the extent that the valence of a commission's recommendation is specific to a certain policy option, the government cannot easily use the commission's research to implement other policies.

In this way, valence (if policy-specific) determines what a commission has to offer the government. On the other side of the table, governments vary in their willingness to bargain. A weak government may have a strong need for a consensus recommendation because consensus indicates that the policy has widespread support (similar to the private valence benefits discussed in Londregan, 2000). A stronger government, on the other hand, may benefit less from a consensus recommendation and may therefore be more inclined to cling to its policy preferences.

\footnotetext{
${ }^{2}$ Also note that, as in Stokes (1963), valence can also be of negative quality. In other words, improved information related to policy implementation may reveal universally negative consequences of a policy option and lessen support for that policy options.

${ }^{3}$ The temporary, ad hoc nature of advisory commissions also weakens their ability to bargain by logrolling. If the commission makes only one recommendation, there is less room to trade favors. See Niskanen (1971).
} 
In general, the government's benefit from a consensus recommendation has two opposing effects on the commission's ability to reach an agreement. If the government does not benefit substantially from a consensus recommendation, the commission will be able to implement only proposals that are relatively close to the government's ideological preference. This puts pressure on commission members to moderate their demands, but the required concessions may be greater than the commission members are willing to make. On the other hand, if the government stands to gain substantially from receiving a consensus recommendation, it has little bargaining power. This makes it easier for the commission to find a proposal that the government would accept but also makes it easier for dissenting commission members to find alternative policies that are also acceptable to the government, potentially dissuading the government from accepting the commission's majority proposal.

This ability of dissenters to discourage the government from implementing a majority recommendation is the third main aspect of the theory. Members of advisory commissions can issue dissenting opinions and reservations, which may contain alternative policy recommendations. Their concerns and suggestions are included in the final report to the government and can potentially discourage the government from adopting the majority recommendation. The commission's majority, therefore, needs to take the threat of dissents into account, creating pressure on the members of the majority to moderate their demands in order to avoid dissent. $^{4}$

To make the argument more complete, it is important to consider the government's decision of whether to appoint a broad, inclusive advisory commission. The government's main alternative is to appoint a narrow panel of experts to prepare policy. From the government's viewpoint, one approach is not universally better than the other. The advantage of appointing a panel of experts is that the government has some control over the policy preferences of the appointees. An advisory commission, if sufficiently inclusive, will include some members who are ideologically distant from the government and from each other. The advantages of appointing a broad, inclusive advisory commission are that the members' ideological differ-

\footnotetext{
${ }^{4}$ Gosnell $(1934,108)$ provides an example of an attempt by the Department Committee on Royal Commissions to abolish minority reports. This attempt was unsuccessful, and after its recommendation, with subsequent commissions sometimes having dissenting reports from a single member. Gosnell pointedly states, "As long as British political institutions remain democratic, [dissents] are to be expected."
} 
ences create pressure to find proposals that have high valence, and the ability of members to dissent creates incentives for commission members to moderate their ideological stances. When deciding which type of body to appoint, the government weighs how much thrust it expects to gain in valence against how much drag it expects from making policy concessions.

The model is not intended as an exhaustive description of all of the forces that contribute to consensual outcomes or governments' willingness to appoint broadly representative commissions. A government and an advisory body (whether an expert panel or broad, inclusive advisory commission) are subject to pressures beyond the ones I consider here. The significance of the aspects of commissions studied here in bringing about consensus is new to the literature, and I argue below that these features are important conceptually and empirically. ${ }^{5}$ Some other factors are incorporated in a reduced form, as the government's private benefit from or need for consensus. As I note above, this private benefit alone is not sufficient to generate consensus but is an important determinant of the amount of pressure on commission members to make ideological concessions and of the willingness of the government to accept a proposal that is imperfectly aligned with its ideology. In this way, the government's private benefit can be thought of as summarizing the weight and lift on the commission. The value of this benefit can vary depending on the political context and culture.

\subsection{Theoretical Framework: Principal-Agent Models of Delegation}

This section describes the theoretical framework used in the formal model. A reader familiar with principal-agent models may skip this section and proceed to Chapter 4, which presents the formal model. The empirical implications of the model are presented in subsection 4.6, and Chapter 5 presents the empirical models and results.

The theory describes a setting in which the government delegates the initial stages of policy formulation to an external body. That body can be a panel of experts or a broader

\footnotetext{
${ }^{5}$ As discussed above, previous research has identified other features of commissions that may also be important factors in their ability to negotiate broad compromise on policy issues. For example, Prasser (2003) and Tama (2014) argue that the independence, publicity, perceived objectivity, and bipartisan nature of commissions allows them to generate more credible policy proposals that can serve as focal points for compromise.
} 
advisory commission that includes stakeholders and, possibly, members of opposition parties. Abstractly, the government is thought of as a principal, hiring an agent to do some work on its behalf.

In other words, the model is based on a standard principal-agent model of delegation. Such models are used in political science as a parsimonious description of strategic interaction between two or more actors in a hierarchical relationship. They are common in studies of bureaucratic delegation (Epstein and O'Halloran, 1994; Hammond and Knott, 1996), democratic transition (Londregan, 2000), electoral accountability (Barro, 1973; Ferejohn, 1986), and legislative committees (Gilligan and Krehbiel, 1987, 1989, 1990; Kiewiet and McCubbins, 1991; Hirsch and Shotts, 2012).

A basic element of principal-agent models of delegation is that the principal appoints an agent to complete some action on his or her behalf, but the agent is motivated to act according to his or her own best interests. A common way to operationalize this conflict of interest is to place the preferred policy positions (ideal points) of the principal and agent on a line (or a policy space, in the spirit of Downs, 1957), where each point represents a different policy option or outcome. The distance between the ideal points of the principal and the agent then represents the amount of policy conflict (or ideological distance) between the two. As this distance increases, the agent has a stronger desire to take actions that lead to policy outcomes that the principal does not like.

The model in Chapter 4 includes several agents (commission members) and one principal (the government), with each actor having his or her own ideal points. The distance between the agents' ideal points then means that they must negotiate with each other before giving a joint policy recommendation.

Policy choices, however, rarely have perfectly anticipated outcomes. The uncertainty governments face over their policy choices creates the need for expertise. A typical modeling choice is to operationalize uncertainty about outcomes by assuming that a policy proposal has a commonly known expected result but that the actual outcome includes this expected result plus one or more random variables, called policy shocks. These shocks are usually assumed to come from either a uniform or a normal distribution, and I follow this convention, assuming normality throughout. 
It is usually also assumed that the agents have an informational advantage over the principal. As a source of expertise, an agent might be tempted to provide information when doing so is to the agent's advantage, and to keep silent otherwise. While this issue of withholding or providing misleading information is clearly important, it has already been studied extensively (examples include Austen-Smith and Riker, 1987; Gilligan and Krehbiel, 1987, 1989, 1990; Battaglini, Lai and Wang, 2019), and I do not pursue the topic here. Instead, I limit attention to the value of expertise in providing policy valence, by benefiting risk-averse decision makers. To the extent commission members can provide expertise that reduces the risk associated with a particular proposal, they can use their research as a basis for compromise, an idea raised in Hirsch and Shotts (2012).

Principal-agent models are useful for focusing on the important aspects of the theory developed below, but they have their limitations. A common criticism is that they ignore the wider policy-making environment and cases where there is no obvious policy conflict between the principal and the agent(s) (Anton, 1969; Mitnick, 1992; Waterman and Meier, 1998). In addition, Mitnick (1992) has criticized principal-agent models as too static because information and policy conflicts are treated as constants, with little change over time or across settings. In the theory presented below, policy conflict is likely to exist, and the membership, policy conflicts, and information are all allowed to vary across commissions. To keep the model tractable, the political context and policy-making environment are represented through a parameter representing the government's preference for broad consensus, but this can vary with the current political or cultural context.

The next section describes the model's extensions of the standard principal-agent framework in more detail. 


\subsection{Description of the Model; Behavioral and Informational Assumptions}

\subsubsection{Description of the model}

The model is an extension of the standard principal-agent model of delegation described above. In the model, the government has a preferred policy outcome in mind but lacks knowledge about its desirability to stakeholders and how to choose the right policy option to get to the desired outcome. For generalizability, the model abstracts from the reasons why the government prefers some policies over others.

The following is a sketch of the main features of the model: the government appoints an advisory commission and delegates policy formulation power to it. The commission members the government chooses can be any mixture of experts, stakeholders, or politicians. The commission researches different policy options and, in doing so, reduces uncertainty about the consequences of these policy options. The commission then issues a report to the government, which includes a policy recommendation. If some of the commission's members oppose the recommendation, they may express dissenting opinions, possibly including alternative policy recommendations, as part of the report. The government receives the report and then makes the final decision about policy. The government is not restricted to choosing the commission's recommendation, alternative recommendations, or the status quo. For example, the government can learn from the commission's report and try to apply the results to other policies when making its decision.

The model extends the standard principal-agent framework in the following ways:

\section{Policy conflict among commission members}

Each member appointed to the commission $N$ has his or her their own ideal point. This contrasts with standard models of legislative committees (such as Gilligan and Krehbiel, $1987,1989,1990)$, in which the committee is thought of a single agent, corresponding to its median voter. The importance of dissents in advisory commissions prevents me from making this standard simplification. Instead, the model incorporates policy conflict among 
the commission members, in addition to the policy conflict between the the government and some or all of the commission's membership.

As an illustration, Figure 3.1 depicts a government with an ideal point $\left(x_{G}\right)$ and a commission with three members $(\mathrm{A}, \mathrm{B}$, and $\mathrm{C})$ with ideal points $\left(x_{A}, x_{B}\right.$, and $x_{C}$, respectively). There is policy conflict between the government and each of the members and policy conflict among the three members. The severity of policy conflicts increases in the ideological diversity of the commission.

Figure 3.1: Policy conflicts among the commission members and the government
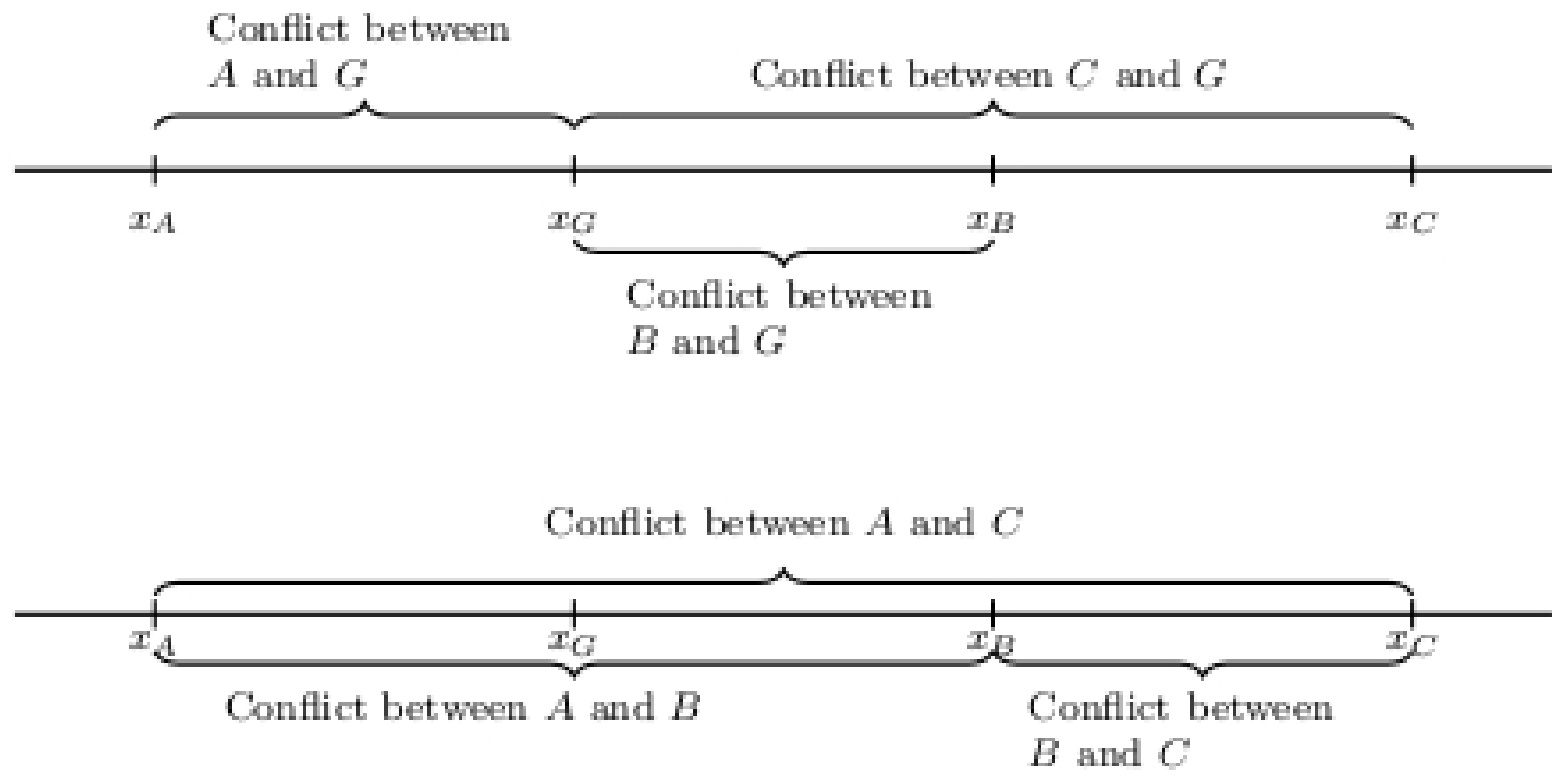

\section{Policy valence}

As discussed in Section 3.1, commission members and the government evaluate potential policy options based on several considerations. The first is their proximity to their ideal points. On balance, a member finds policy options which are closer to his or her ideal point more desirable than policy options which are farther from his or her ideal point. The second is the amount of policy valence a policy option has in terms of shared values. As discussed above, policy valence is operationalized as a decrease in policy uncertainty, and can be conceptualized as an improved implementability of the policy, broadly construed. For now, it may help to imagine a common value as an added policy dimension that provides 
shared valence (rather than ideology- or preference-specific valence, which may be shared only by those with similar preferences) benefitting all parties. See Figure 3.2. The figure shows two dimensions for purpose of illustrating the concept. However, in the formal model, both the ideal points and uncertainty are represented on a single policy axis.

Figure 3.2: Policy conflict and shared valence benefit

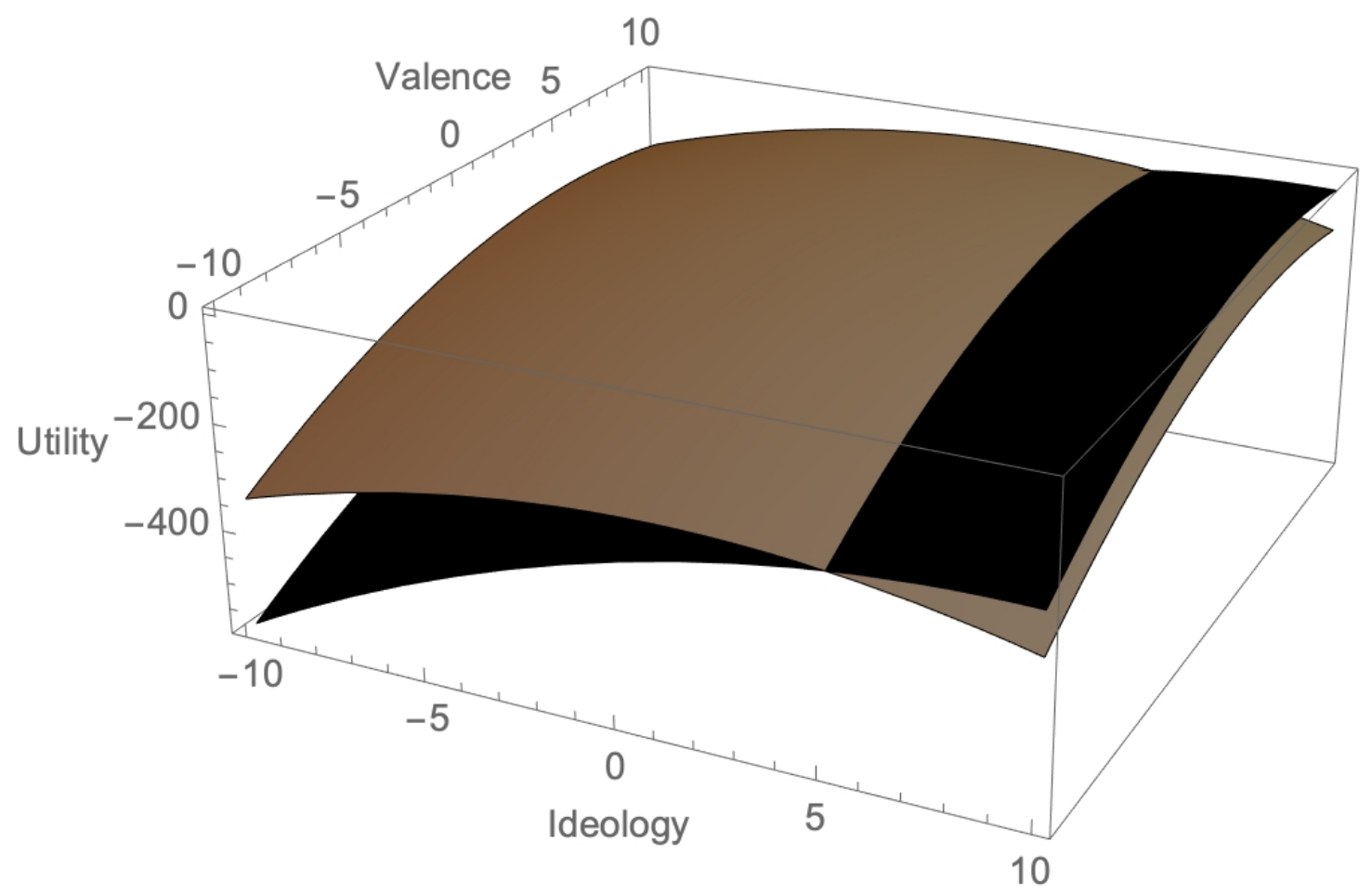

The figure depicts the utility surfaces of two commission members with different ideal points. Each values the other dimension equally. Moving from the front of the picture toward the back represents an increase in the valence direction. For both commissioners, the valence values toward the back are associated with higher utilities than those toward the front, at any given ideological value.

\section{Three types of members}

Commission members are either experts, stakeholders, or politicians. Experts, which include academics and high-level bureaucrats, have general expertise on the subject matter of the policy inquiry. ${ }^{6}$ Stakeholders, or interested/affected parties (Fung, 2013; Goodin,

\footnotetext{
${ }^{6}$ In the empirical analyses that follow, I provide a robustness check where academics and bureaucrats are separated into their own categories.
} 
2007; Shapiro, 2003), ${ }^{7}$ represent groups, organizations, or localities that are affected by the policy change and have knowledge about how different policy options will affect the groups or localities they represent. Politicians represent partisan interests but have no subject matter knowledge to contribute. ${ }^{8}$ The member types and their roles are summarized in Table 3.1.

Table 3.1: Member types

\begin{tabular}{lll}
\hline Member type & Informational role & Representative role \\
\hline Experts & Yes & No \\
Stakeholders & Yes & Yes \\
Politicians & No & Yes \\
\hline
\end{tabular}

This classification of member types is by no means the only possible one. However, it has appeared in studies of advisory commissions going back to Gosnell (1934, 93-94), who writes

Once it has been decided to appoint a commission on a given subject the next question that arises is its composition. A commission may be a small body of supposedly impartial persons, it may be a small body of experts, it may be a large body which is representative of all the main interests concerned. Most of the royal commissions appointed in the last fifteen years have been of the last-mentioned variety. The representative commissions have ranged in size from ten to twenty-three. In one sense, these commissions are more representative than committees of Parliament would be. In addition to nominees of the main political groups found in Parliament these commissions also contain delegates from the important social and economic interests concerned and scholars who have made a reputation in the field.

\section{Government receives a private benefit from consensus}

In the model, the government receives a private benefit from obtaining a consensus recommendation. The value of this benefit can vary across governments or political contexts, but I assume that it is always better for the government to obtain a consensus recommendation

\footnotetext{
${ }^{7}$ The Commission of the European Union defines an interested party as "an individual or group that is concerned about, or stands to be affected by, directly or indirectly, the outcome of a policy process; or that represents the general interest of groups concerned by such an outcome" http://ec.europa.eu/governance/docs/archives_en.htm, https://ec.europa.eu/europeaid/ european-governance-white-paper_en. Similarly, the International Standards Organization (ISO 14001, ISO 45001) defines interested parties as a "person or organization that can affect, be affected by, or perceive itself to be affected by a decision or activity."

${ }^{8}$ This assumption is made for analytical simplicity. An equivalent assumption would be that the information politicians have is always available to the government. In practice, politicians who are appointed to commissions often have relevant subject matter expertise (Cartwright, 1975; Hesslén, 1927; Meijer, 1956).
} 
than one with dissent. In addition, I assume the government values a consensus recommendation from a broadly representative commission more than a consensus recommendation from a less representative commission. These assumptions are similar to the private benefit that Londregan (2000) uses to model valence.

There can be many reasons why a consensus recommendation, especially from a broadly representative commission, is beneficial for the government. For example, legislative proposals based on consensus recommendations from broadly representative commissions may be seen as more legitimate or objective and may encounter less resistance in the legislature. A legislative proposal based on a consensus recommendation may also be less likely to be overturned by a subsequent government. Finally, behavioral norms and ongoing relationships among the political actors may dictate that important decisions should be based on broad consensus among interested parties (Anton, 1969).

\section{Two sources of uncertainty: generalizable and policy-specific}

The model includes two independent sources of uncertainty: (partially) transferable policy uncertainty (Gilligan and Krehbiel, 1987, 1989, 1990) and policy-specific policy uncertainty (Hirsch and Shotts, 2012). These are best described through an example by Hirsch and Shotts $(2012,68)$. During the Obama administration, a bipartisan group in the Senate Finance Committee planned to gather information that would improve the efficiency of Medicare reimbursements. In addition, the Senate Committee on Health, Education, Labor, and Pensions planned to gather information on efficient design of public health insurance plans. The first type of information would have improved all proposals for health policy reform irrespective of their ideological content and thus reduced generalizable policy uncertainty. The second type of information would have been useful only for reducing policy uncertainty if the public health insurance component would have been included in the proposal.

Knowledge about either source of uncertainty increases the government's ability to implement a policy successfully. However, policy-specific information provides this valence benefit only if the government selects that particular policy. To the extent that stakeholders have more specialized knowledge than experts have, or greater incentive to learn about the implementation details of specific policies, they will produce information that is more 
policy-specific. This gives stakeholders more leverage in influencing which policies the commission will recommend, reflecting the fact that, compared with experts, stakeholders' roles are more closely connected to negotiation. Nevertheless, some of the information experts produce could be at least partially policy-specific. I allow this expertise to vary in the degree to which it is transferrable.

Note that, although information reduces policy uncertainty, neither type of information is restricted to being purely technocratic in nature. In particular, because policy-specific information is intimately connected to particular policy positions, it is likely to be the type of information that Wicksell $(1896,79)$ had in mind: "Whether the benefits of the proposed activity to the individual citizens would be greater than its cost to them, no one can judge this better than the individuals themselves."

Table 3.2 summarizes the two types of information and their effects on policy valence.

Table 3.2: Generalizable and policy-specific information

\begin{tabular}{lll}
\hline Member type & Type of information & Effect \\
\hline Experts & $\begin{array}{l}\text { Generalizable (imperfectly } \\
\text { informative about } \\
\text { policy-specific information) }\end{array}$ & $\begin{array}{l}\text { Increases policy valence } \\
\text { for all policies (in varying degrees) }\end{array}$ \\
Stakeholders & Policy-specific & $\begin{array}{l}\text { Increases policy valence } \\
\text { for specific policies }\end{array}$ \\
\hline
\end{tabular}

\subsubsection{What the model does not include}

For simplicity, the model abstracts from issues of information withholding and cheap talk. These issues have been discussed extensively in previous literature, starting with AustenSmith and Riker (1987). In addition, Milgrom and Roberts (1986) give reason to suggest that complete and honest disclosure would occur: anything one party learns is something someone with opposing views can discover.

The model also differs from canonical models of bureaucratic delegation, such as Epstein and O'Halloran (1994), in that the government does not restrict the investigation to a certain area of the policy space. In other words, the model abstracts from issues of bureaucratic 
discretion. There are two reasons for this omission. First, public inquiries, or at least the types of inquiries that are most interesting from a theoretical point of view, are often given a wide mandate to investigate novel solutions to policy problems. Second, adding bureaucratic discretion to the model would muddle the effects of the government's preference for broad consensus and would not change the main results, except at the margin. Adding bureaucratic discretion would be a potential extension of the model, however.

\subsection{Collective Choice Mechanism}

The model focuses on two institutional features of advisory commissions as a collective choice mechanism: their lack of decision-making authority and the ability of commission members to include reservations and dissenting opinions in the commission's final report. There are, of course, other features of policy advisory commissions that contribute to their ability to generate consensus. These have either been discussed in previous literature (see, e.g., Prasser, 2003) or are beyond the scope of this study but would be interesting extensions for future work.

\section{The government makes a unilateral decision}

Advisory commissions have no decision-making power. Instead, their output is a report with the findings of the inquiry and one or more nonbinding policy recommendations. The government then makes the final decision about policy.

\section{Members can express reservations or dissenting opinions}

If the commission fails to reach consensus, its report may include reservations or dissenting opinions. These are similar to minority opinions in the U.S. Supreme Court, which do not create binding precedent but nevertheless provide dissenting members an influential voice. However, they differ from minority opinions in the U.S. Supreme Court in that the dissent may affect the government's willingness to implement the commission's recommendation. For example, internal dissent can signal to the government that the proposal may 
meet opposition during the later stages of legislative process or that the proposal is opposed by peak interest groups instrumental to implementing the policy. This may lead the government to abandon its plans for policy change, to order another inquiry (Johansson, 1979), or to use the information gathered during the inquiry to implement another policy.

\subsection{Behavioral Outcomes}

The model makes two main predictions. The first is that the presence of stakeholders in broad, ideologically diverse commissions can contribute to increased consensus. The second is that the government is more likely to appoint ideologically diverse commissions with policy stakeholders when there is political polarization.

Two forces contribute to the first result: coalition and blackmail potential (Sartori, 2005).

\section{Coalition potential}

By conducting policy research and increasing the stock of policy-relevant knowledge, commission members generate policy valence. If this valence is tied to implementation details of a specific proposal, it can serve as a basis for compromise, provided the commission members do not have irreconcilable ideological differences. This means that each member has coalition potential to the extent to which he or she contributes to the policy valence of the recommended policy (Sartori, 2005). As discussed above, a broadly representative commission with experts and stakeholders can produce more policy valence than a commission of experts.

\section{Blackmail potential}

Because the government has the final say and cares about consensus, commission members have an incentive to coordinate on a recommendation that both the government and the commission members find acceptable. Commission members who do not agree with the majority therefore have blackmail potential (Sartori, 2005): if they dissent, they can influence the government not to implement the majority recommendation. This threat of 
dissuading the government from adopting a policy provides the commission's members with an additional incentive to compromise. This incentive is particularly strong in a broadly representative commission with experts and stakeholders, because governments are more likely to appoint broadly representative commissions when they value consensus highly, and are therefore more likely to reject recommendations with dissents.

In sum, ideologically diverse commissions with both experts and stakeholders have more coalition and blackmail potential. Together, the coalition and blackmail potentials push commission members toward compromise.

\section{Appointment outcomes}

The model makes a counterintuitive prediction at it is often rational for the government to appoint ideologically diverse commissions with stakeholders, politicians and experts as opposed to more narrow expert commissions, because such commissions produce more policy valence, and the coalition and blackmail potential inherent in such commissions pushes the commission towards consensus. These results hold, unless the government or some of the commission members are ideologically too extreme. This is because it is difficult for a commission to produce enough valence to convince ideologically extreme members (or a government) to support the commission proposal without making too many policy concessions.

The model also predicts that governments are more likely to appoint broadly representative commissions with politicians when there is party polarization. This is because party polarization means there are more likely to be parties which are ideologically to the left and to the right of the government. This means the government can find politicians from both its left and right to appoint to the commission. Since politicians constrain the set of proposals that the commission will consider, this means that the leftmost and rightmost politicians balance each other out in the commission. However, this approach only works if there are parties to both to the left and to the right of the government. If there are potential commission members with extreme preferences only to the left and to the right, if they are appointed to the commission, they are likely to dissent, and demand excessive policy concessions from other commission members and the govenrment. In addition, there may be a point at which 
party polarization gets so extreme that compromise is no longer possible. Estimating this point would be an interesting topic for future research. This also means that commissions may be less suitable as consensus-building instititions in extremely polarized societies.

\subsection{Summary of the Theoretical Framework}

Figure 3.3 presents an overview of the theoretical framework. The top of the figure depicts contextual factors that are likely to affect the government's willingness to appoint broadly representative commissions. These include aspects of the political and economic context, such as the government's level of parliamentary support, the degree of political polarization, the nature of the policy issue, and commonly accepted norms about the inclusion of stakeholders in the policy-making process. These are not included in the formal model, except through the parameter that summarizes the government's benefit from a consensus recommendation, but I include controls for them in the empirical models. For simplicity, the figure depicts the government having to choose between a (narrowly representative) expert or a (broadly) representative commission. In the model, the government's choice of membership composition is not restricted to these two ideal types. 
Figure 3.3: Theoretical framework

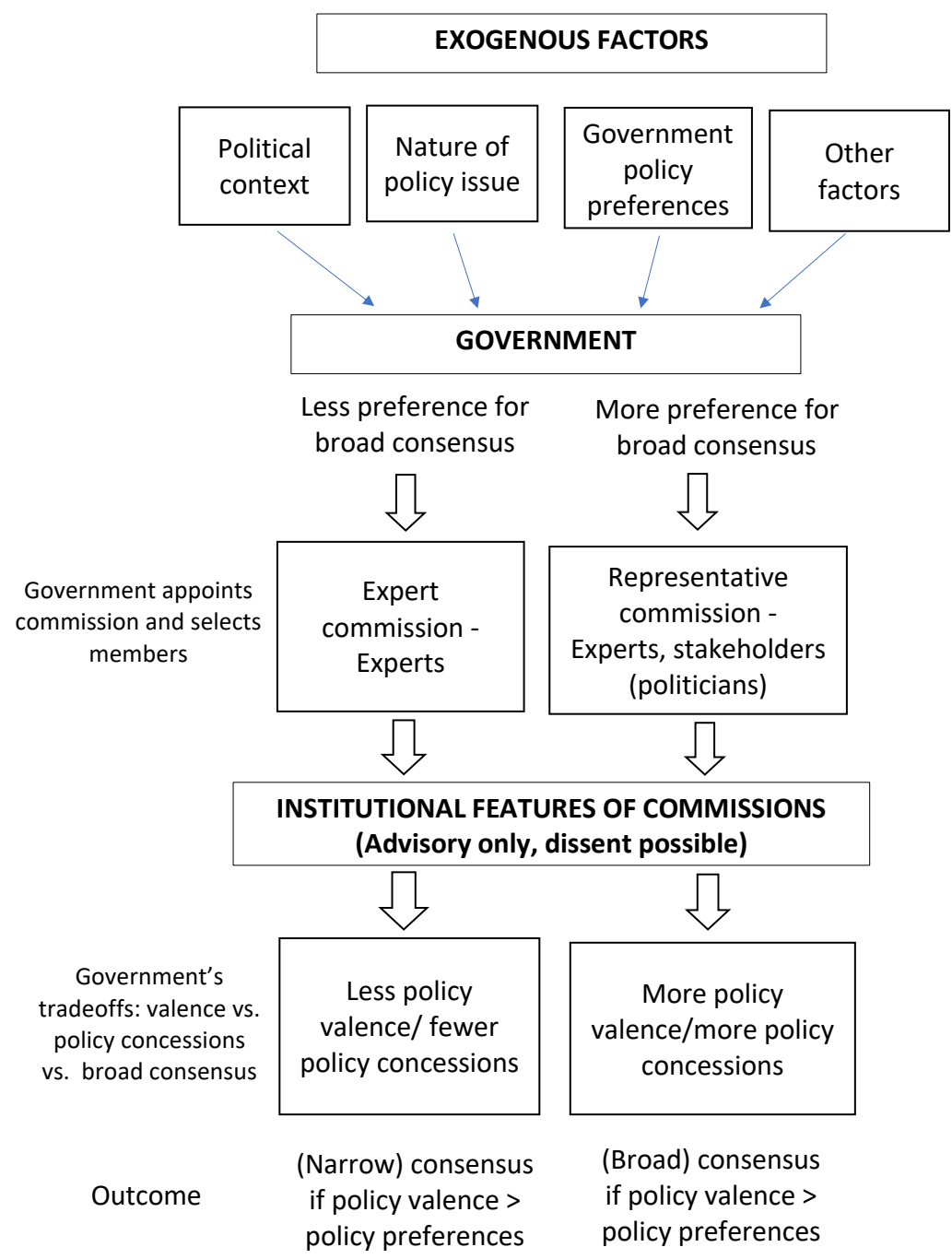




\subsection{Formal Model}

This chapter presents the formal model that is used to derive the hypotheses tested in Chapters 5 and 6 .

\subsection{Setup: Players, General Sequence of Play, and Preferences}

The game has four types of players:

- a government $G$

- a set $A$ of $n_{a}$ experts (subject matter specialists from government agencies, academics, etc.)

- a set $B$ of $n_{b}$ stakeholders (interest groups and local government employees, etc.)

- a set $C$ of $n_{c}$ politicians

The government $G$ appoints a policy advisory commission, denoted $N$, to study a policy issue with an uncertain outcome. The government is not part of the commission because it does not need to advise itself.

I do not investigate how many members of each type the government rationally appoints, as this would take me too far from my main question of the inclusion of different member types. Instead, I focus on whether the government chooses to include or exclude members of a given type. This corresponds to the observation that governments sometimes appoint broadly inclusive commissions, and at other times appoint commissions consisting mostly of one type (such as a group of experts). Accordingly, the members of the commission $N$ can include or exclude each type:

$$
N \in\{A, B, C, A \cup B, A \cup C, B \cup C, A \cup B \cup C\}
$$

The commission investigates the policy issue and recommends a policy $\tilde{x}(p)$ whose outcome is uncertain, as described below. Each player $i \in N \cup\{G\}$ has a unique ideal point $g_{i}$, 
representing the outcome that $i$ most prefers. All else equal, players get higher utility from outcomes closer to their ideal points. All players are risk averse and are thus willing to accept a policy that differs in expectation from their ideal point if, in exchange, the policy outcome is more predictable. The following expected utility function, similar to Austen-Smith and Riker (1987) and Gilligan and Krehbiel (1987, 1989, 1990), captures this tension:

$$
\begin{aligned}
E U_{i}(\tilde{x}(p)) & =-E\left[\left(\tilde{x}(p)-g_{i}\right)^{2}\right] \\
& =-\left(E\left[\operatorname{Var}(\tilde{x}(p)]-g_{i}\right)^{2}-\operatorname{Var}(\tilde{x}(p))\right.
\end{aligned}
$$

Because the quadratic preferences in (4.1) are sensitive to variance, they are not entirely spatial, as both Londregan (2000) and Hirsch and Shotts (2012) observe. Reduction of uncertainty is appealing on its own, an aspect of preferences known since Stokes (1963) as a valence aspect of a policy. This valence aspect has the form of a public good: it is nonrival and nonexcludable.

In addition to the quadratic preference above, the government receives a private benefit from consensus. This benefit has two aspects. First, if there is internal consensus within the commission, the government gains utility from receiving a public signal about the quality of the policy preparation. Second, if the commission is broad and includes experts, stakeholders, and politicians, that is, $N=A \cup B \cup C$, the government gains utility from receiving a public signal that the proposed policy is viable and widely acceptable.

Similar to Londregan (2000), I incorporate the government's private benefit as an additively separable component. This is because it is distinct from valence arising from reduced uncertainty. Let $k>0$ be the private benefit to the government from consensus in a narrow commission, that is, one that excludes at least one of $\{A, B, C\}$, and let $K>k$ be the private benefit to the government from consensus in a broadly representative commission. Then

$$
\begin{aligned}
& E U_{G}(\tilde{x}(p))=-E\left[\left(\tilde{x}(p)-g_{G}\right)^{2}\right] \\
& + \begin{cases}K, & \text { if } \tilde{x}(p) \text { is a consensus recommendation and } N=\{A \cup B \cup C\}, \\
k, & \text { if } \tilde{x}(p) \text { is a consensus recommendation and } N \neq\{A \cup B \cup C\}, \\
0, & \text { if there is no consensus. }\end{cases}
\end{aligned}
$$




\subsection{Uncertainty}

I assume that policy proposal $\tilde{x}(p)$ is normally distributed with an uncertain outcome and with prior mean $p$. Two independent sources of uncertainty affect the proposal: a (partially) transferable, or generalizable, policy shock $\tilde{\eta}$, which is normally distributed with prior mean 0 and prior variance $h_{\eta}^{-1}$, and a policy-specific shock $\tilde{\varepsilon}_{p}$, which is normally distributed with

prior mean 0 and prior variance $h_{\varepsilon}^{-1}$. These two types of shocks are best understood by an example given by Hirsch and Shotts $(2012,68)$, as described in the Theory section. In what follows, I express the variances as their inverses or their prior precisions, $h_{\eta}$ and $h_{\varepsilon}$. This simplifies the mathematical expressions.

Even information that is generalizable is not necessarily as applicable to one policy as to another. In the context of the Hirsch and Shotts (2012) example, a policy that would scale down or privatize Medicare would be minimally affected by changes in the efficiency of reimbursements. By contrast, a policy of expanding Medicare or making it universal would be highly sensitive to the same changes. Therefore, even though the information may be generalizable across a wide range of policies, the sensitivity to this generalizable information can vary.

To operationalize this idea and to include both types of valence in the model, let the policy $\tilde{x}(p)$ generate an outcome as follows:

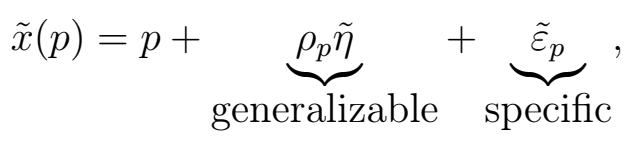

where

$\forall p, p^{\prime} \in \mathbb{R}$

$$
\begin{array}{r}
\tilde{\eta} \sim N\left(0, h_{\eta}^{-1}\right), \\
\tilde{\varepsilon}_{p} \sim N\left(0, h_{\varepsilon}^{-1}\right), \\
\operatorname{corr}\left(\tilde{\eta}, \tilde{\varepsilon}_{p}\right)=\operatorname{corr}\left(\tilde{\varepsilon}_{p}, \tilde{\varepsilon}_{p^{\prime}}\right)=0 .
\end{array}
$$

Here $p$ is any real number, representing the policy's ex ante expected outcome. Likewise, $\rho_{p}$ can be any real number. This allows for the possibility that the generalizable shock affects different policies in entirely different ways, perhaps even in different directions. 


\subsection{Information}

\subsubsection{Generalizable information}

The commission receives new information from the experts and stakeholders, provided they serve on the commission. If $A \subset N$, then each expert $i \in A$ provides a signal $\tilde{s}_{i}$ about the generalizable uncertainty $\tilde{\eta}$. Conditional on the unobserved true value $\eta$ of the generalizable uncertainty, $\tilde{s}_{i}$ has mean $\eta$ and precision $h_{s}$ :

$$
\tilde{s}_{i} \mid \eta \sim N\left(\eta, h_{s}^{-1}\right)
$$

The assumption (4.3) is equivalent to assuming that each expert $i \in A$ observes $\eta$ with some error and that these errors are normally distributed with mean 0 and variance $h_{s}^{-1}$.

After $i$ receives the signal $s_{i}$, $i$ 's posterior beliefs about the generalizable uncertainty become

$$
\tilde{\eta} \mid s_{i} \sim N\left(\frac{h_{s} s_{i}}{h_{\eta}+h_{s}},\left(h_{\eta}+h_{s}\right)^{-1}\right),
$$

which means that the effect of the generalizable shock on policy $\tilde{x}(p)$ is distributed as

$$
\rho_{p} \tilde{\eta} \mid s_{i} \sim N\left(\frac{\rho_{p} h_{s} s_{i}}{h_{\eta}+h_{s}}, \frac{\rho_{p}^{2}}{h_{\eta}+h_{s}}\right) .
$$

The effect on policy $\tilde{x}(p)$ in (4.5) comes directly from the fact that, for any random variable $\tilde{y}$ and any constant $c$, the mean of $c \tilde{y}$ is $c E[\tilde{y}]$ and the variance of $c \tilde{y}$ is $c^{2} \operatorname{Var}[\tilde{y}]$.

Given the signals $s:=\left(s_{i}\right)_{i \in A}$ of all the $n_{a}$ experts on the commission, the common posterior beliefs of the generalizable uncertainty are

$$
\tilde{\eta} \mid s \sim N\left(\frac{h_{s} \sum_{i=1}^{n_{a}} s_{i}}{h_{\eta}+n_{a} h_{s}},\left(h_{\eta}+n_{a} h_{s}\right)^{-1}\right) .
$$




\subsubsection{Policy-specific information}

If the commission includes stakeholders, then each $j \in B$ chooses a policy proposal $\tilde{x}(j)$ to investigate and receives a signal $\tilde{\tau}_{j}$ on that policy. Conditional on Nature's choice of $\varepsilon_{j}$, the signal $\tilde{\tau}_{j}$ has mean $\varepsilon_{j}$ and precision $h_{\tau}$ :

$$
\tilde{\tau}_{j} \mid \varepsilon_{j} \sim N\left(\varepsilon_{j}, h_{\tau}^{-1}\right) .
$$

Assumption (4.6) is equivalent to assuming that each stakeholder $j \in B$ observes $\varepsilon_{j}$ with some error and that these errors are normally distributed with mean zero and variance $h_{\tau}^{-1}$.

After observing the signal $\tau_{j}$, $j$ 's posterior beliefs about the policy-specific uncertainty become

$$
\tilde{\varepsilon}_{j} \sim N\left(\frac{h_{\tau} \tau_{j}}{h_{\varepsilon}+h_{\tau}},\left(h_{\varepsilon}+h_{\tau}\right)^{-1}\right) .
$$

For convenience, assume that each stakeholder $j \in B$ investigates a different policy and that, if stakeholders are on the commission, then each policy in the report is evaluated by a stakeholder (so that all policies on which the commission reports include updated information on policy-specific uncertainty). Given the signals $\tau:=\left(\tau_{j}\right)_{j \in B}$ of all the $n_{b}$ experts on the commission, the common beliefs about the policy-specific shocks are distributed as in (4.7) for $n_{b}$ distinct policies.

\subsection{Sequence of Events}

The sequence of events is as follows:

1. The government $G$ appoints the commission.

2. Each $i \in A$ and $j \in B$, if appointed to the commission, investigates an exogenously chosen policy, receives a signal, and truthfully reveals it.

3. The commission chooses its policy recommendation $\tilde{x}(r)=r+\rho_{r} \tilde{\eta}+\tilde{\varepsilon}_{r}$ from among the policies that the commission investigates. If no policy is acceptable to the commission's members, it can choose the government's outside option $\tilde{x}(q)$.

4. Each commission member decides whether to support the recommendation or dissent. 
5. $G$ receives a report, consisting of

a. the commission's recommendation $\tilde{x}(r)$, along with any alternative proposal $\tilde{x}(p)$ the commission has investigated;

b. the signals $s=\left(s_{1}, \ldots, s_{n_{a}}\right)$ of the experts, if on the commission;

c. the signals $\tau=\left(\tau_{1}, \ldots, \tau_{n_{b}}\right)$ of the stakeholders, if on the commission;

d. any dissents.

6. $G$ chooses a policy.

I treat the policy alternatives that the commission investigates as exogenously given. In practice, commissions likely differ in how much latitude the commission chair and the government give the commission members on what to research. Endogenous policy selection is a potentially interesting future topic, though it would raise numerous complications (such as beliefs about what other commission members would research), many of which would be too remote to the question at hand.

By assuming that the commission members report their information truthfully, I ignore the effects of strategic withholding of information or of cheap talk. This issue is discussed extensively in the literature, and I comment only briefly here. In commissions that make decisions in addition to providing information, Austen-Smith and Riker (1987) give reason to question complete and faithful information disclosure. However, in commissions that are purely advisory, Milgrom and Roberts (1986) offer a simple explanation for why we might expect complete and honest disclosure: anything one party learns is something someone with opposing views can discover.

\subsection{Solving the Game}

I assume rational expectations and solve the game by backward induction, as follows. 


\subsubsection{Last stage: the government's policy decision}

After receiving the report, $G$ knows the signals of the experts, $s=\left(s_{i}\right)_{i \in A}$, and those of the stakeholders, $\tau=\left(\tau_{j}\right)_{j \in B}$, provided they were included on the commission. Additionally, $G$ knows the commission's recommended policy proposal $\tilde{x}(r)$ and whether it is a consensus recommendation or if any of the commission members issued dissenting opinions.

For convenience, I treat consensus as the absence of dissent, similar to the veto-player theory of Tsebelis $(1995,2002)$. The results would still hold if the definition of consensus were weakened to mean that the recommendation had the support of a supermajority but not necessarily universal support, provided each commission member chooses a support or dissent decision as if he or she were pivotal. The veto of commission members, however, is only partial, because they cannot block the government from choosing an outside option, or even from implementing a recommendation for which there was no consensus. In sum, although the commission members lack a full veto, they do have a voice.

The government $G$, however, has the final say. This makes the model closely related to the veto-based delegation theory of Mylovanov (2008), in which a principal delegates a decision to a better-informed agent but retains a veto over the agent's recommendation. In Mylovanov's theory, the principal designs a default option, used to enforce an equilibrium. The present model instead does not involve commitment on the government's behalf to any particular default option. In fact, the government's default action can depend on the information the commission provides. In this respect, the structure is similar to bargaining under an open rule (see Baron and Ferejohn, 1989). Because the government is the last mover, it can use the information it receives from the commission to advance its own ends, and it does so, unless there is a consensus policy that gives $G$ at least its outside option.

\section{Benchmark: goverment's payoff without consensus recommendation}

Begin by considering the government's outside option. This is the policy $\tilde{x}(q)$ that the government chooses if either the commission's recommendation is not consensual or if the government chooses not to follow the consensus recommendation. To get a sharp prediction 
on the government's outside option, I need to add an assumption that is justified only on purely technical grounds: ${ }^{1}$

Assumption 1. For policy $\tilde{x}(p)$, the sensitivity $\rho_{p}$ to generalizable noise is nondifferentiable in $p$.

Proposition 1. Let $\left\{\tilde{x}_{1}, \ldots, \tilde{x}_{m}\right\}$ be the policies the commission evaluates in its report.

Given Assumption 1, either the government chooses its outside option $\tilde{x}(q)$ as one of the commission's reported alternatives $\tilde{x}_{j}$ or the government bypasses the commission and chooses $\tilde{x}(q)$ so that

$$
E[\tilde{x}(q)]=g_{G}
$$

If experts are included on the commission and $G$ does not choose one of the commission's reported alternatives, then

$$
q=g_{G}-\rho_{q} E[\tilde{\eta} \mid s]
$$

Otherwise, $q=g_{G}$. The expected payoff to the government of its outside option is then

$$
E U_{G}[\tilde{x}(q)]=-\rho_{q}^{2} \begin{cases}\left(h_{\eta}+n_{a} h_{s}\right)^{-1}-h_{\varepsilon}^{-1}, & \text { if } A \subset N \\ h_{\eta}^{-1}-h_{\varepsilon}^{-1}, & \text { otherwise }\end{cases}
$$

or, if it chooses an alternative from the report,

$E U_{G}[\tilde{x}(q)]=-\left(E\left[\tilde{x}_{j}\right]-g_{G}\right)^{2}-\rho_{j}^{2}\left\{\begin{array}{ll}\left(h_{\eta}+n_{a} h_{s}\right)^{-1}, & \text { if } A \subset N \\ h_{\eta}^{-1}, & \text { otherwise }\end{array}- \begin{cases}\left(h_{\varepsilon}+h_{\tau}\right)^{-1}, & \text { if } B \subset N \\ h_{\varepsilon}^{-1}, & \text { otherwise. }\end{cases}\right.$

Equation (4.8) does not uniquely specify $q$. To address this nonuniqueness, I will assume that the government picks the outside option that is most agreeable to the commission. In other words, the government does not deliberately choose anything that is Pareto dominated. If this requirement still does not uniquely specify the government's outside option, then I assume without further comment that one is focal.

The following is an immediate consequence of Proposition 1:

Corollary 1. The government's utility from its outside option is always higher if $A \subset N$.

\footnotetext{
${ }^{1}$ Without Assumption 1, the government's outside option could deviate arbitrarily far from its ideal point, even if no commission is appointed. Assumption 1 rules out this possibility.
} 


\section{Benefit to government of consensus}

Because of Corollary 1, the government always includes experts on the commission. As I show below, the ability of the commission to reach a consensus recommendation will increase in the policy valence. From (4.9), the valence (i.e., reduction in variance) is higher with experts on the commission. This gives the government a better outside option and the commission a greater chance of improving on the government's outside option.

It is useful to decompose the possible commissions that the government might appoint as follows:

Definition 1. A commission that includes experts but does not include stakeholders is an expert commission. A commission of experts and stakeholders is a representative commission. A commission that includes experts, stakeholders, and politicians is a parliamentary commission:

$$
N \text { is } \begin{cases}\text { an expert commission, } & \text { if } N \in\{A, A \cup C\} \\ \text { a representative commission, } & \text { if } N=A \cup B \\ \text { a parliamentary commisssion, } & \text { if } N=A \cup B \cup C .\end{cases}
$$

Let $\Delta_{G}(r)=E U_{G}(\tilde{x}(r))-E U_{G}(\tilde{x}(q))$ be the government's net benefit of adopting a consensus recommendation. If $E[\tilde{x}(q)]=g_{G}$, then

$$
\begin{aligned}
\Delta_{G}(r) & = \begin{cases}-\left(E[\tilde{x}(r) \mid s, \tau]-g_{G}\right)^{2}, & \text { for parliamentary and representative commissions } \\
-\left(E[\tilde{x}(r) \mid s]-g_{G}\right)^{2}, & \text { for expert commissions }\end{cases} \\
& + \begin{cases}\left(\rho_{q}^{2}-\rho_{r}^{2}\right)\left(h_{\eta}+n_{a} h_{s}\right)^{-1}+h_{\varepsilon}^{-1}-\left(h_{\varepsilon}+h_{\tau}\right)^{-1}+K, & \text { if } N \text { is parliamentary } \\
\left(\rho_{q}^{2}-\rho_{r}^{2}\right)\left(h_{\eta}+n_{a} h_{s}\right)^{-1}+h_{\varepsilon}^{-1}-\left(h_{\varepsilon}+h_{\tau}\right)^{-1}+k, & \text { if } N \text { is representative } \\
\left(\rho_{q}^{2}-\rho_{r}^{2}\right)\left(h_{\eta}+n_{a} h_{s}\right)^{-1}+k, & \text { if } N \text { is an expert commission. }\end{cases}
\end{aligned}
$$

If $\tilde{x}(q)$ is one of the alternatives from the commission's report, then the commission type is the same for both the recommended policy and the outside option. In this case,

$$
\Delta_{G}(r)=\left(E[\tilde{x}(q)]-g_{G}\right)^{2}-\left(E[\tilde{x}(r)]-g_{G}\right)^{2}+\left(\rho_{q}^{2}-\rho_{r}^{2}\right)\left(h_{\eta}+n_{a} h_{s}\right)^{-1}+ \begin{cases}K, & \text { if parliamentary } \\ k, & \text { otherwise }\end{cases}
$$


The government's individual rationality (IR) constraint is then

$$
\Delta_{G}(r) \geq 0
$$

The following immediately follows from (4.11):

Proposition 2. All else equal, the willingness of the government to accept policy recommendations that differ in expectation from its ideal point is greatest with parliamentary commissions and least with expert commissions. In particular, let $b \in\{k, K\}$ be the private benefit to the government from consensus, and let $v$ be the valence benefit of the recommendation. The government accepts consensus recommendation $\tilde{x}(r)$ if

$$
g_{G}-\sqrt{b+v} \leq E[\tilde{x}(r)] \leq g_{G}+\sqrt{b+v}
$$

where

- if $\tilde{x}(q)$ is an alternative from the report, then $v=\left(\rho_{q}^{2}-\rho_{r}^{2}\right)\left(h_{\eta}+n_{a} h_{s}\right)^{-1}, b=K$ for parliamentary commissions, and $b=k$ for expert and representative commissions. Otherwise,

- for parliamentary commissions, $b=K$ and

$$
v=\left(\rho_{q}^{2}-\rho_{r}^{2}\right)\left(h_{\eta}+n_{a} h_{s}\right)^{-1}+h_{\varepsilon}^{-1}-\left(h_{\varepsilon}+h_{\tau}\right)^{-1}
$$

- for representative commissions, $b=k$ and

$$
v=\left(\rho_{q}^{2}-\rho_{r}^{2}\right)\left(h_{\eta}+n_{a} h_{s}\right)^{-1}+h_{\varepsilon}^{-1}-\left(h_{\varepsilon}+h_{\tau}\right)^{-1}
$$

- for expert commissions, $b=k$ and

$$
v=\left(\rho_{q}^{2}-\rho_{r}^{2}\right)\left(h_{\eta}+n_{a} h_{s}\right)^{-1} .
$$




\subsubsection{Commission's recommendation and the decision to support or dissent}

Prior to issuing the report but after the commission has adopted a recommendation, each commission member $i \in N$ must decide whether to support the recommendation or issue a dissenting opinion. At this stage, all the commission members know the signals of the experts $s$ and, for representative and parliamentary commissions, those of the stakeholders $\tau$, along with the commission's recommended policy proposal $\tilde{x}(r)$. Each commission member uses this knowledge to anticipate the government's outside option $\tilde{x}(q)$.

When deciding whether to support $\tilde{x}(r)$ or to dissent, commission member $i$ evaluates the difference in his or her utility from having $\tilde{x}(r)$ implemented over having the government instead choose its outside option $\tilde{x}(q)$. Let $\Delta_{i}(r)=E U_{i}(\tilde{x}(r))-E U_{i}(\tilde{x}(q))$ :

$$
\begin{gathered}
\Delta_{i}(r)=E^{2}[\tilde{x}(q)]-E^{2}[\tilde{x}(q)]-2 g_{i}(E[\tilde{x}(r)]-E[\tilde{x}(q)])+\left(\rho_{q}^{2}-\rho_{r}^{2}\right)\left(h_{\eta}+n_{a} h_{s}\right)^{-1}+ \\
\begin{cases}0, & \text { if expert commission or } q \text { in report } \\
h_{\varepsilon}^{-1}-\left(h_{\varepsilon}+h_{\tau}\right)^{-1}, & \text { otherwise, }\end{cases}
\end{gathered}
$$

where the expectations are conditional on the commission's information $(s$ if an expert commission and $s, \tau$ if a parliamentary or representative commission).

The following result characterizes the willingness of commission members to support the recommendation:

Theorem 1. Let $b \in\{k, K\}$ be the private benefit to the government from supporting consensus recommendation $\tilde{x}(r)$. Assume $\Delta_{G}(r) \geq 0$. Let $\gamma=\Delta_{G}(r)-b$ be the benefit to the government net of $b$. Let $g_{1}$ be the ideal point of the leftmost commission member, and let $g_{n}$ be the ideal point of the rightmost commission member. Then,

1. if $\gamma \leq 0$, then there is no dissent only if either the entire commission is to the right of $G$ or the entire commission is to the left of $G$, or if the commission recommendation is the government's outside option;

2. if $\gamma>0$, then there is no dissent only if, for each commission member $i \in N$,

$$
g_{G}-\frac{\gamma}{2\left(g_{n}-g_{G}\right)} \leq E[\tilde{x}(r)] \leq g_{G}+\frac{\gamma}{2\left(g_{G}-g_{1}\right)}
$$


Conversely, a commission that is entirely to the left or entirely to the right of $G$ can extract all the benefits from the government. For a commission with members both to the left and to the right of $G$, the ability to achieve consensus is increasing in the net benefit $\gamma$ to the government.

\subsubsection{Decision on policy to research}

There are many equilibria in the possible policies that the stakeholders could choose to research, as these depend on the beliefs about other stakeholders' decisions. I limit attention here to a minimal requirement: a stakeholder researches a policy only if it can pass.

If commission member $i$ maximizes its expected benefit from having its policy chosen, then it is straightforward to show that $i$ maximizes $\Delta_{i}(p)$ at $p=g_{i}$. Therefore $i$ would prefer to provide policy-specific information about its ex ante ideal policy, $\tilde{\varepsilon}_{g_{i}}$.

However, $i$ also needs to believe that $\Delta_{1}\left(g_{i}\right), \Delta_{G}\left(g_{i}\right)$, and $\Delta_{n}\left(g_{i}\right) \geq 0$. Otherwise, the policy-specific information is of no benefit, and $i$ would be better off providing information on other policies that are further from $g_{i}$ but that would have a chance of passing.

For example, if the constraint that $\Delta_{n}(p) \geq 0$ binds, then it must be the case that

$$
-p^{2}+2 g_{n} p+g_{G}-2 g_{n} g_{G}+h_{\varepsilon}^{-1}-\left(h_{\varepsilon}+h_{\tau}\right)^{-1}=0 .
$$

As $g_{n}$ is the rightmost ideal point, the constraint determines the leftmost policy that $i$ can credibly consider. This is given by

$$
p_{\min }=g_{n}-\sqrt{g_{G}-2 g_{g} g_{n}+g_{n}^{2}+h_{\varepsilon}^{-1}-\left(h_{\varepsilon}+h_{\tau}\right)^{-1}} .
$$

Other constraints are similar.

A consequence is that including politicians to the commission can lead the stakeholders to temper their demands. The reason is that including politicians may increase $\left(g_{G}-g_{1}\right)$ or $\left(g_{n}-g_{G}\right)$. This has a direct effect of making (4.13) more difficult to satisfy for a given proposal $\tilde{x}(r)$. However, the indirect effect is to create incentives for stakeholders to research proposals that are closer to the government's ideal point. 


\subsubsection{Government's appointment decision}

Theorem 1 illustrates the trade-off the government faces when appointing a commission. For an expert commission, the government's net benefit from a consensus report is

$$
-\left(E[\tilde{x}(r)]-g_{G}\right)^{2}+\left(\rho_{q}^{2}-\rho_{r}^{2}\right)\left(h_{\eta}+n_{a} h_{s}\right)^{-1}+k
$$

This benefit is maximized at $r=q$, that is, at the government's outside option. If the effect of policy-specific uncertainty is small, or if the outside option is no less sensitive to the generalizable noise than other policy alternatives, then it will be difficult to make this benefit larger than $k$. By Theorem 1, the government would either face dissent and lose $k$ or face a commission that would expropriate the government's benefits unless it can assure that $r=q$. In this case, the government could not improve on an expert commission, and adding additional members could only increase the probability of dissent.

If instead there is a large potential benefit of policy-specific information, then the government will have incentive to appoint stakeholders. As argued above, the government may have incentive to appoint politicians as well, both to increase the private gain (from $k$ to $K)$ and as a potential way to discipline the stakeholders on what they demand. This latter benefit will occur only if the parliament is sufficiently ideologically diverse.

\subsection{Empirical Predictions}

These considerations lead to the following hypotheses, stated in the alternative form.

Hypothesis 1. Experts: Dissent decreases in the number of experts.

From Theorem 1, the ability of the commission to reach consensus is increasing in $\gamma$, the valence benefit to the government. From Proposition 4.11, the valence effect from appointing experts is

$$
\left(\rho_{q}^{2}-\rho_{r}^{2}\right)\left(h_{\eta}+n_{a} h_{s}\right)^{-1}
$$

As noted in Subsection 4.5.4, if G's outside option is no less sensitive to the generalizable noise than other policy alternatives, then $\gamma$ will typically be nonpositive, and the government 
appoints an expert commission and $r=q$. Therefore the valence effect of experts affects consensus only if $\rho_{q}^{2}<\rho_{r}^{2}$.

In this case, the first term in (4.14) is negative, and the second term asymptotically approaches 0 as $n_{a}$ increases.

In words, adding experts to commissions makes the proposed alternatives less risky and therefore more acceptable. Because the variance is bounded below at 0 , this benefit grows at a decreasing rate.

Hypothesis 2. Stakeholders and representative commissions: Stakeholders decrease dissent more in parliamentary and representative commissions than in expert commissions.

Note that in the model, stakeholders would not be appointed to expert commissions. In practice, however, a small number sometimes are. Hypothesis 2 concerns this case, though in the model it is off the equilibrium path.

From Subsection 4.5.4, expert commissions are appointed in Case 1 of Theorem 1, where the government expects $\gamma \leq 0$. In this case, adding a stakeholder to the commission would create policy-specific information on the policy the stakeholder researches. This increases the probability that a commission member would prefer the alternative to $q$, but the government in general prefers an expert commission that would recommend $q$ and focus on implementation. In this way, appointing a stakeholder to an expert commission produces information that the commission cannot use and creates reason for dissent.

Hypothesis 3. Commission size and probability of dissent: Let $p$ be the probability that a commission member dissents to the recommended proposal. As the number of members $n$ on a commission increases, the overall probability of dissent is less than $1-(1-p)^{n}$, if the commission contains stakeholders and experts.

From (4.12), the net benefit to the commission members of a proposed policy over the outside option increases as the number of experts increases and if stakeholders are present. In (4.13), the effect of adding stakeholders or experts to the commission is to increase the overall valence benefits, partially offsetting the denominator effect of larger commissions having more policy outliers. If an additional member is a politician, there is also a mitigating effect, 
because the larger membership leads stakeholders to alter the policies that they research and focus on more moderate ones (see Subsection 4.5.3).

Hypothesis 4. Politicians vs. stakeholders: Adding politicians increases dissent more than adding stakeholders.

Hypothesis 5. Politicians vs. experts: Adding politicians increases dissent more than adding experts.

Hypotheses 4 and 5 come from Theorem 1, in particular (4.13). The government's overall benefit $\Delta_{G}(r)$ of accepting the policy recommendation has an informational benefit due to greater knowledge of the generalizable uncertainty and the policy-specific uncertainty. These benefits are due, respectively, to the stakeholders and the experts. The government also gains from consensus, and this benefit is increased if the politicians serve on the commission.

Although Proposition 2 shows that the politicians, by increasing the gain from consensus, make the government more willing to accept proposals, we see in Theorem 1 that this gain does not help improve consensus. Only $\gamma$, the valence benefit, affects whether the commission will support a given recommendation. Thus, even though all types of commission members bring something to the table, Theorem 1 shows that it is the informational gain, and not the gain to the government of consensus, that reduces dissent on the commission.

Last, observe that if the need for consensus is greater if there is more ideological polarization, the following hypothesis follows:

Hypothesis 6. Political polarization: As political polarization increases, the government is more likely to appoint representative commissions with politicians.

With more polarization, the government will be able to use more policy preference outliers to contain the policies that the commission recommends, as argued in Subsection 4.5.3. This increases the ability to find a policy satisfying Inequality (4.13). Moreover, from Theorem 1, the government can lose its benefits from appointing the commission if the commission is entirely to its left or to its right, decreasing the government's incentive to appoint a parliamentary commission. With more polarization, the government has an easier time finding politicians both to its left and to its right. 


\subsection{Empirical Design and Results}

This section presents the empirical design and the results from the empirical models. First, I discuss the case selection, sampling, and data collection procedures, and present some descriptive statistics. I then describe the variables used in the empirical models, and their operationalization and measurement. After describing the variables, I present two sets of empirical models. The first set of models is used to test hypotheses 1, 2, 4, and 5. The second set of models, which adjusts for selection issues, is used to test hypotheses 3 and 6 . The second set of models also provides an additional test of hypotheses 1 and 4. Most of the variables, except a few selection variables, are used in both models. For this reason, I present the variables first, and the empirical models afterwards. Finally, I present the results of the empirical models and conclude with a short discussion.

\subsection{Case Selection, Sampling, and Data Collection}

To test the hypotheses, I use novel, hand-collected data on 2,705 Swedish policy advisory commissions whose reports were published in the Government Official Reports (Statens offentliga utredningar or SOU) series in 1990-2018. Policy advisory commissions are unusually prevalent in Sweden compared with most countries which use them. In recent decades, the Swedish government has initiated about 68-134 public inquiries per year (2016/17: KU10, 74). These have ranged from inquiries conducted by a single investigator and a few sub-

ject matter experts to large parliamentary commissions with representatives from organized interests and all major political parties. In addition, until recently, it has been normative to send all significant legislative initiatives to a broadly representative advisory commission for initial policy formulation (Premfors, 1983). This makes Swedish data appealing from a sampling point of view.

I chose the time period of 1990-2018 because of availability of electronic data starting in 1990, and to complement existing studies on Swedish commissions of inquiry (Hesslén, 
1927; Meijer, 1956; Johansson, 1992; Hermansson, 1993). From a sampling point of view, the selected time period offers significant variation in policymaking eras from the end of the Cold War through the information technology revolution, Sweden's accession to the European Union in 1995, the 2007-2009 global economic recession, to the 2015 migrant crisis.

The main threat to validity is that Sweden has long been known by its distinctively consensus-oriented political culture, high level of corporatism, and its highly developed and centralized interest groups. However, during the time period under consideration, these features of Swedish politics are less present (Lindvall and Sebring, 2005; Öberg et al., 2011; Petersson, 2016) (see discussion in the next section). This should improve the generalizability of the results.

Table 5.1 summarizes the sampling procedure. From a population sample of 3,560 SOUs published in 1990-2018, I identified 2,995 SOUs with a policy recommendation. These formed my initial sample. I then excluded twelve inquiries by two permanent commissions (Jo 1968:A and I 1968:14), and 260 inquiries with fewer than three members (not counting secretaries) because none of them had dissent. Because inquiry lengths vary a great deal, especially in the 1990s and earlier, working backwards from published inquiry reports resulted in oversampling longer inquiries established in the 1980s. I chose to remove eighteen inquiries which were established before 1987, in order to have at least 30 observations per government to calculate random effects. As inquiries are appointed and completed on a rolling basis, cutoff points are necessarily somewhat arbitrary.

The final sample includes 2,705 policy inquiries appointed by ten governments (see Table 5.2). Examples of excluded inquiries include an inquiry into Russian submarine activity in the Swedish coastal waters (SOU 1995:135), an expert report on the psychosocial health of school children (SOU 2010:80), and long term economic forecasts (Långtidsutredningen).

Other studies of Scandinavian commissions of inquiry (e.g., Petersson, 2016; Christensen and Hesstvedt, 2019) have also used inquiry reports as their primary data source. An alternative would have been to use Kommittèberättelsen, a yearly report from the Cabinet to the parliament on inquiries which are either active or completed during that year. The main advantage of using inquiry reports is that they are available electronically and contain more background information about commission members. In addition, they include reservations 
Table 5.1: Sample selection

\begin{tabular}{rrl}
\hline Total & Excluded & Explanation \\
\hline 3,560 & & Initial sample: Inquiry reports (SOUs) published in 1990-2018 \\
& 491 & SOUs with no policy recommendation \\
54 & SOUs containing additional volumes or appendices \\
15 & SOUs by investigative inquiries \\
5 & SOU or membership information not found \\
& \\
& Total policy inquiries \\
& 12 SOUs by a permanent commission (Jo 1968:A and I 1968:14) \\
& 260 Inquiries with fewer than 3 members (excl. secretaries) \\
& 18 & Inquiries initiated before 1987 \\
& & Total policy inquiries in the final sample \\
\hline
\end{tabular}

Table 5.2: Governments

\begin{tabular}{lllll}
\hline Name & Start/end dates & Parties & Type & Obs \\
\hline Carlsson I & $1986-03-12$ to 1988-09-18 & s & Single-party minority & 40 \\
Carlsson II & $1988-09-18$ to 1991-10-03 & s & Single-party minority & 227 \\
Bildt & $1991-10-03$ to 1994-10-06 & c-fp-m-kd & Minority coalition & 330 \\
Carlsson III & $1994-10-06$ to 1996-03-21 & s & Single-party minority & 203 \\
Persson I & $1996-03-21$ to 1998-09-20 & s & Single-party minority & 269 \\
Persson II & $1998-09-20$ to 2002-09-15 & s & Single-party minority & 365 \\
Persson III & $2002-09-15$ to 2006-10-05 & s & Single-party minority & 336 \\
Reinfeldt I & $2006-10-05$ to 2010-10-05 & c-fp-m-kd & Majority coalition & 360 \\
Reinfeldt II & $2010-10-05$ to 2014-10-03 & c-fp-m-kd & Minority coalition & 336 \\
Löfven I & $2014-10-03$ to 2019-01-21 & s-mp & Minority coalition & 239 \\
\hline
\end{tabular}

$\mathrm{s}=$ Social Democrats, $\mathrm{c}=$ Centre Party, $\mathrm{fp}=$ Liberals, $\mathrm{m}=$ Moderate Party, $\mathrm{kd}=$ Christian Democrats, $\mathrm{mp}=$ Green Party 
and dissenting opinions. The main disadvantage of using inquiry reports is that commissions which did not publish a report, did not complete their inquiry or published their findings in a different report series, are found only in the Kommittèberättelsen. Comparing my sample to scraped data on Kommittèberättelsen for 2006-2016, I estimate that my sample of 2,995 policy inquiries includes at least 84 percent of all inquiries.

To obtain information about commission members, I scraped the Swedish government's open document database ${ }^{1}$ using Python 3.0 and BeautifulSoup 4.6. I then removed members of external reference groups, as these were not always recorded consistently. Instead, I included a variable noting the presence of a reference group. Assisted by several coders, I added missing information from electronic copies of inquiry reports stored on the Swedish Law web page, Linköping University's Open SOU web page, the Swedish Royal Library's SOU archive, and the Swedish government's SOU web page. ${ }^{2}$ I obtained four SOUs, which I could not find in electronic format, from the Law Library of Uppsala University. The final data set, with the reference groups removed, includes 35,987 commission members.

I classified commission members into the following categories: Academics, Civil servants, Interest groups, Politicians, Public servants, and Other using the coding criteria in Appendix B. I also created a separate category for Judges. Although the theory makes no predictions about judges, there were sufficiently many in the data set to justify a separate category. Members who could not be categorized were marked as Unclassified. For the empirical analyses, I combined the membership categories as shown in Table 5.3.

In addition, I classified the gender of each member using a list of most common male and female names from the population registry records at Statistics Sweden (SCB). I also added party affiliations for members of parliament from the Swedish parliament's database of past and present MPs. ${ }^{3}$

Finally, I collected data on dissents from the inquiry reports, counting each time a member expressed a reservation or dissenting opinion as one instance of dissent. Since members can dissent more than once, shares of dissent may exceed one.

\footnotetext{
${ }^{1}$ http://rkrattsbaser.gov.se/sf.sr

${ }^{2}$ https://lagen.nu, http://www.ep.liu.se/databases/sou/, http://regina.kb.se/sou/, http: //www .regeringen.se/rattsdokument/statens-offentliga-utredningar/

${ }^{3}$ https://data.riksdagen.se/data/ledamoter/
} 
Table 5.3: Member categories

\begin{tabular}{lll}
\hline Original category & Main empirical models & Robustness check \\
\hline Academics & Experts & Academics \\
Civil servants & Experts & Bureaucrats \\
Interest groups & Stakeholders & Interest groups \\
Judges & Judges & Judges \\
Politicians & Politicians & Politicians \\
Public servants & Stakeholders & Bureaucrats \\
Other & Other & Other \\
Unclassified & Unclassified & Unclassified \\
\hline
\end{tabular}

The data collection procedures for control variables are discussed in Section 5.7.

\subsection{Case Context}

Sweden is a parliamentary democracy with a proportional electoral system and a unicameral legislature (Riksdag) with 349 members, elected every four years. The main parliamentary parties are the Social Democratic Party, The Green Party, four center-right parties (Centre Party, Liberals, Moderate Party, Christian Democrats), and, more recently, the populist Sweden Democrats party. Since 1932, the Social Democratic Party has dominated cabinet formation, and there have been only five elections (1976, 1979, 1991, 2006 and 2010) in which the center-right bloc has received enough seats to form a government. Other core features of Swedish political system include relatively weak ministries, independent governmental agencies, and strong parliamentary committees.

From early 1930s to the 1980s, Swedish policymaking could be described as highly centralized, rationalistic, and consensus-oriented (Petersson, 2016). Political power was shared by a dual structure of societal power: a strong central government and highly organized interest groups. Virtually all social interests of any significance were organized into local, regional, and national associations, and the most important interests (labor and industry) were organized into national confederations representing a majority of the labor force and 
industries (Anton, 1969). Within this dual structure, politicians and parties decided the overall policy goals in collaboration with leaders of main interest groups. The government then appointed commissions of inquiry to conduct policy analysis and to seek consensus on policy with the relevant political actors (Anton, 1969; Meijer, 1956, 346). For particularly significant policy initiatives, the government appointed parliamentary commissions, which contained parliamentarians from all major political parties.

After the commission completed its inquiry, its report was sent for further comments to relevant referral bodies such as government agencies, interest groups and local government authorities through a process known as the remiss procedure. When the referral bodies had submitted their comments, the ministry responsible for the policy area drafted the bill. Commission reports and referral comments were often influential, and bills usually passed by a wide margin (Rustow, 1955; Premfors, 1983; Hermansson, 1993, 663). More generally, the prevailing political culture had a strong norm that political decisions should not be made without hearing the affected parties (Petersson, 2016, 650).

The consensus orientation of the Swedish policymaking system was influenced by predemocratic institutions in place at the time of the introduction of parliamentary democracy in 1917, and arose largely as a response to political realities and tensions between the labor and capital in the first two decades of the 20th century. During this time, there was no stable majority in the Riksdag, and several cabinets had extremely low levels of parliamentary support. For example, the Ekman government had only a 14 percent of the seats in the Riksdag. Minority goverments used their position in the ideological middle to alternate between seeking voting majorities from the left and the right (Lewin, 1998). They also relied on the independent bureaucracy, commissions of inquiry, and strong parliamentary committees to negotiate compromise and to maintain a workable regime (Tingsten, 1940; Meijer, 1956; Zetterberg, 1990; Lindvall et al., 2017, 186). These practices gradually altered the logic of interaction among political actors to create the rationalistic, consensus-oriented policymaking system that characterized Swedish politics during most of the 20th century (Anton, 1969). In general, seeking broad agreement on policy has remained a practical necessity for most Swedish governments. With the exception of the Social Democratic government between 1968 and 1970, and the grand coalition during the Second World War, between 1944 
and 2014 Swedish governments have had the support of only 46 percent of the members of parliament (Lewin, 1998; Lindvall et al., 2020).

The basis of the policymaking system started to shift in the 1980s. Interest groups continued to participate in the policymaking process, but increasingly through other means than corporatist arrangements, such as lobbying (Hermansson, Svensson and Öberg, 1997). The inclusion of organized interests in the policy implementation process through participation on governmental agency board also declined (Blom-Hansen, 2000; Lindvall and Sebring, 2005; Petersson, 2016; Lindvall et al., 2017). Parliamentary commissions, which used to comprise about a half of new inquiries (Meijer, 1969; Hedborg, 1998; Petersson, 2016), became increasingly rare (Petersson, 2016), and commissions became less independent and were given less time to complete their work (Petersson, 2016). In addition, political norms regarding the social partnership between the state and peak interest groups gradually weakened (Rothstein and Bergström, 1999; Christiansen, 1999; Lindvall and Sebring, 2005; Lindvall and Rothstein, 2006; Öberg et al., 2011; Petersson, 2016, 660). Some of these developments were a consequence of wider societal and economic changes, such as the overall decline in labor union membership, and Sweden's accession to the European Union in 1995 (Petersson, 2016).

Currently, the Swedish government makes around 200 legislative proposals each year, normally in the form of a government bill. Some contain proposals which require extensive deliberation and debate before a vote can be taken, while others are amendments to existing laws. Before the government draws up a legislative proposal, it assigns ministerial staff, a commission of inquiry, or a special investigator inquiry to analyze the issue. Typically, proposals which require extensive deliberation and debate are assigned to commissions of inquiry, while more technocratic and less controversial topics are assigned to special investigator inquiries or to ministerial staff. The government initiates both commissions of inquiry and special investigator inquiries on an ad hoc basis by issuing a a commission directive (kommittéedirektiv). The directive describes the inquiry's terms of reference, i.e. what issues it is to examine, whether it should be completed by a commission of inquiry or a special investigator, and the date by which it should be completed. 
A commission of inquiry consists of a chairperson and several commissioners. ${ }^{4}$ The chairperson is typically high ranking civil servant (often a director of a central agency or a county governor) or a member of parliament with relevant subject matter expertise (Meijer, 1956, 86-90). The commissioners are generally members of parliament from all major parliamentary parties (such commissions are called parliamentary commissions), but can also include various types of civil servants and professionals. The commissioners are allowed to participate in all meetings and deliberations and to express reservations and dissenting opinions if they disagree with the conclusions of the inquiry. Reservations are a stronger form of dissent and are more likely to express ideological disagreement, while dissenting opinions are more likely to cite technical reasons (Johansson, 1992).

In addition, commissions have two kinds of subject matter experts: subject specialists and experts. These can include ministerial or agency staff, university professors, representatives of interest groups, or other professionals. Subject matter specialists are somewhat more likely to be drawn from the civil service and government agencies, whereas experts are somewhat more likely to be academics.

Subject specialists can participate in all meetings and deliberations and write dissenting opinions. The role of experts, by contrast, is determined by the chairperson (Kommitteeförordingen, SFS 1998:1474). Typically, experts are allowed to write dissenting opinions but only on topics related to their assignment (Rapport, 1996/97:6, 12).

Commissions also include one or more secretaries and support staff. The role of secretaries is more significant, since they participate in the actual drafting of the final policy document, whereas support staff have a purely clerical function. Secretaries are usually middle-level civil servants from ministries and central agencies, while support staff are usually lower level civil servants from ministries (Premfors, 1983).

Commissions may also consult with other outside parties who are not formally part of the commission. These are sometimes organized into an external expert or reference group, which has no formal powers. There may also be a reference group of parlamentarians attached to the inquiry.

\footnotetext{
${ }^{4}$ Both commissions of inquiry and special investigator inquiries are regulated by a government ordinance, which describes their basic composition (SFS 1998:1474) https : //www.riksdagen.se/sv/dokument-lagar/ dokument/svensk-forfattningssamling/kommitteforordning-19981474_sfs-1998-1474.
} 
Special investigator inquiries, on the other hand, are headed by a special investigator (särskild utredare), usually a high ranking civil servant, or a judge. He or she is usually supported by a number of experts and one or more secretaries. As a rule, special investigator inquiries have no commissioners. However, they usually (but not always) contain subject matter specialists, and occasionally, experts.

The findings of commissions and special investigator inquiries are presented to the government in the form of a report, published the Swedish Government Official Reports (SOU) series. By contrast, inquiries conducted by ministries publish their results in the Ministry Publications Series (Ds). In rare cases, a commission or special investigator report may also be published in the Ds series. The report (or reports, if there are several) are then sent for further comments to relevant government agencies, special interest groups, local government authorities, and other affected parties through the remiss procedure. After all the referral bodies have sent in their comments, the ministry responsible for the policy area drafts the bill, which is then submitted to the parliament.

Table 5.4 summarizes the main differences between commissions of inquiry and special investigator inquiries.

Table 5.4: Commissions of inquiry vs. special investigator inquiries

\begin{tabular}{|c|c|c|}
\hline Feature & Commissions of inquiry & Special inv. inquiries \\
\hline Member roles & $\begin{array}{l}\text { Chairperson/Vice chair } \\
\text { Experts } \\
\text { Subject matter specialists } \\
\text { Secretaries } \\
\text { Support staff }\end{array}$ & $\begin{array}{l}\text { Special investigator } \\
\text { Experts } \\
\text { Subject matter specialists } \\
\text { Secretaries } \\
\text { Support staff }\end{array}$ \\
\hline Type of dissent & Reservations/Dissenting opinions & Dissenting opinions \\
\hline Includes politicians & Often & Rarely \\
\hline Broadly representative & Yes & Sometimes \\
\hline
\end{tabular}




\subsection{Variables}

This section discusses the operationalization and measurement of the dependent, independent, and control variables used in the empirical models.

\subsubsection{Dependent variables}

The main dependent variable (presence of dissent) is an indicator of whether the commission reached consensus or not (see Table 5.5). This variable equals zero if there was consensus (i.e. there was no dissent), and one if there was at least one reservation or dissenting opinion. An alternative strategy would have been to use shares of dissent. However, individual dissents are not independent from each other. This is because commission members may write multiple reservations or dissenting opinions. In addition, members from the same side of the political issue tend to write common reservations and dissenting opinions.

Another dependent variable, used in a separate selection model, is an indicator whether the government appointed a representative commission or an expert commission to conduct the inquiry. I coded all inquiries headed by a chairperson (ordförande) as representative commissions, and all inquiries headed by a special investigator (särskild utredare) as expert commissions, regardless of their size or membership composition. The only exception were two inquiries which were headed by a special investigator, but had several commissioners (SOU 1993:15 and SOU 2008:16). There were also several inquiries which were not clearly in one or the other category, such as inquiries assigned to a working group or delegation. Most of these were coded as expert commissions, unless it was obvious from the context and the size or membership composition of the inquiry that it was intended to be broadly representative.

\subsubsection{Independent variables}

The main independent variables are the numbers of experts, stakeholders, and politicians (see Table 5.6). Experts include academics and civil servants employed at ministries, govern- 
Table 5.5: Dependent variables

\begin{tabular}{lll}
\hline Variable & Variable name & Operationalization \\
\hline Main analyses: & & \\
Presence of dissent & presence_dissent & $0=$ no dissent \\
& & \\
& & \\
Selection model: & & \\
Indicator variable for & & \\
representative commissions & commission & $0=$ representative commission \\
& &
\end{tabular}

ment agencies, and research agencies. Stakeholders include interested or affected parties. ${ }^{5}$ These include representatives of interest groups and regional or municipal employees who implement government policies at the local level, such as doctors, nurses, and teachers. The latter are classified as public servants in the data set. Politicians include those who hold public office and have been elected in their position. More detailed coding rules for these and other variables can be found in Appendix B.

Hypotheses 1, 4, and 5 state that dissent should decrease in the number of experts, that an increase in the number of politicians should increase dissent more than an increase in the number of stakeholders, and that an increase in the number of politicians should increase dissent more than an increase in the number of experts. I would therefore expect the coefficient of the number of experts to be negative, and the coefficient of the number of politicians to be positive and larger in magnitude than the coefficient of stakeholders.

\footnotetext{
${ }^{5}$ The Commission of the European Union defines interested parties as "an individual or group that is concerned about, or stands to be affected by, directly or indirectly, the outcome of a policy process; or that represents the general interest of groups concerned by such an outcome" (http://ec.europa.eu/governance/docs/archives_en.htm, https://ec.europa.eu/europeaid/ european-governance-white-paper_en). Similarly, the International Standards Organization (ISO 14001, ISO 45001) defines interested parties as a: "person or organization that can affect, be affected by, or perceive itself to be affected by a decision or activity."
} 
To test Hypothesis 2, I include an interaction variable of the number of stakeholders and a dummy which equals one if the inquiry was conducted by a representative commission and zero if it was conducted by an expert commission. Since the Hypothesis 2 states that increasing the number of stakeholders in broadly representative commissions of inquiry would result in a decrease of dissent, the coefficient of this variable should be negative. ${ }^{6}$

I also include a variable for the number of judges. Although the theory makes no predictions about judges, there were sufficiently many in the data set to justify a separate category. I also include a leftover category (other) for members who did not fit in any of the other categories. Members in this category included employees of private accountancy firms, consultants, artists, journalists, and representatives of private companies. Finally, I include a variable for members who could not be classified (unclassified).

I repeat the empirical analyses using an alternative coding scheme, also shown in Table 5.3. In the alternative coding scheme, academics and interest groups members are separated into their own categories, and civil servants and public servants are combined into a single category (bureaucrats).

The reason for using both coding schemes is that the categorization of public servants is challenging. They are interested parties in the sense that they are directly affected by changes to existing policies in their professional life and their knowledge arises partly from their work within the public sector (Peters, 2001). However, they are also government employees. As a further robustness check, I perform some empirical analyses using public servants as a separate category.

\subsubsection{Control and selection variables}

Table 5.7 lists two types of control variables used in the empirical models. The first type are control variables used in the main empirical inquiries. The second type are selection variables used in an empirical model which predicts whether the government is more likely to appoint a representative commission or an expert commission. Note that some variables are used in both the main empirical models and the selection model.

\footnotetext{
${ }^{6}$ I discuss Hypothesis 6 in the next section. Testing Hypothesis 3 properly requires an adjustment to the empirical model, which I will discuss in Section 5.5.3.
} 
Table 5.6: Independent variables

\begin{tabular}{|c|c|c|}
\hline Variable & Variable name & Operationalization \\
\hline \multicolumn{3}{|l|}{ Member variables: } \\
\hline Nr experts & experts & $\mathrm{Nr}$ academics + civil servants \\
\hline Nr politicians & politicians & Nr politicians \\
\hline Nr judges & judges & Nr judges \\
\hline Nr stakeholders & stakeholders & $\begin{array}{l}\text { Nr int. group members }+ \\
\text { public servants }\end{array}$ \\
\hline Nr other members & other & $\mathrm{Nr}$ other types of members \\
\hline Nr unclassified members & unclassified & Nr unclassified \\
\hline \multicolumn{3}{|l|}{$\begin{array}{l}\text { Indicator variable for } \\
\text { repr. commissions: }\end{array}$} \\
\hline Representative commission & commission & $\begin{array}{l}1=\text { repr } . \text { commission } \\
0=\text { expert commission }\end{array}$ \\
\hline \multicolumn{3}{|l|}{ Interaction variables: } \\
\hline Repr. commission x experts & commexp & experts $\mathrm{x}$ commission \\
\hline Repr. commission x politicians & commpol & politicians $\mathrm{x}$ commission \\
\hline Repr. commission x stakeholders & commstake & stakeholders $\mathrm{x}$ commission \\
\hline
\end{tabular}

\section{Alternative coding:}

Member variables:

$\mathrm{Nr}$ academics

academics

$\mathrm{Nr}$ academics

$\mathrm{Nr}$ buraucrats

bureaucrats

$\mathrm{Nr}$ int. group members

int_groups

judges

politicians

$\mathrm{Nr}$ politicians

Nr other members

$\mathrm{Nr}$ unclassified members

other

unclassified

$\mathrm{Nr}$ civil servants + public servants

$\mathrm{Nr}$ int. group members

Nr judges

$\mathrm{Nr}$ politicians

$\mathrm{Nr}$ other types of members

Nr unclassified

\section{Dummy variable for}

representative commissions:

Representative commission

commission

$1=$ representative commission

$0=$ expert commission

\section{Interaction variables:}

Repr. commission $\mathrm{x}$ academics

commaca

Repr. commission $\mathrm{x}$ int. group members

commint

Repr. commission $\mathrm{x}$ politicians

commpol

academics $\mathrm{x}$ commission

int_groups $\mathrm{x}$ commission

politicians $\mathrm{x}$ commission 
Table 5.7: Control/selection variables

\section{Variable}

\section{Control variables:}

Commission size

$\mathrm{Nr}$ commission directives

$\mathrm{Nr}$ of previous SOUs

N_members

Nr members (excl. secretaries)

$n r_{-} d i r$

$\mathrm{Nr}$ commission directives

$\mathrm{Nr}$ of previous SOUs published by same commission or special investigator

Parliamentary reference group parl_ref $\quad 0=$ no, $1=$ yes

attached to inquiry

Political polarization

Policy area of inquiry

\section{Selection variables:}

Political polarization

Budget deficit

An EU directive mentioned in directive or $\mathrm{SOU}$

Policy area of inquiry

Government random effects rile_pol

Dalton (2008)

deficit

eupolicy

See Appendix B

Comparative Agendas Project 
The first variable, commission size, equals the number of commission members, excluding secretaries. ${ }^{7}$ Other things being equal, larger commissions should be less consensual (Cartwright, 1975, 186). However, as I discuss in Section 5.5, this variable enters the model non-linearly, and requires a correction for this nonlinearity in the empirical models.

The second variable, number of commission directives, equals the number of directives the inquiry has received from the government. Directives are one of the main tools that the government uses to ensure that the commission arrives at the anticipated results. A commission which has received multiple directives is likely to have less discretion in deciding its policy recommendation. This may mean that the commission is more likely to be consensual. However, the government is also more likely to issue multiple directives to inquiries investigating significant policy initiatives, which are likely to be more conflictual. For these reasons, I refrain from making hypotheses about the sign of the coefficient of this variable.

The third variable, number of previous SOUs, equals the number of previous reports published by the same commission of special investigator inquiry. A higher number of previous reports could indicate that the policy issue is significant and requires extensive preparation, which would mean that the inquiry is more likely to be conflictual. Alternatively, it could indicate that commission members have worked through most their points of conflict, and that the outcome of the present inquiry is less likely to be conflictual. Again, I refrain from making hypotheses about the sign of this coefficient.

The fourth variable, parl_ref, indicates the presence or absence of a parliamentary reference group. The presence of a parliamentary references group can indicate that the policy issue is politically significant, and therefore more likely to be conflictual, or that the commission is using the parliamentary reference group to resolve political conflicts. Again, I refrain from making hypotheses about the sign of the coefficient.

Finally, I adjust for other sources of conflict. Since some policy areas are likely to be more conflictual than others, I include 18 policy area indicator variables based on the 21 policy issue categories in the Comparative Agendas Project (CAP) codebook. ${ }^{8}$ Following a recent study of Norwegian and Danish commissions of inquiry (Hesstvedt and Christiansen,

\footnotetext{
${ }^{7}$ Secretaries are excluded because they cannot express reservations or dissenting opinions.

${ }^{8} \mathrm{https}$ ://www. comparativeagendas.net/pages/master-codebook
} 
2020), I combine the following CAP policy areas into a single category: (1) Culture and Education; (2) Energy, Environment, and Public lands. I use Law and Crime as the dummy category.

I also include a variable measuring the level of political polarization (rile_pol) (Dalton, 2008) from the election-level database of the Manifesto Project (Volkens et al., 2019). The rile polarization index measures the degree of polarization in a party system. Each party's position is estimated on a single policy dimension is estimated, as is an overall average position, weighted by vote share. The polarization index is a scaled standard deviation. The definition for a system with $n$ parties is

$$
\text { rile_polarization }=\sqrt{\sum_{i=1}^{n}\left[\left(\frac{\text { position }_{i}-\text { weighted mean position }}{100}\right)^{2} \cdot \text { vote }^{2} \text { share }_{i}\right]}
$$

The division by 100 under the square root is a normalization. Dalton (2008, 910-912) shows that this index correlates with overall voter polarization (so that limits on alternatives parties offer are not so large as to mask overall voter polarization). Other things being equal, I expect the sign of this variable to be negative in the main empirical models, as political polarization will make it more difficult to negotiate consensus.

To test Hypothesis 6, I include the polarization variable in a separate selection model, which predicts whether the government appoints a representative or expert commission. In the same model, I also include a variable indicating whether the commission directive mentioned an EU directive which applies to the inquiry (eupolicy). This variable equals one if there is an EU directive which applies to the inquiry and is mentioned in the text of the commission directive or the report, and zero if no EU directives are specifically mentioned. Since EU policy issues are less likely to be negotiable, I expect inquiries concerning EU policy issues to be assigned to expert inquiries rather than representative/parliamentary commissions.

The selection model also includes a variable representing the yearly budget deficit/surplus (deficit), where negative values indicate a deficit and positive values a budget surplus. Although the model does not make direct predictions about commission appointment and budget deficits, Cartwright (1975) suggests that governments are more likely to appoint broadly 
representative commissions during more prosperous economic times due to their distributive nature.

I also include the policy area indicators in the selection model.

Initially, I included other control variables that could predict the government's willingness to appoint broadly representative commissions (Petersson, 2016; Hesstvedt and Christiansen, 2020). The first was the share of positions in the cabinet held by members of Left or Right parties (gov_left1 and gov_right1, respectively) from the Comparative political data set (Armingeon et al., 2019). The second was share_seat, a measure of the government's level of parliamentary support, also from the Comparative political data set. The third was rile_wmean from the Manifesto Project's election-level database (Volkens et al., 2019) ${ }^{9}$, which measures the left-right position of the legislature (Gross and Sigelman, 1984). However, these variables caused significant multicollinearity, so they were dropped from the final models.

I also included a measure of saliency of the policy issue based on the Most Important Policy Issue (MIP) question in the SOM Institute Cumulative Dataset (Super-Riks SOM) ${ }^{10}$ with SOM policy areas mapped to the CAP policy areas. However, this variable was collinear with defence and immigration so I had to drop it. There was also not much variation in the saliency of policy issues across time.

I also checked whether adding controls for cabinet type (e.g., minority government, minority coalition, etc.). The results did not change, and the additional controls were either not significant or caused multicollinearity with the government random effects. I will not discuss these alternative specifications further.

\subsubsection{Descriptive statistics}

Tables 5.8 and 5.9 show descriptive statistics for representative commissions (commissions of inquiry) and expert commissions (special investigator inquiries). Of the 2,705 inquiries in the data set, $683(25.25 \%)$ are representative and 2,022 (74.75\%) expert commissions. Due

\footnotetext{
${ }^{9}$ https://doi.org/10.25522/manifesto.mpds.2019b

${ }^{10}$ https://snd.gu.se/en/catalogue/study/snd1018
} 
to dropping inquiries with fewer than three members (excluding secretaries), the share of representative commissions is larger than their share of the population total.

Table 5.8: Summary statistics for representative commissions

\begin{tabular}{lccccccc}
\hline \hline & mean & $\mathrm{sd}$ & $\mathrm{min}$ & $\mathrm{p} 25$ & $\mathrm{p} 50$ & $\mathrm{p} 75$ & $\max$ \\
\hline Presence of dissent & 0.58 & 0.49 & 0.00 & 0.00 & 1.00 & 1.00 & 1.00 \\
Nr members & 19.21 & 9.12 & 3.00 & 13.00 & 18.00 & 23.00 & 75.00 \\
Nr directives & 1.46 & 0.82 & 1.00 & 1.00 & 1.00 & 2.00 & 6.00 \\
Nr previous inquiries & 0.85 & 1.53 & 0.00 & 0.00 & 0.00 & 1.00 & 11.00 \\
Parl. reference group & 0.02 & 0.15 & 0.00 & 0.00 & 0.00 & 0.00 & 1.00 \\
Nr experts & 7.47 & 5.06 & 0.00 & 4.00 & 7.00 & 10.00 & 43.00 \\
Nr stakeholders & 2.79 & 3.51 & 0.00 & 0.00 & 2.00 & 4.00 & 28.00 \\
Nr politicians & 4.82 & 4.11 & 0.00 & 0.00 & 6.00 & 8.00 & 21.00 \\
Nr gvt party members & 2.06 & 2.00 & 0.00 & 0.00 & 2.00 & 4.00 & 9.00 \\
Nr opp. party members & 2.76 & 2.63 & 0.00 & 0.00 & 2.00 & 5.00 & 14.00 \\
Nr judges & 0.52 & 1.07 & 0.00 & 0.00 & 0.00 & 1.00 & 10.00 \\
Nr others & 0.19 & 0.57 & 0.00 & 0.00 & 0.00 & 0.00 & 5.00 \\
Nr unclassified & 3.02 & 3.43 & 0.00 & 1.00 & 2.00 & 4.00 & 38.00 \\
Ideol. polarization (Dalton 2008) & 2.12 & 0.40 & 1.47 & 1.64 & 2.31 & 2.34 & 3.24 \\
\hline Observations & 683 & & & & & & \\
\hline \hline
\end{tabular}

Table 5.9: Summary statistics for expert inquiries (expert commissions)

\begin{tabular}{lccccccc}
\hline \hline & mean & $\mathrm{sd}$ & $\mathrm{min}$ & $\mathrm{p} 25$ & $\mathrm{p} 50$ & $\mathrm{p} 75$ & $\max$ \\
\hline Presence of dissent & 0.33 & 0.47 & 0.00 & 0.00 & 0.00 & 1.00 & 1.00 \\
Nr members & 11.24 & 5.82 & 3.00 & 7.00 & 10.00 & 14.00 & 55.00 \\
Nr directives & 1.43 & 0.74 & 1.00 & 1.00 & 1.00 & 2.00 & 6.00 \\
Nr previous inquiries & 0.28 & 0.65 & 0.00 & 0.00 & 0.00 & 0.00 & 6.00 \\
Reference group of politicians & 0.02 & 0.15 & 0.00 & 0.00 & 0.00 & 0.00 & 1.00 \\
Nr experts & 6.65 & 3.84 & 0.00 & 4.00 & 6.00 & 8.00 & 38.00 \\
Nr stakeholders & 1.54 & 2.08 & 0.00 & 0.00 & 1.00 & 2.00 & 13.00 \\
Nr politicians & 0.13 & 0.57 & 0.00 & 0.00 & 0.00 & 0.00 & 12.00 \\
Nr judges & 0.53 & 0.98 & 0.00 & 0.00 & 0.00 & 1.00 & 12.00 \\
Nr others & 0.16 & 0.56 & 0.00 & 0.00 & 0.00 & 0.00 & 7.00 \\
Nr unclassified & 2.02 & 2.74 & 0.00 & 0.00 & 1.00 & 3.00 & 19.00 \\
Ideol. polarization (Dalton 2008) & 2.00 & 0.38 & 1.47 & 1.62 & 2.09 & 2.34 & 3.24 \\
\hline Observations & 2022 & & & & & & \\
\hline \hline
\end{tabular}

The average representative commission had roughly 19 members, and the lower and upper quartiles were 13 and 23. There was dissent in $58 \%$ of inquiry reports, which means that $42 \%$ of reports by representative commissions did not have a single dissenting opinion or 
reservation. Theis level of consensus is remarkable when viewed in terms of the probability that a given member dissents, an issue I return to below when testing Hypothesis 3 (Commission size and probability of dissent). Let $p$ be the probability that a single member on a commission dissents. If all 19 members on an average-sized commission can either dissent or have someone submit dissents on their behalves, then the probability of unanimous support for a recommendation is

$$
(1-p)^{19}=0.42
$$

meaning the chance an individual dissents on an average commission is

$$
p \approx 4.3 \%
$$

To understand how unthinkably high this level of consensus is, recall that these are ad hoc commissions, often comprised of people who have different policy objectives. Yet when the final recommendation is made, there is nearly a $96 \%$ chance that a given member will support the recommendation.

Turning to Table 5.9, it is clear that dissent is also low on expert commissions (special investigator inquiries). These are considerably smaller than representative commissions, but still have a lower and upper quartile of 7 and 14 members, respectively. Two thirds issue a report without any dissent, corresponding to an individual member dissent probability of $3.5 \%$ for an average inquiry, or again roughly a $96 \%$ probability that a given member will support the proposal.

The low rate of dissent on the expert commissions is less surprising. Experts constitute about $59 \%$ of an average inquiry's membership, politicians are rarely included, and stakeholder representation is at roughly half the level as in representative commissions.

Moving onto stakeholder representation, Table 5.10 shows the shares of different types of interest groups in representative commissions (commissions of inquiry) and expert commissions (special investigator inquiries), and Table 5.11 the top ten interest groups, representing $44.45 \%$ of interest groups in the sample.

The largest category $(24.67 \%)$ of interest groups are NGOs, which range from large pensioners' organizations to small organizations representing religious and ethnic minorities. The overwhelming majority of NGOs appear in the data only a few times. 
The second largest category are government interest groups representing Swedish municipalities and regions. The largest of these is the Swedish Association of Local Authorities and Regions (SALAR), which advocates for all of Sweden's municipalities and regions. Before 2007, SALAR consisted of two separate organizations - the Swedish Association of Local Authorities and the Swedish Association of Regions. Together, SALAR, the Swedish Association of Local Authorities, and the Swedish Association of Regions represent about 24.04\% of all interest groups in the sample.

The third largest category $(16.92 \%)$ are employers' organizations. The largest of these is the Confederation of Swedish Enterprise, an employers' organization for private sector and business sector companies representing 60,000 member companies with more than 1.6 million employees.

The fourth largest category (14.94\%) are professional associations such as the Swedish Medical Association or teachers' or farmers' associations.

Finally, the fifth largest category (14.49\%) are labor unions and organizations. The most frequent of these are the three largest labor union organizations: the Swedish Trade Union Confederation (LO), the Swedish Confederation of Professional Employees (TCO), and the Swedish Confederation of Professional Associations (SACO). Although this is the smallest category, the three largest labor unions comprise $9.97 \%$ of interest groups in the sample, which is more than the percentage of the Confederation of Swedish Enterprise and the Swedish Federation of Business Owners combined (6.58\%).

Only a negligible percentage of interest groups were in the Other category. In addition, $4.73 \%$ of members of interest groups could not be classified. The was usually because the commission member was identified as a chairperson of an interest group, but the name of the interest group was not included in the report.

Table 5.12 shows the percentages of policy areas by inquiry type (expert vs. representative commissions). The five top policy areas are Domestic commerce (12.2\% of representative commissions and $10.0 \%$ of expert commissions), Education and culture (8.9\% of representative commissions and 13.6 percent of expert commissions), Government operations (8.5\% of representative commissions and $13.9 \%$ of expert commissions), Law and crime $8.9 \%$ of 
Table 5.10: Shares of types of interest groups, commissions and spec. inv.

\begin{tabular}{lrrrrr}
\cline { 2 - 3 } Type of interest group & \multicolumn{2}{c}{ Repr. commissions } & & \multicolumn{2}{c}{ Expert commisions } \\
\cline { 2 - 3 } Mean & sd & & Mean & sd \\
\hline Employers/Industry organizations & 0.18 & 0.32 & & 0.12 & 0.25 \\
Government interest groups (SALAR) & 0.28 & 0.39 & & 0.39 & 0.38 \\
Labor unions/organizations & 0.07 & 0.20 & & 0.15 & 0.27 \\
NGOs & 0.23 & 0.35 & & 0.22 & 0.32 \\
Professional organizations & 0.17 & 0.30 & & 0.10 & 0.24 \\
Other interest groups & 0.00 & 0.04 & & 0.00 & 0.02 \\
\hline Observations & 811 & & 359 & \\
\hline \hline
\end{tabular}

Table 5.11: Ten most frequent interest groups

\begin{tabular}{lrrr}
\hline Interest group & Freq & \% & Cum. \% \\
\hline Swedish Association of Local Authorities and Regions (SALAR) & 301 & 9.35 & 9.35 \\
Swedish Association of Local Authorities & 272 & 8.45 & 17.80 \\
Swedish Association of Regions & 201 & 6.24 & 24.04 \\
Confederation of Swedish Enterprise (Svenskt Näringsliv) & 122 & 3.79 & 27.83 \\
Swedish Trade Union Confederation (LO) & 117 & 3.63 & 31.47 \\
Swedish Confederation of Professional Employees (TCO) & 105 & 3.26 & 34.73 \\
The Federation of Swedish Farmers (LRF) & 101 & 3.14 & 37.87 \\
Swedish Confederation of Professional Associations (SACO) & 99 & 3.08 & 40.94 \\
The Swedish Federation of Business Owners (Företagarna) & 61 & 1.89 & 42.84 \\
The Swedish Property Owners' Association (Fastighetsägarna) & 52 & 1.62 & 44.45 \\
\hline
\end{tabular}


representative commissions and $6.9 \%$ of expert commissions) and Environment and energy (9.7\% of of representative commissions and $7.3 \%$ of expert commissions).

Table 5.12: Policy areas by type of inquiry

\begin{tabular}{|c|c|c|c|c|c|c|}
\hline \multirow[b]{2}{*}{ Policy area } & \multicolumn{2}{|c|}{ Expert comm. } & \multicolumn{2}{|c|}{ Repr. comm } & \multicolumn{2}{|c|}{ Total } \\
\hline & No. & $\%$ & No. & $\%$ & No. & $\%$ \\
\hline Agriculture & 57 & 2.8 & 11 & 1.6 & 68 & 2.5 \\
\hline Civil Rights & 51 & 2.5 & 29 & 4.2 & 80 & 3.0 \\
\hline Defense & 95 & 4.7 & 22 & 3.2 & 117 & 4.3 \\
\hline Domestic commerce & 246 & 12.2 & 68 & 10.0 & 314 & 11.6 \\
\hline Education/culture & 179 & 8.9 & 93 & 13.6 & 272 & 10.1 \\
\hline Environment/energy & 196 & 9.7 & 50 & 7.3 & 246 & 9.1 \\
\hline Foreign trade & 26 & 1.3 & 8 & 1.2 & 34 & 1.3 \\
\hline Govt operations & 172 & 8.5 & 95 & 13.9 & 267 & 9.9 \\
\hline Health & 135 & 6.7 & 48 & 7.0 & 183 & 6.8 \\
\hline Housing & 66 & 3.3 & 16 & 2.3 & 82 & 3.0 \\
\hline Immigration & 59 & 2.9 & 20 & 2.9 & 79 & 2.9 \\
\hline International affairs & 56 & 2.8 & 21 & 3.1 & 77 & 2.8 \\
\hline Labor & 116 & 5.7 & 25 & 3.7 & 141 & 5.2 \\
\hline Law and crime & 180 & 8.9 & 47 & 6.9 & 227 & 8.4 \\
\hline Macroeconomics & 104 & 5.1 & 35 & 5.1 & 139 & 5.1 \\
\hline Social welfare & 119 & 5.9 & 43 & 6.3 & 162 & 6.0 \\
\hline Technology/media & 60 & 3.0 & 24 & 3.5 & 84 & 3.1 \\
\hline Transportation & 105 & 5.2 & 28 & 4.1 & 133 & 4.9 \\
\hline Total & 2,022 & 100.0 & 683 & 100.0 & 2,705 & 100.0 \\
\hline
\end{tabular}

\section{$5.4 \quad(2 \times 2)$ Analysis}

Before going through the details of the empirical models, it may be useful to review the overall effects of inclusivity on dissent. Table 5.13 shows a $(2 \times 2)$ matrix of the probability of individual dissent. The rows split the sample by inquiry type, that is, whether the inquiries are commissions or special investigations, i.e. expert inquiries. The colums then split each inquiry type by whether the number of stakeholders included is above or below the median for that type of inquiry. Any inquiries that had the median number of stakeholders included were excluded here. 
Each cell in the table shows the inferred probability of an individual dissent for the inquiry type and level of stakeholder inclusivity. As discussed above, inferring the probability of individual dissent helps adjust for the sizes of the average inquiry in each cell.

Table 5.13: Individual dissent by inclusivity and inquiry type

\begin{tabular}{|l|c|c|c|}
\hline & Inclusive & Exclusive & Likelihood Ratio \\
\hline Commissions & $4.09 \%$ & $4.96 \%$ & $\mathbf{1 . 2 1}$ \\
\hline Expert inquiries & $3.72 \%$ & $2.91 \%$ & $\mathbf{0 . 7 8}$ \\
\hline
\end{tabular}

As the table shows, commissions address issues that are generally more controversial or significant. Regardless of how inclusive an inquiry is, we see a somewhat higher probability of individual dissent on matters sent to commissions. This is reassuring, as it indicates that governments overall are not burying controversial issues in expert inquiries and using commissions largely for show, although naturally this could be the case for some individual inquiries.

More critically for the theory discussed here, we see that inclusivity on commissions is associated with a lower probability of dissent for commissions, but with a higher probability of dissent on expert inquiries, both of which are in keeping with the predictions of the theory. Excluding stakeholders from commissions increases the probability of individual dissent by a factor of 1.21, while excluding stakeholders from expert inquiries decreases the probability of individual dissent by factor of 0.78 .

These results are in keeping with the general findings of the theory. To verify that these findings are not artifacts of other factors, I now turn to the main empirical analysis.

\subsection{Empirical Models}

\subsubsection{Empirical challenges}

The data present multiple empirical challenges, which cannot all be solved within a single model. I therefore present two sets of models. The first set of models adjust for the hier- 
archical nature of the data and the unobserved heterogeneity within individual commissions and governments, which may directly or indirectly affect the probability of dissent. The second set of models adjust for the endogenous selection of policy issues into representative and expert commissions. In addition, they provide a statistical adjustment to measuring the effects of an increase of different member types by controlling for commission size.

\subsubsection{Adjusting for nesting: a multilevel probit model}

The data contain 2,023 individual commissions which conducted 2,705 inquiries. There is significant overlap on the membership composition and other variables across inquiries conducted by the same commission. For this reason, the individual inquiries cannot be considered as independent observations. The data are also hierarchical in nature: individual inquiries are nested within commissions, and commissions are nested within governments. Both individual commissions and governments are likely to have unobserved heterogeneity, which may directly or indirectly affect the probability of dissent.

To adjust for the hierarchical nature of the data and to control for the lack of independence and unobserved heterogeneity, I use a multilevel probit model (see Raudenbush and Bryk, 2001). ${ }^{11}$ In addition, I use Cluster-Robust Variance Matrix Estimates (CRVE) (Cameron and Miller, 2011), clustered by individual governments (gvt_id), to obtain clustered standard errors (the list of governments was shown earlier in Table 5.2). The specification at the lowest level is:

$$
\begin{aligned}
\text { presence_dissent } & =\beta_{0 j k}+\beta_{1} \text { experts }+\beta_{2} \text { politicians }+\beta_{3} \text { stakeholders } \\
& +\beta_{4} \text { commission }+\beta_{5} \text { commexp }+\beta_{6} \text { commstake }+ \text { controls }
\end{aligned}
$$

with random intercept effects for governments (the $j$ grouping) and individual commissions (the $k$ grouping). ${ }^{12}$

\footnotetext{
${ }^{11}$ Multilevel models require that the residuals are uncorrelated across levels and at the highest level. Both of these assumptions appear to hold (details available on request).

${ }^{12}$ Table 5.9 shows that very few special investigator inquiries include politicians. Therefore, the interaction variable of politicians with commission type (commpol) was highly collinear with politicians. I dropped the interaction term from the model since it was not necessary for testing any of the hypotheses. As a robustness
} 
Model (5.1) lets me test Hypotheses 1-2 and 4-5. I present a different model for testing Hypotheses 3 and 6 in the Section 5.5.3. Table 5.14 shows the predicted signs of the coefficients.

Table 5.14: Predicted signs of coefficients for Model (5.1)

\begin{tabular}{ll}
\hline Hypothesis & Prediction \\
\hline $\mathbf{H}_{\mathbf{A}}^{1}$ Experts & $\beta_{1}<0$ \\
$\mathbf{H}_{\mathbf{A}}^{2}$ Stakeholders x representative commission & $\beta_{6}<0$ \\
$\mathbf{H}_{\mathbf{A}}^{4}$ Politicians vs. stakeholders & $\beta_{2}>\beta_{3}$ \\
$\mathbf{H}_{\mathbf{A}}^{5}$ Politicians vs. experts & $\beta_{2}>\beta_{1}$ \\
\hline
\end{tabular}

\subsubsection{Adjusting for selection and commission size: a bivariate probit with a correction for commission size}

Model (5.1) does not provide a straightforward test of Hypothesis 6 (Political polarization). This is because the government's decision to assign a policy issue to to a representative commission or expert commission is treated as exogenous. However, $H^{6}$ (Political polarization) suggests that there is a selection issue. In addition, although Hypothesis 3 (Commission size and probability of dissent) could in principle be tested from the fitted values of Model (5.1), doing so would require an additional test to control for selection issues in commission assignment.

To address these issues, I separate the selection issue from the prediction of dissent. This approach corresponds to a bivariate probit model model, with each stage evaluated separately.

I also test whether the results from adjusting for selection are consistent with the results on $H^{1}$ (Experts), $H^{2}$ (Stakeholders x representative commissions), $H^{4}$ (Politicians vs. stakeholders), and $H^{5}$ (Politicians vs. experts) from Model (5.1).

For the selection stage, I use the following specification:

$$
\text { commission }=\gamma_{0}+\gamma_{1} \text { rile_pol }+\gamma_{2} \text { eupolicy }+ \text { policy areas }+ \text { controls }
$$

check, I also ran (5.1) with two alternative specifications, as a multilevel logit and as a multilevel linear probability model. The results did not change in any important way, and I will not discuss these checks further (details available on request). 
Table 5.15 shows the main prediction of Model (5.2). A natural interpretation of Hypothesis 6 is that the government appoints broadly representative commissions to address conflict, rather than using expert commissions to bury conflict. In addition, I expect the coefficient of eupolicy to be negative because inquiries dealing with matters of EU policy implementation tend to be more narrow in focus and involve less uncertainty than more open-ended inquiries, and therefore more likely to be sent to expert commissions.

Table 5.15: Predicted sign of coefficient for Model (5.2)

\begin{tabular}{ll}
\hline Hypothesis & Prediction \\
\hline $\mathbf{H}_{\mathrm{A}}^{6}$ Political polarization & $\gamma_{1}>0$ \\
\hline
\end{tabular}

To test Hypothesis 3 (Commission size and probability of dissent) with an adjustment for selection, I ran two separate probits on a sample split by commission type (representative commission vs. expert commission). I used the following probit specification:

$$
\begin{aligned}
\text { presence_dissent } & =\delta_{0}+\delta_{1} \text { experts }+\delta_{2} \text { politicians }+\delta_{3} \text { stakeholders } \\
& +\delta_{4} \text { commission }+\delta_{5} \text { commexp }+\delta_{6} \text { commstake }+ \text { controls }
\end{aligned}
$$

running separately for each inquiry type.

I then used the predicted values from Model (5.3) as an estimated probability that there would be dissent on a given inquiry. To estimate the effect of commissions on individual dissent, I created a new value, similar to the value $p$ in Subsection 5.3.4:

$$
\begin{aligned}
r a w \_d i s s \_p r o b & =\text { fitted values from }(5.3) \\
\text { individ_diss_prob } & =1-\left(1-r a w \_d i s s e n t \_p r o b\right)^{1 / N \_m e m b e r s}
\end{aligned}
$$

This adjustment adjusts for unobserved dissent, i.e. the dissent of individuals who were excluded from the commission but would have dissented if they would have been included in the commission.

Table 5.16 shows the prediction for Hypothesis 3 and the additional tests on the hypotheses for Model (5.1). 
Table 5.16: Predicted signs of coefficients for Model (5.3)

\begin{tabular}{ll}
\hline Hypothesis & Prediction \\
\hline $\mathbf{H}_{\mathbf{A}}^{1}$ Experts & Corr $($ ind_diss_pr,experts $)<0$ for both subsamples \\
$\mathbf{H}_{\mathbf{A}}^{3} \mathbf{N r}$ members & Corr $($ ind_diss_pr,stakeholders $)<0$ \\
$\begin{array}{l}\text { \& prob. of dissent } \\
\mathbf{H}_{\mathbf{A}}^{4} \text { Politicians }\end{array}$ & Corr $($ ind_diss_pr,politicians $)>$ Corr $($ ind_diss_pr, stakeholders $)$ \\
vs. stakeholders & for the subsample of representative commissions \\
$\mathbf{H}_{\mathbf{A}}^{\mathbf{5}}$ Politicians & Corr $($ ind_diss_pr,politicians $)>$ Corr $($ ind_diss_pr,experts $)$ \\
vs. experts & for the subsample of special investigator inquiries \\
\hline
\end{tabular}

To illustrate why it is important to adjust for the unobserved dissent, suppose there are two potential commission members, Alice (A) and Biff (B), who share a common assessment of the merits of a proposed policy. If the probability that A dissents to a proposal is $p$, assume that the probability $\mathrm{B}$ dissents is also $p$.

If $\mathrm{A}$ is the on a commission but $\mathrm{B}$ is not, then the probability that one of $\{\mathrm{A}, \mathrm{B}\}$ dissents is then $p$. Likewise, if $\mathrm{B}$ is on a commission but $\mathrm{A}$ is not, then the observed probability of dissent from $\{\mathrm{A}, \mathrm{B}\}$ remains $p$. However, in both cases, the probability that one of $\{\mathrm{A}, \mathrm{B}\}$ dissents is actqually $1-(1-p)^{2}$. In other words, the true probability of dissent equals one minus the probability that all parties have no objections.

Commissions that include both $\mathrm{A}$ and $\mathrm{B}$ will then have dissent with probability $1-(1-p)^{2}$. If a researcher looks solely at the probability of dissent as a function of representation, he or she will be tempted to infer that increasing representation causes conflict. For instance, if $p=0.2$, commissions with just A or just B will show them dissenting $20 \%$ of the time, but those with both $\mathrm{A}$ and $\mathrm{B}$ included will show them dissenting $36 \%$ of the time, a likelihood ratio of 1.8. Even if the researcher is careful, and qualifies the inference by noting that the preferences of excluded parties are unobservable, it will be natural to focus on the high likelihood ratio.

This method of adjusting for the unobserved dissent is equivalent to establishing a baseline/benchmark for the effect of a unit increase of a certain member type, similar to the 
'truth-wins' method in team performance research discussed in Cooper and Kagel (2005). The basic idea behind the 'truth-wins' method is that the researcher constructs a benchmark of what one team member would be able to do acting alone, and then compares the performance of the team with this norm. Of course, it is not possible to find those who could have been included in the commission, but who, for whatever reason, were not. But it is possible to compare the effects of inclusion on the probability that an individual commission member might dissent.

In the context of the example, this approach would work as follows: on the commissions that include either Alice (A) or Biff (B) but not both, estimate the probability that A or B would dissent, for example by a probit, if there are known variables that affect this probability. On commissions that include both $\mathrm{A}$ and $\mathrm{B}$, estimate $1-(1-p)^{2}$ rather than the overall probability that there is dissent given both members of $\{\mathrm{A}, \mathrm{B}\}$ are on the commission. Rather than estimating a probit, the appropriate likelihood function to maximize would estimate the likelihood that the most extreme of two draws leads to a dissent.

This approach addresses the counterfactual in the following sense: suppose someone is included on a commission. Now imagine, contrary to fact, that this person had been excluded. How much would this exclusion affect the probability of dissent to the commission's final report? The appropriate test is then whether this reduction differs from what can be attributable to simply observing one fewer draw. If excluding the individual would reduce the dissent probability by more than attributable to the unobserved dissents, then adding more individuals of this type can safely be claimed to increase dissent. If excluding the individual would reduce the dissent probability by less than attributable to unobserved dissents, then adding more individuals of this type might actually increase consensus.

\subsection{Results from the Multilevel Probit}

Table 5.17 presents the results from the multilevel probit (5.1) with random intercept effects for governments (the $j$ grouping) and individual commissions (the $k$ grouping). The 
standard errors are calculated with Cluster-Robust Variance Matrix Estimates (CRVE) (Cameron and Miller, 2011), using the government id (gvt_id) as the clustering variable.

Model 1 presents results with inquiry-specific control variables. Model 2 is similar to Model 1, but adds the variable rile_pol indicating the level of ideological polarization in the legislature (Dalton, 2008).

Table 5.18 presents the results from a multilevel probit with the alternative coding of commission members (Academics, Bureaucrats, Interest groups, and Politicians instead of Experts, Stakeholders and Politicians). Table 5.19 shows statistics for the group variables, gvt_id and comm_code..$^{13}$

Note that the number of observations is smaller for Model 2. This is because the Persson I government does not have a value for political polarization in the Manifesto Project's election-level database.

Table 5.17: Multilevel probit model; DV: presence of dissent, cluster robust SE

\begin{tabular}{lcccc}
\hline \hline & \multicolumn{3}{c}{ Model 1 } & \multicolumn{2}{c}{ Model 2} \\
\hline Nr experts & $-0.0419^{* * *}$ & $(0.0101)$ & $-0.0439^{* * *}$ & $(0.0105)$ \\
Nr stakeholders & $0.0626^{* *}$ & $(0.0226)$ & $0.0622^{* *}$ & $(0.0235)$ \\
Nr politicians & $0.105^{* * *}$ & $(0.0237)$ & $0.0866^{* * *}$ & $(0.0166)$ \\
Repr. commission $=1$ & 0.137 & $(0.200)$ & 0.228 & $(0.193)$ \\
Repr. commission x experts & -0.0110 & $(0.0198)$ & -0.0176 & $(0.0202)$ \\
Repr. commission x stakeholders & $-0.108^{* *}$ & $(0.0405)$ & $-0.0859^{*}$ & $(0.0401)$ \\
Nr judges & 0.0955 & $(0.0490)$ & 0.0872 & $(0.0521)$ \\
Nr others & 0.0315 & $(0.0483)$ & 0.0330 & $(0.0537)$ \\
Nr members & $0.0763^{* * *}$ & $(0.0140)$ & $0.0734^{* * *}$ & $(0.0142)$ \\
Nr directives & $0.140^{* *}$ & $(0.0514)$ & $0.126^{* *}$ & $(0.0485)$ \\
Nr previous inquiries & 0.0467 & $(0.0428)$ & 0.0579 & $(0.0434)$ \\
Parl. reference group & 0.00435 & $(0.123)$ & -0.0613 & $(0.101)$ \\
Agriculture & 0.283 & $(0.255)$ & 0.249 & $(0.279)$ \\
Civil rights & 0.119 & $(0.292)$ & 0.128 & $(0.332)$ \\
Defense & $-0.659^{*}$ & $(0.280)$ & $-0.627^{*}$ & $(0.287)$ \\
Domestic commerce & 0.211 & $(0.143)$ & 0.251 & $(0.139)$ \\
Macroeconomics & $0.813^{* *}$ & $(0.293)$ & $0.902^{* *}$ & $(0.309)$ \\
Education/ culture & $-0.476^{* *}$ & $(0.160)$ & $-0.446^{* *}$ & $(0.172)$ \\
Environment/energy & 0.257 & $(0.177)$ & 0.146 & $(0.160)$ \\
Foreign trade & -0.278 & $(0.354)$ & -0.405 & $(0.445)$ \\
Govt operations & -0.0205 & $(0.175)$ & -0.0212 & $(0.185)$ \\
\hline
\end{tabular}

\footnotetext{
${ }^{13}$ Using presence of dissenting opinions without reservations gives the same results.
} 


\begin{tabular}{lcccc}
\hline Health & -0.0862 & $(0.104)$ & -0.110 & $(0.124)$ \\
Housing & $0.513^{*}$ & $(0.218)$ & $0.413^{*}$ & $(0.198)$ \\
Immigration & 0.270 & $(0.261)$ & 0.140 & $(0.236)$ \\
International affairs & -0.324 & $(0.203)$ & -0.252 & $(0.205)$ \\
Labor & -0.339 & $(0.197)$ & -0.308 & $(0.217)$ \\
Technology/media & -0.448 & $(0.290)$ & -0.388 & $(0.310)$ \\
Transportation & 0.0151 & $(0.229)$ & 0.0777 & $(0.229)$ \\
Social welfare & -0.0347 & $(0.211)$ & -0.00572 & $(0.224)$ \\
Ideol. polarization (Dalton 2008) & & & $0.391^{* *}$ & $(0.128)$ \\
Constant & $-1.532^{* * *}$ & $(0.126)$ & $-2.283^{* * *}$ & $(0.294)$ \\
\hline Govt id & $0.0755^{* *}$ & $(0.0281)$ & 0.0452 & $(0.0316)$ \\
Govt id > Comm code & $0.784^{* * *}$ & $(0.135)$ & $0.701^{* * *}$ & $(0.109)$ \\
\hline Observations & 2,705 & & 2,436 & \\
\hline \hline
\end{tabular}

Standard errors in parentheses

${ }^{*} p<0.05,{ }^{* *} p<0.01,{ }^{* * *} p<0.001$

Table 5.18: Multilevel probit; DV: presence of dissent, cluster robust SE

\begin{tabular}{lcccc}
\hline \hline & \multicolumn{2}{c}{ Model 1 } & \multicolumn{2}{c}{ Model 2} \\
\hline Nr academics & $-0.107^{* * *}$ & $(0.0257)$ & $-0.0969^{* * *}$ & $(0.0243)$ \\
Nr bureaucrats & $-0.0391^{* * *}$ & $(0.00958)$ & $-0.0409^{* * *}$ & $(0.00990)$ \\
Nr interest groups & $0.0837^{* *}$ & $(0.0256)$ & $0.0843^{* *}$ & $(0.0267)$ \\
Nr politicians & $0.0959^{* * *}$ & $(0.0256)$ & $0.0768^{* * *}$ & $(0.0183)$ \\
Repr. commission=1 & 0.140 & $(0.204)$ & 0.251 & $(0.187)$ \\
Repr. commission x academics & 0.00624 & $(0.0560)$ & -0.0197 & $(0.0544)$ \\
Repr. commission x bureaucrats & -0.0136 & $(0.0171)$ & -0.0163 & $(0.0176)$ \\
Repr. commission x int. groups & $-0.131^{* *}$ & $(0.0453)$ & $-0.110^{*}$ & $(0.0452)$ \\
Nr judges & 0.0888 & $(0.0468)$ & 0.0809 & $(0.0502)$ \\
Nr others & 0.0313 & $(0.0559)$ & 0.0305 & $(0.0592)$ \\
Nr members & $0.0812^{* * *}$ & $(0.0138)$ & $0.0779^{* * *}$ & $(0.0141)$ \\
Nr directives & $0.136^{* *}$ & $(0.0517)$ & $0.123^{*}$ & $(0.0492)$ \\
Nr previous inquiries & 0.0420 & $(0.0437)$ & 0.0535 & $(0.0444)$ \\
Parl. reference group & 0.00386 & $(0.115)$ & -0.0584 & $(0.0959)$ \\
Agriculture & 0.242 & $(0.254)$ & 0.200 & $(0.278)$ \\
Civil rights & 0.132 & $(0.279)$ & 0.136 & $(0.318)$ \\
Defense & $-0.617^{*}$ & $(0.299)$ & -0.587 & $(0.308)$ \\
Domestic commerce & 0.156 & $(0.130)$ & 0.188 & $(0.131)$ \\
Macroeconomics & $0.758^{* *}$ & $(0.272)$ & $0.831^{* *}$ & $(0.292)$ \\
Education/culture & $-0.489^{* *}$ & $(0.152)$ & $-0.458^{* *}$ & $(0.162)$ \\
Environment/energy & 0.190 & $(0.181)$ & 0.0736 & $(0.163)$ \\
Foreign trade & -0.324 & $(0.362)$ & -0.460 & $(0.455)$ \\
\hline
\end{tabular}




\begin{tabular}{lcccc}
\hline Govt operations & -0.0784 & $(0.174)$ & -0.0856 & $(0.186)$ \\
Health & -0.0805 & $(0.107)$ & -0.105 & $(0.124)$ \\
Housing & $0.465^{*}$ & $(0.217)$ & 0.373 & $(0.202)$ \\
Immigration & 0.222 & $(0.264)$ & 0.0841 & $(0.237)$ \\
International affairs & -0.355 & $(0.200)$ & -0.293 & $(0.205)$ \\
Labor & $-0.402^{*}$ & $(0.197)$ & -0.377 & $(0.219)$ \\
Technology/media & -0.480 & $(0.296)$ & -0.420 & $(0.317)$ \\
Transportation & -0.0466 & $(0.220)$ & 0.0114 & $(0.222)$ \\
Social welfare & -0.0917 & $(0.216)$ & -0.0664 & $(0.231)$ \\
Ideol. polarization (Dalton 2008) & & & $0.397^{* *}$ & $(0.132)$ \\
Constant & $-1.479^{* * *}$ & $(0.131)$ & $-2.242^{* * *}$ & $(0.315)$ \\
\hline Govt id & $0.0807^{* *}$ & $(0.0302)$ & 0.0517 & $(0.0346)$ \\
Govt id > Comm code & $0.777^{* * *}$ & $(0.137)$ & $0.697^{* * *}$ & $(0.115)$ \\
\hline Observations & 2,705 & & 2,436 & \\
\hline \hline
\end{tabular}

Standard errors in parentheses

${ }^{*} p<0.05,{ }^{* *} p<0.01,{ }^{* * *} p<0.001$

Table 5.19: Group variables

\begin{tabular}{lrrrr}
\hline Group variable & Nr in group & Min obs. & Avg obs. & Max obs. \\
\hline Model 1 & 10 & 40 & 270.5 & 365 \\
Government id & 2,023 & 1 & 1.3 & 12 \\
Commission code & & & & \\
\hline Model 2 & 9 & 40 & 270.7 & 365 \\
Government id & 1,813 & 1 & 1.3 & 12 \\
Commission code & & & &
\end{tabular}

After adjusting for the random-effects structure, the coefficient on the number of experts is significant at the 0.001 level, with the predicted negative sign. In practical terms, the presence of experts at the overall mean value of 6.86 would be expected to decrease the probability of dissent by 0.3 standard deviations. Therefore, I can reject the null in favor of $H_{A}^{1}$ (Experts) with high confidence, and find that the effect is practically meaningful. The Wald chi-sq for Model 1 is 85.11, with 9 degrees of freedom, and 33.01, with 8 degrees of freedom for Model. Both of these are significant at the 0.0001 significance level, indicating a good level of fit.

The coefficient on the interaction between representative commissions and stakeholders is also significant, at the 0.01 significance level in both Model 1 and at the 0.05 significance 
level in Model 2, with the predicted sign. In practical terms, the presence of experts at the mean value of 2.79 on representative commissions would be expected to decrease the probability of dissent by -0.1 standard deviations (adding the overall coefficient and the interaction effect). On expert commissions, by contrast, the effect at this same level would be to increase the probability of dissent by 0.2 standard deviations. Combined, the presence of stakeholders on representative commissions leads to an estimated net decrease in the probability of dissent of 0.3 standard deviations. I therefore reject the null in favor of $H_{A}^{2}$ (Stakeholders $\mathrm{x}$ representative commission), and find that this effect is practically meaningful.

Further empirical analysis using subcategories of interest groups (labor unions, employers' organizations, NGOs, professional interest groups, government interest groups, and other interest groups) reveals that the interaction effect is largely due to NGOs (coefficient $=-0.240$ in Model 1 and -0.151 in Model 2) and government interest groups (coefficient $=-0.189$ in Model 1 and -0.225). The coefficient of the interaction variable between NGOs and representative commissions is not significant in Model 2, once political polarization is included, but it is significant in Model 1 at the at the 0.05 significance level. The coefficients for government interest groups are significant at the 0.05 significance level in both models. The category of government interest groups consists almost entirely of the Swedish Association of Local Authorities and Regions (SALAR), which represents Sweden's municipalities and regions.

The coefficient on the number of politicians is larger than the coefficients of the number of stakeholders and of the number of experts, as stated in Hypotheses $H^{4}$ (Politicians vs. stakeholders) and $H^{5}$ (Politicians vs. experts). The difference between the coefficients on the number of politicians and the number of stakeholders is not significant, while the difference between the coefficients on the number of politicians and the number of experts is significant at the 0.001 significance level. I therefore fail to reject the null for $H^{4}$ and reject the null in favor of the alternative for $H^{5}$.

Finally, the coefficients of three policy area variables are singificant at least at the 0.05 significance level in both models: Defense (negative), Macroeconomics (positive), Education/culture (negative), and Housing (positive). In other words, inquiries concerning defense or education and culture are less conflictual on average, whereas inquiries concerning macroeconomics and housing are more conflictual. 
The results from the robustness check are similar to Model (5.1). Both academics and bureaucrats are associated with decreased dissent; the coefficients are significant the 0.001 significance levels for both variables in both Model 1 and 2. In addition, the interaction variable of interest groups and representative commissions is associated with decreased dissent (the coefficient is significant at the 0.01 significance level in Model 1 and at the 0.05 significance level in Model 2).

Note that the coefficient of political polarization (rile_pol) is highly significant in the second model, but the intercept coefficient for governments, gvt_id, is not. This variable seems to capture some unobserved heterogeneity across governments. I attempted to include other variables from the Control variables section to gain insight. Unfortunately, these caused significant multicollinearity and had to be dropped from the regression. On their own, they were less significant than political polarization.

\subsection{Results from the Bivariate Probit}

Table 5.20 shows the results for the selection equation (5.2). Model 1 is the base model. Model 2 includes government fixed effects. The base category for governments is Carlsson II. Note that the Persson I government is not included because it has no data for political polarization.

Consistent with the prediction of $H_{A}^{6}$ (Political polarization), the coefficient on ideological polarization is positive and significant at the 0.05 significance level for the base model and at the 0.001 significance level for the model with government fixed effects. I therefore reject the null in favor of $H_{A}^{6}$. The government effects are positive and significant, with the exception of the Bildt and Persson II governments, which are negative, and Persson III, which is not significant. The Wald chi-sq equals 59.58 with 20 degrees of freedom for the first model, which is significant at the $\mathrm{p}<0.001$ significance level, indicating a good level of fit.

Table 5.21 shows the results of the probits for the split sample (5.3). Model 1 shows the estimates for representative commissions. Model 2 shows the estimates for expert commissions. The Wald chi-sq equals 126.94 for Model 1, and 148.68 for Model 2, with 25 degrees 
Table 5.20: Probit model, DV: Repr. commission(=1), cluster robust SE

\begin{tabular}{|c|c|c|c|c|}
\hline \multirow[b]{2}{*}{ Ideol. polarization (Dalton 2008) } & \multicolumn{2}{|c|}{$\begin{array}{c}(1) \\
\text { Base model }\end{array}$} & \multicolumn{2}{|c|}{$\begin{array}{c}(2) \\
\text { Govt effects }\end{array}$} \\
\hline & $0.351^{*}$ & $(0.150)$ & $7.268^{* * *}$ & $(0.902)$ \\
\hline EU policy & $-0.453^{* *}$ & $(0.164)$ & $-0.475^{* *}$ & $(0.164)$ \\
\hline Govt deficit/surplus & $-0.0427^{* * *}$ & $(0.0112)$ & -0.0418 & $(0.0364)$ \\
\hline Agriculture & -0.181 & $(0.327)$ & -0.217 & $(0.326)$ \\
\hline Civil rights & $0.629^{*}$ & $(0.275)$ & $0.765^{* *}$ & $(0.282)$ \\
\hline Defense & -0.107 & $(0.292)$ & -0.147 & $(0.312)$ \\
\hline Domestic commerce & 0.0502 & $(0.221)$ & 0.0667 & $(0.211)$ \\
\hline Macroeconomics & 0.176 & $(0.249)$ & 0.189 & $(0.249)$ \\
\hline Education/culture & 0.352 & $(0.211)$ & 0.384 & $(0.205)$ \\
\hline Environment/energy & -0.0504 & $(0.280)$ & -0.0425 & $(0.273)$ \\
\hline Foreign trade & 0.261 & $(0.399)$ & 0.313 & $(0.418)$ \\
\hline Govt operations & 0.397 & $(0.228)$ & 0.425 & $(0.225)$ \\
\hline Health & 0.101 & $(0.244)$ & 0.173 & $(0.244)$ \\
\hline Housing & -0.159 & $(0.279)$ & -0.168 & $(0.277)$ \\
\hline Immigration & -0.0205 & $(0.284)$ & 0.0230 & $(0.286)$ \\
\hline International affairs & 0.192 & $(0.258)$ & 0.219 & $(0.247)$ \\
\hline Labor & 0.0203 & $(0.251)$ & 0.0571 & $(0.245)$ \\
\hline Technology/media & 0.448 & $(0.270)$ & 0.420 & $(0.279)$ \\
\hline Transportation & 0.0328 & $(0.264)$ & 0.00400 & $(0.254)$ \\
\hline Social welfare & 0.209 & $(0.239)$ & 0.223 & $(0.236)$ \\
\hline Bildt & & & $-1.281^{* *}$ & $(0.469)$ \\
\hline Carlsson III & & & $4.619^{* * *}$ & $(0.670)$ \\
\hline Persson II & & & $-0.398^{*}$ & $(0.198)$ \\
\hline Persson III & & & 0.0673 & $(0.229)$ \\
\hline Reinfeldt I & & & $5.413^{* * *}$ & $(0.799)$ \\
\hline Reinfeldt II & & & $3.979^{* * *}$ & $(0.665)$ \\
\hline Löfven I & & & $0.720^{*}$ & $(0.333)$ \\
\hline Constant & $-1.639^{* * *}$ & $(0.328)$ & $-17.17^{* * *}$ & $(2.207)$ \\
\hline Observations & 2,308 & & 2,308 & \\
\hline
\end{tabular}

Standard errors in parentheses

${ }^{*} p<0.05,{ }^{* *} p<0.01,{ }^{* * *} p<0.001$ 
of freedom. These are significant at the $\mathrm{p}<0.001$ significance level, indicating a good level of fit.

Finally, Table 5.22 shows the estimated probability an individual member of a certain type dissents (individ_dissent_prob), adjusted as in (5.4) for each subsample.

After adjusting for selection and estimating the probability of individual dissent, I reject the nulls in favor of $H_{A}^{1}$ (Experts), $H_{A}^{3}$ (Commission size and probability of dissent), $H_{A}^{4}$ (Politicians vs. stakeholders), and $H_{A}^{5}$ (Politicians vs. experts).

Note that the multilevel probit could not find enough evidence to reject the null for $H_{A}^{4}$ (Politicians vs. stakeholders). However, Tables 5.20 and 5.21 show that, after controlling for selection, the coefficient on politicians becomes considerably larger than that on stakeholders for representative commissions. The results are similar for expert commissions.

\subsection{Discussion and Conclusions}

The theoretical model makes six predictions. The evidence, taken together, provides support for all of them, and where the evidence is weak, it becomes stronger after controlling for selection issues. Table 5.23 summarizes the hypotheses and results.

The most surprising finding is that increasing stakeholder involvement in broad, ideologically diverse commissions decreases the probability that any commission member will dissent. Their ability to build consensus is unlikely to be a question of bargaining, because politicians are also accustomed to bargaining and to reaching compromise, but adding politicians does not increase consensus. Instead, the model suggests that commissions which produce most information have the best chance of generating policy valence and reaching consensus, and that the information stakeholders bring to the discussion is of particular importance.

Because selection plays a role, it is natural to wonder whether governments stack the deck, appointing broad commissions when they face no risk of serious opposition to their desired policies, and sticking to narrow expert commissions whenever there are serious political divisions. The data show that this does not generally appear to be the case. Instead, governments are most inclined to appoint broadly representative commissions when party 
Table 5.21: Probit by inquiry type, cluster robust SE

\begin{tabular}{lcccc}
\hline \hline & \multicolumn{2}{c}{$(1)$} & \multicolumn{2}{c}{$(2)$} \\
& \multicolumn{1}{c}{ Repr. commission } & \multicolumn{2}{c}{ Expert commission } \\
\hline Nr experts & 0.00605 & $(0.0133)$ & 0.0136 & $(0.00971)$ \\
Nr stakeholders & 0.0312 & $(0.0200)$ & $0.0833^{* * *}$ & $(0.0177)$ \\
Nr politicians & $0.122^{* * *}$ & $(0.0174)$ & $0.177^{* *}$ & $(0.0589)$ \\
Nr judges & $0.201^{* *}$ & $(0.0760)$ & 0.0949 & $(0.0502)$ \\
Nr others & 0.0366 & $(0.122)$ & $0.125^{*}$ & $(0.0621)$ \\
Nr directives & $0.159^{*}$ & $(0.0762)$ & 0.0129 & $(0.0474)$ \\
Nr previous inquiries & -0.00239 & $(0.0372)$ & 0.0825 & $(0.0531)$ \\
Parl. reference group & -0.152 & $(0.352)$ & -0.0347 & $(0.205)$ \\
Agriculture & 0.510 & $(0.466)$ & 0.326 & $(0.237)$ \\
Civil rights & 0.448 & $(0.375)$ & 0.120 & $(0.227)$ \\
Defense & -0.623 & $(0.542)$ & $-0.500^{*}$ & $(0.215)$ \\
Domestic commerce & 0.582 & $(0.355)$ & 0.289 & $(0.148)$ \\
Macroeconomics & $0.806^{*}$ & $(0.400)$ & $0.873^{* * *}$ & $(0.190)$ \\
Education/culture & 0.414 & $(0.340)$ & $-0.584^{* *}$ & $(0.191)$ \\
Environment/energy & 0.325 & $(0.360)$ & $0.351^{*}$ & $(0.175)$ \\
Foreign trade & -0.412 & $(0.524)$ & -0.00456 & $(0.366)$ \\
Govt operations & -0.171 & $(0.355)$ & 0.225 & $(0.158)$ \\
Health & 0.132 & $(0.351)$ & 0.0154 & $(0.183)$ \\
Housing & $1.575^{* *}$ & $(0.582)$ & 0.255 & $(0.209)$ \\
Immigration & 0.351 & $(0.433)$ & 0.137 & $(0.210)$ \\
International affairs & 0.381 & $(0.455)$ & -0.276 & $(0.241)$ \\
Labor & 0.430 & $(0.435)$ & -0.258 & $(0.196)$ \\
Technology/media & -0.314 & $(0.443)$ & -0.174 & $(0.248)$ \\
Transportation & 0.490 & $(0.401)$ & 0.143 & $(0.188)$ \\
Social welfare & 0.402 & $(0.419)$ & 0.00704 & $(0.183)$ \\
Constant & $-1.087^{* * *}$ & $(0.325)$ & $-0.926^{* * *}$ & $(0.157)$ \\
\hline Observations & 584 & & 1,812 & \\
\hline \hline
\end{tabular}

Standard errors in parentheses

${ }^{*} p<0.05,{ }^{* *} p<0.01,{ }^{* * *} p<0.001$ 
Table 5.22: Correlation with estimated probability of an individual dissent

\begin{tabular}{lcc}
\hline \hline & $(1)$ & $(2)$ \\
& Repr. commission & Expert commission \\
\hline Probability of individual dissent & & \\
Stakeholders & $-0.1520^{* * *}$ & $0.0919^{* * *}$ \\
Experts & $-0.2807^{* * *}$ & $-0.2949^{* * *}$ \\
Politicians & $0.4161^{* * *}$ & $0.1712^{* * *}$ \\
\hline Observations & 584 & 1,812 \\
\hline \hline
\end{tabular}

Table 5.23: Summary of results

\begin{tabular}{lll}
\hline Hypothesis & Effect & Reject $\mathbf{H}_{\mathbf{0}}$ ? \\
\hline $\mathbf{H}_{\mathbf{A}}^{1}$ Experts & Dissent $\downarrow$ & Yes \\
$\mathbf{H}_{\mathbf{A}}^{\mathbf{A}}$ Stakeholders x repr. comm. & Dissent $\downarrow$ & Yes \\
$\mathbf{H}_{\mathbf{A}}^{3}$ Commission size and & Prob dissent $<1(1-p)^{n}$ & Yes \\
dissent in repr. comm. & & \\
$\mathbf{H}_{\mathbf{A}}^{4}$ Politicians vs. stakeholders & Politicians $\rightarrow$ higher dissent & Yes \\
$\mathbf{H}_{\mathbf{A}}^{5}$ Politicians vs. experts & Politicians $\rightarrow$ higher dissent & Yes \\
$\mathbf{H}_{\mathbf{A}}^{6}$ Political polarization & Prob of appt of repr. comm. $\uparrow$ & Yes \\
\hline
\end{tabular}

polarization is high. However, this result may not be fully generalizable to societies with extreme levels of political polarization, as the levels of party polarization in the Swedish data may be relatively low, internationally speaking. For example, some amount of party polarization may lead governments to seek broader consensus, but extreme amounts of polarization may lead to an opposite effect.

These results raise questions about why ideological inclusiveness can work on commissions, when in everyday life, including more people with less aligned values makes it harder to reach a decision. If the theory is a guide, the important feature is that stakeholder involvement comes at an advisory stage, and is separated from the final decision making. Even though limiting involvement to recommendations has a direct effect of limiting the commission members' power, it has the indirect of strengthening those who might be inclined to dissent. The commission's recommendation is not the final word, and someone who objects to the recommendation can offer a dissenting opinion that can influence the government to choose another course of action. 


\subsection{The Decline of Parliamentary Commissions and the Role of Politicians}

\subsection{Introduction and Sample Selection}

Chapters 3, 4, and 5 provide a theory and empirical support for the claim that broadly representative commissions with experts and stakeholders are useful in building consensus. The inclusion or exclusion of politicians as commission members is a more complex issue, however. One advantage of including politicians from all major parliamentary parties is that their support of a proposal gives the government some assurance that the proposal has wide political support. Another advantage, which is a consequence of the theory presented in Chapter 4, is that politicians can help discipline the range of the proposals that other commission members can make (see Theorem 1). Thus, even though politicians are more likely to dissent, if they are included in a counterbalanced, bipartisan fashion, they constrain the range of proposals that stakeholders will make.

Both these advantages are important to weak governments, which have a greater need to show that their policies are widely acceptable and which may benefit politically from showing openness to the ideas of those outside of the government. This is consistent with findings of Hesstvedt and Christiansen (2020) in their analysis of Danish and Norwegian commissions and with the historical experience in Sweden, where extremely weak minority governments in the 1920s used parliamentary commissions to broker agreement between the labor and capital, and the left and right, factions in the Riksdag (Tingsten, 1940; Meijer, 1956; Lindvall et al., 2020). Conversely, for a strong government, and particularly for a majority government, there is less need for wide political support. Additionally, if a government would have difficulty appointing acceptable politicians both to its left and to its right, it would find it disadvantageous to include politicians on commissions. This condition, which is also an empirical implication of the theory in Chapter 4, was discussed in Subsection 4.5.2.

These insights from the theory are important in the Swedish context because of a longterm trend among Swedish governments toward appointing fewer parliamentary commissions with politicians from all major parliamentary parties. As mentioned earlier, for most of the 
twentieth century, about half of Swedish governmental inquiries were conducted by parliamentary commissions (Petersson, 2016, 660). Since the 1980s, parliamentary commissions have become less common, but their share remained above 20 percent of new commissions at least until the 1980s (Johansson, 1992; Petersson, 2016). However, from 1990 to 2016, their share declined from 19.4 percent to only 2.9 percent (see Figure 6.1 and Table 6.4).

A side effect of this trend is that the numbers of reservations and dissenting opinions have also declined. For example, in 1990, 26 percent of inquiries had at least one reservation, and 44 percent had least one dissenting opinion. In 2018, the corresponding figures were 0 percent and 22 percent (see Table 6.8). This decrease should not be taken as a sign of increased consensus, however, since political polarization and fractionalization have, in general, increased during this time period (Lindvall et al., 2020). Instead, the decline is likely a result of the intentional exclusion of politicians, who are the greatest source of dissent in commissions. The decline may therefore signal a shift in the government's ability to get its proposals through the legislature without involving the opposition, or it may be a sign of decreasing openness in the Swedish policy-making system.

In this chapter, I analyze these trends using the insights from the theory presented in Chapter 4. After presenting descriptive statistics, I discuss potential reasons for the seemingly terminal decline of parliamentary commissions in light of the theory. With only nine governments in the data set, it is not possible to perform rigorous hypothesis testing. Rather, the purpose in this chapter is to produce additional hypotheses, which could then be tested in future work with comparative data or a longer time series.

In addition to contributing to the literature on advisory commissions, this chapter contributes to the literature of explaining change in policy advisory systems (Craft and Howlett, 2013), which remains understudied (Craft and Howlett, 2013; Giuliani, 2016). Investigating these questions is important, because changes in advisory systems have large implications for how well policies are prepared, how successfully they are implemented, and how legitimate the public views them as. This chapter also contributes to a small body of literature that investigates the connection between the political context and the appointment of commissions of inquiry (McEachern, 1987; Hesstvedt and Christiansen, 2020). 
This chapter uses the same data as before, with some exceptions. First, the sample includes the 260 inquiries with fewer than three members, which were excluded earlier. Second, I removed all intermediate inquiries, only keeping the final inquiry by the commission or special investigator inquiry. This was done because a commission or special investigator is appointed only once, even if it performs subsequent inquiries. Third, I eliminated all commissions and special investigator inquiries whose first commission directive was dated before 1990 or after 2016. This is because the original data collection was based on completed inquiries in 1990-2018. Including commissions and special investigator inquiries initiated before 1990 would have resulted in oversampling larger, more important commissions. It was also necessary to exclude inquiries initiated after 2016 because many commissions were appointed during the Löfven I government that had not completed by the end of 2018, so they were not in the original data set. The final sample includes 2,088 commissions and special investigator inquiries appointed in 1990-2016 (see Table 6.1) under nine governments. These were collapsed into yearly or per government averages.

Table 6.1: Sample selection

\begin{tabular}{lll}
\hline Total & Excluded & Explanation \\
\hline 2,722 & & $\begin{array}{l}\text { Policy advisory inquiries initiated in 1990-2016 } \\
\text { including intermediate inquiries }\end{array}$ \\
& & Intermediate policy advisory inquiries \\
2,088 & & $\begin{array}{l}\text { Total new policy advisory commissions and special investigators } \\
\text { appointed in 1990-2016 }\end{array}$ \\
\hline
\end{tabular}

All tables and figures in this chapter are based on this sample, with the exception of Figures 6.2 and 6.5. Figure 6.5 is based on the sample used in earlier chapters, which is, again, collapsed into yearly averages. Figure 6.2 is based on a sample that includes all published SOUs in 1990-2018, including those that do not make a policy recommendation, except periodic long-term economic forecasts (Långtidsutredningen) and five SOU reports missing from all archives.

Table 6.2 lists the governments included in the data and values of the variables related to the political context. 
Table 6.2: Governments

\begin{tabular}{llllcc}
\hline Cabinet & Start date & Govt. parties & Type govt. & Parl. supp. & No. parties \\
\hline Carlsson II & $1988-09-18$ & s & Min. & 48.30 & 6 \\
Bildt & $1991-10-03$ & c-fp-m-kd & Min. coal. & 46.29 & 7 \\
Carlsson III & $1994-10-06$ & s & Min. & 45.63 & 7 \\
Persson I & $1996-03-21$ & s & Min. & 38.09 & 7 \\
Persson II & $1998-09-20$ & s & Min. & 37.50 & 7 \\
Persson III & $2002-09-15$ & s & Min. & 41.53 & 7 \\
Reinfeldt I & $2006-10-05$ & c-fp-m-kd & Maj. coal. & 50.49 & 7 \\
Reinfeldt II & $2010-10-05$ & c-fp-m-kd & Min. coal. & 49.03 & 8 \\
Löfven I & $2014-10-03$ & s-mp & Min. coal. & 39.99 & 8 \\
\hline
\end{tabular}

Note: $\mathrm{s}=$ Social Democrats; $\mathrm{c}=$ Centre Party; $\mathrm{fp}=$ Liberals; $\mathrm{m}=$ Moderate Party; $\mathrm{kd}=$ Christian Democrats; $\mathrm{mp}=$ Green Party; Type govt. = type of government;

Parl. supp. = seat share of parties in government (Armingeon et al., 2019);

No. parties $=$ number of political parties in the Riksdag. (Lindvall et al., 2020)

The rest of this chapter is organized as follows. Section 6.2 describes trends in the appointment, membership composition, publication volume, and dissent patterns of Swedish commissions of inquiry and special investigator inquiries in 1990-2016. Section 6.3 then relates these empirical trends to the empirical predictions of the model. Finally, Section 6.4 discusses the likely consequences of these trends to the Swedish policy-making system.

\subsection{Trends in Appointments, Membership, Report Volumes, and Dissent}

\subsubsection{New commission appointments and report volumes}

Figure 6.1 and Table 6.4 display the relative shares of different types of advisory commissions and special investigator inquiries appointed in 1990-2016. The categories, which are described in Table 6.3, are used in official reports, such as Hedborg (1998) and the 2017/2018 report of the Swedish Riksdag's standing Committee on the Constitution (2017/18:KU10 64). The categories are presented in decreasing order of representativeness. 
Table 6.3: Types of policy advisory inquiries, 1990-2016

\begin{tabular}{ll}
\hline Type of structure & Operationalization \\
\hline 1. Parliamentary commissions & $\begin{array}{l}\text { A commission with a chairperson and } \\
\text { at least three parliamentarians }\end{array}$ \\
$\begin{array}{ll}\text { 2. Nonparliamentary commissions } \\
\text { with a parliamentary reference group }\end{array}$ & $\begin{array}{l}\text { A commission with a chairperson, } \\
\text { maximum of one to two parliamentarians, } \\
\text { and a parliamentary reference group }\end{array}$ \\
$\begin{array}{ll}\text { 3. Nonparliamentary commissions } \\
\text { w/o a parliamentary reference group }\end{array}$ & $\begin{array}{l}\text { A commission with a chairperson, } \\
\text { maximum of one to two parliamentarians } \\
\text { with no parliamentary reference group }\end{array}$ \\
$\begin{array}{ll}\text { 4. Special investigator inquiry } \\
\text { with a parliamentary reference group }\end{array}$ & $\begin{array}{l}\text { An inquiry led by a special investigator } \\
\text { andiamentary reference group }\end{array}$ \\
5. Special investigator inquiry & $\begin{array}{l}\text { An inquiry with a special investigator and } \\
\text { no parliamentary reference group }\end{array}$ \\
\hline
\end{tabular}

The first category includes parliamentary commissions, which have parliamentarians from all major political parties as members. These are generally the most representative of all policy inquiries. They were relatively common earlier, comprising about 50 percent of new commission appointments during most of the twentieth century (Meijer, 1969; Hedborg, 1998; Petersson, 2016). By 1990, their share had declined 19.4 percent and was only 2.9 percent in 2016.

The second category includes nonparliamentary commissions with at most two politicians and a parliamentary reference group. A parliamentary reference group is a consultative body of parliamentarians from all major political parties, which is attached to the inquiry. This category represents only a marginal percentage ( 0.1 percent) of new policy inquiry appointments.

The third category includes nonparliamentary commissions with at most two politicians without a parliamentary reference group. These were more common in the 1990s, when their shares varied between 5.3 and 16.7 percent. After 2000, their shares have remained in the single digits. In 2016, their share was only 4.3 percent of new policy inquiry appointments. 
The fourth category includes special investigator inquiries with a parliamentary reference group. These were only 3.2 percent of new inquiry appointments in 1990, and zero during much of the 1990s. However, they have become more common in recent years. In 2016, their share was 8.7 percent of new policy inquiry appointments.

The fifth category includes special investigator inquiries without a parliamentary reference group. Their share has steadily increased, from 67.5 percent in 1990 to 84.1 percent in 2016, peaking at 93.4 in 2014.

Figure 6.1: Shares of types of policy inquiries, 1990-2016. From

Dahlström, Lundberg and Pronin (2019, 2020)

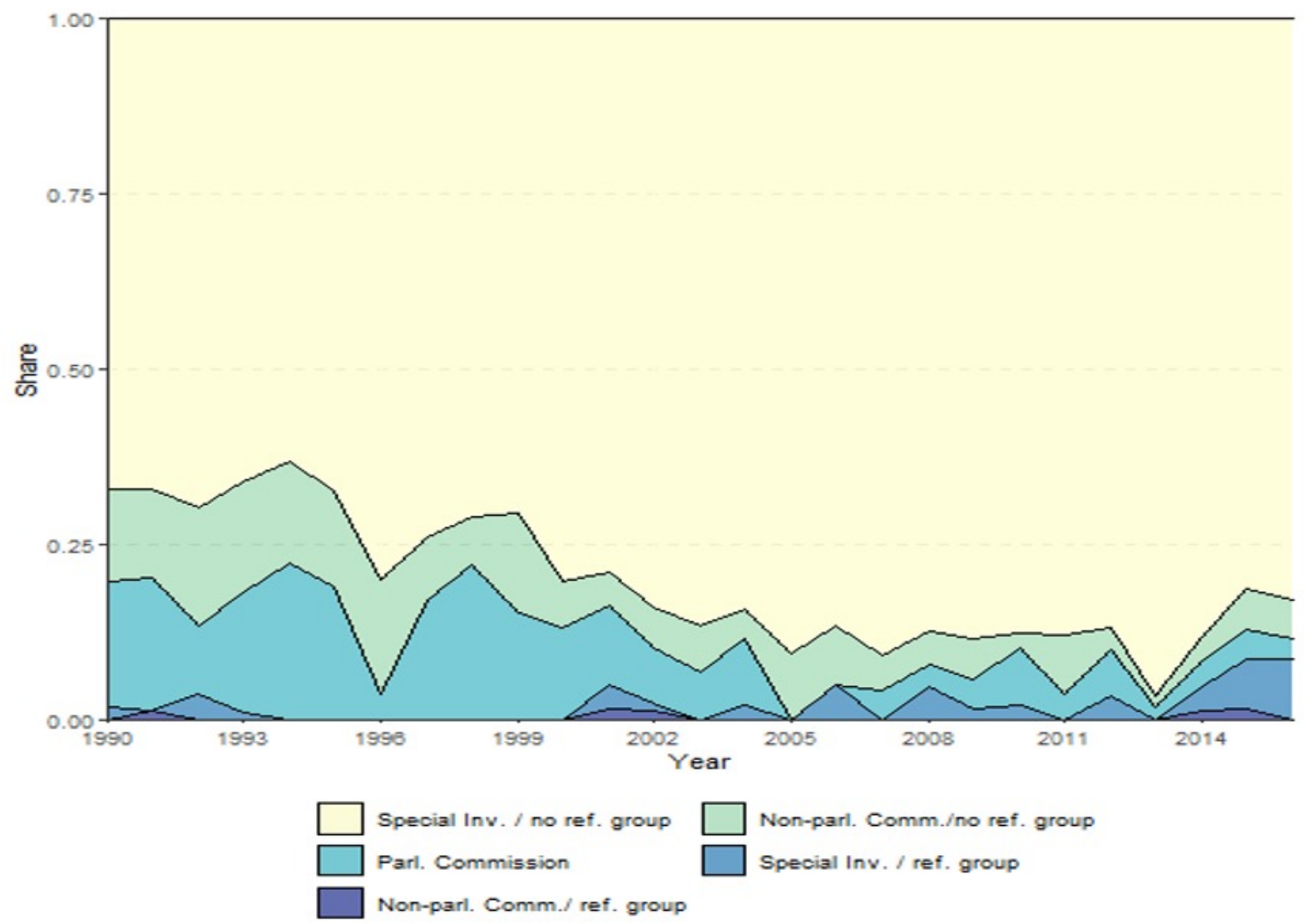

With the exception of the second category, these trends appear to be statistically significant. Regressing the shares against appointment years, I obtain a $t$-statistic of -5.81 $(p=0.000)$ for parliamentary commissions, $-4.13(p=0.000)$ for nonparliamentary commissions without a parliamentary reference group, $3.10(p=0.005)$ for special investigator 
Table 6.4: Types of commissions and special investigator inquiries, 1990-2016.

Sample: 2,088 new policy advisory commissions and special investigator inquiries appointed in 1990-2016

Inquiry type

\begin{tabular}{|c|c|c|c|c|c|c|c|c|c|c|c|}
\hline \multirow[b]{2}{*}{ Year } & \multicolumn{2}{|c|}{1} & \multicolumn{2}{|c|}{2} & \multicolumn{2}{|c|}{3} & \multicolumn{2}{|c|}{4} & \multicolumn{2}{|c|}{5} & \multirow{2}{*}{$\frac{\text { Total }}{\text { No }}$} \\
\hline & No & $\%$ & No & $\%$ & No & $\%$ & No & $\%$ & No & $\%$ & \\
\hline 1990 & 12 & 19.4 & 0 & 0.0 & 6 & 9.7 & 2 & 3.2 & 42 & 67.7 & 62 \\
\hline 1991 & 16 & 20.5 & 1 & 1.3 & 8 & 10.3 & 0 & 0.0 & 53 & 67.9 & 78 \\
\hline 1992 & 10 & 12.0 & 0 & 0.0 & 13 & 15.7 & 3 & 3.6 & 57 & 68.7 & 83 \\
\hline 1993 & 17 & 16.8 & 0 & 0.0 & 10 & 9.9 & 1 & 1.0 & 73 & 72.3 & 101 \\
\hline 1994 & 17 & 22.4 & 0 & 0.0 & 4 & 5.3 & 0 & 0.0 & 55 & 72.4 & 76 \\
\hline 1995 & 23 & 19.7 & 0 & 0.0 & 15 & 12.8 & 0 & 0.0 & 79 & 67.5 & 117 \\
\hline 1996 & 3 & 3.6 & 0 & 0.0 & 14 & 16.7 & 0 & 0.0 & 67 & 79.8 & 84 \\
\hline 1997 & 20 & 17.7 & 0 & 0.0 & 10 & 8.8 & 0 & 0.0 & 83 & 73.5 & 113 \\
\hline 1998 & 16 & 21.9 & 0 & 0.0 & 5 & 6.8 & 0 & 0.0 & 52 & 71.2 & 73 \\
\hline 1999 & 13 & 15.3 & 0 & 0.0 & 11 & 12.9 & 0 & 0.0 & 61 & 71.8 & 85 \\
\hline 2000 & 8 & 13.1 & 0 & 0.0 & 3 & 4.9 & 0 & 0.0 & 50 & 82.0 & 61 \\
\hline 2001 & 8 & 12.9 & 1 & 1.6 & 2 & 3.2 & 2 & 3.2 & 49 & 79.0 & 62 \\
\hline 2002 & 7 & 8.0 & 0 & 0.0 & 6 & 6.8 & 1 & 1.1 & 74 & 84.1 & 88 \\
\hline 2003 & 6 & 7.9 & 0 & 0.0 & 4 & 5.3 & 0 & 0.0 & 66 & 86.8 & 76 \\
\hline 2004 & 9 & 9.5 & 0 & 0.0 & 3 & 3.2 & 4 & 4.2 & 79 & 83.2 & 95 \\
\hline 2005 & 0 & 0.0 & 0 & 0.0 & 3 & 4.7 & 0 & 0.0 & 61 & 95.3 & 64 \\
\hline 2006 & 1 & 1.7 & 0 & 0.0 & 4 & 6.7 & 2 & 3.3 & 53 & 88.3 & 60 \\
\hline 2007 & 4 & 4.1 & 0 & 0.0 & 6 & 6.1 & 0 & 0.0 & 88 & 89.8 & 98 \\
\hline 2008 & 2 & 3.1 & 0 & 0.0 & 3 & 4.6 & 3 & 4.6 & 57 & 87.7 & 65 \\
\hline 2009 & 3 & 4.3 & 0 & 0.0 & 3 & 4.3 & 1 & 1.4 & 63 & 90.0 & 70 \\
\hline 2010 & 3 & 6.4 & 0 & 0.0 & 1 & 2.1 & 1 & 2.1 & 42 & 89.4 & 47 \\
\hline 2011 & 3 & 3.6 & 0 & 0.0 & 7 & 8.4 & 1 & 1.2 & 72 & 86.7 & 83 \\
\hline 2012 & 4 & 6.6 & 0 & 0.0 & 3 & 4.9 & 3 & 4.9 & 51 & 83.6 & 61 \\
\hline 2013 & 2 & 3.3 & 0 & 0.0 & 1 & 1.6 & 1 & 1.6 & 57 & 93.4 & 61 \\
\hline 2014 & 4 & 4.8 & 0 & 0.0 & 4 & 4.8 & 3 & 3.6 & 73 & 86.9 & 84 \\
\hline 2015 & 3 & 4.2 & 0 & 0.0 & 5 & 6.9 & 5 & 6.9 & 59 & 81.9 & 72 \\
\hline 2016 & 2 & 2.9 & 0 & 0.0 & 3 & 4.3 & 6 & 8.7 & 58 & 84.1 & 69 \\
\hline Total & 216 & 10.3 & 2 & 0.1 & 157 & 7.5 & 39 & 1.9 & 1,674 & 80.2 & 2,088 \\
\hline
\end{tabular}

Note: $1=$ parliamentary commissions; $2=$ nonparliamentary commissions with parliamentary reference group; $3=$ nonparliamentary commissions without parliamentary reference group; $4=$ special investigator inquiries with parliamentary reference group; $5=$ special investigator inquiries without parliamentary reference group. 
inquiries with a parliamentary reference group, and $5.77(p=0.000)$ for special investigator inquiries without a parliamentary reference group. In other words, there has been a significant decline in the share of both parliamentary and nonparliamentary commissions and a corresponding increase in special investigator inquiries.

Figure 6.2 displays the volume of SOUs published each year. The numbers are based on a population sample $(N=3,516)$ of all published SOUs in 1990-2018, with the exception of periodic long-term economic forecasts (Långtidsutredningen) and five SOU reports missing from all archives. The figure shows an overall negative trend, which is statistically significant $(t$-statistic $=-4.22, p=0.000)$, with a peak in activity in the mid- to late 1990s. A likely explanation for the peak is the prevalence of large and extremely prolific commissions of inquiry during this time. An example is the Commission on the Swedish Democracy (Demokratiutredningen), which was appointed in March 1996 to investigate the state of the Swedish democracy. The commission produced 45 expert reports of findings and 2 reports with policy recommendations, submitting its final report in February 2000. Another is the Information Technology Commission (IT-kommissionen), which was appointed in March 1998 to analyze the impact of new information technology on Swedish society. The commission delivered its final report in May 2003, after producing 31 expert reports. These types of large, multiyear inquiries have become increasingly rare in recent years.

\subsubsection{Membership composition}

Figures 6.3 and 6.4 and Tables 6.5 and 6.6 display the membership composition of Swedish commissions of inquiry and special investigator inquiries in 1990-2016 using the member types described in Table 5.3. If a commission or special investigator inquiry completed multiple inquiries, membership shares were calculated from the final inquiry.

The figures reveal a decline in the share of politicians, which parallels the decline in the share of parliamentary commissions. In 1990, the mean share of politicians was 11 percent, but by 2016, it was only 2 percent, a 9 percentage point drop from 1990 to 2016. Using linear regression (regressing the share of politicians on appointment years) and a Student's t-test, 
Figure 6.2: Number of published SOUs, 1990-2018. Population sample $(N=3,516)$ of all published SOUs in 1990-2018, with long-term economic forecasts (Långtidsutredningen) and five SOU reports missing from all archives excluded

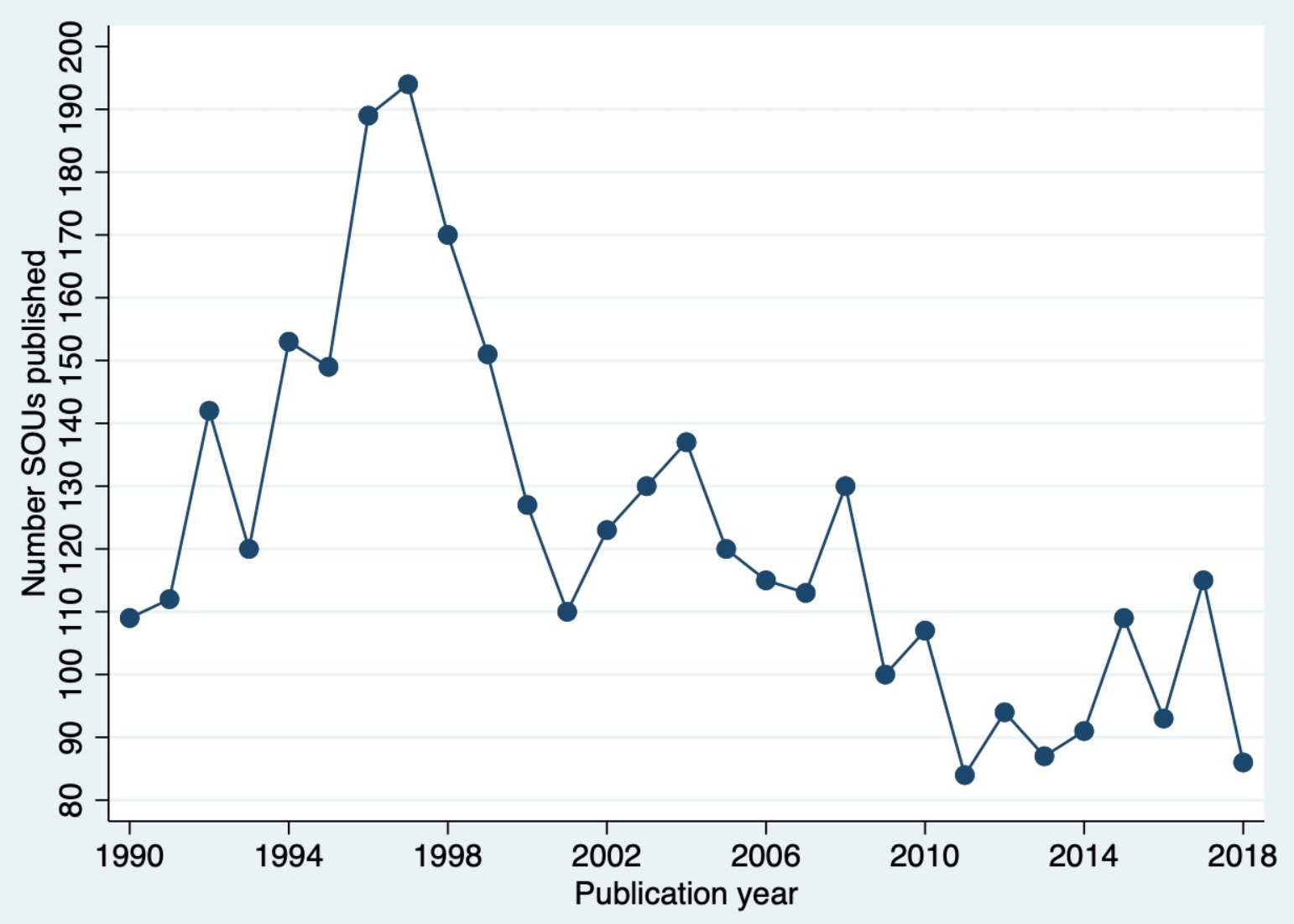


Figure 6.3: Shares of experts, stakeholders, politicians, and judges in new commissions and special investigator inquiries, 1990-2016

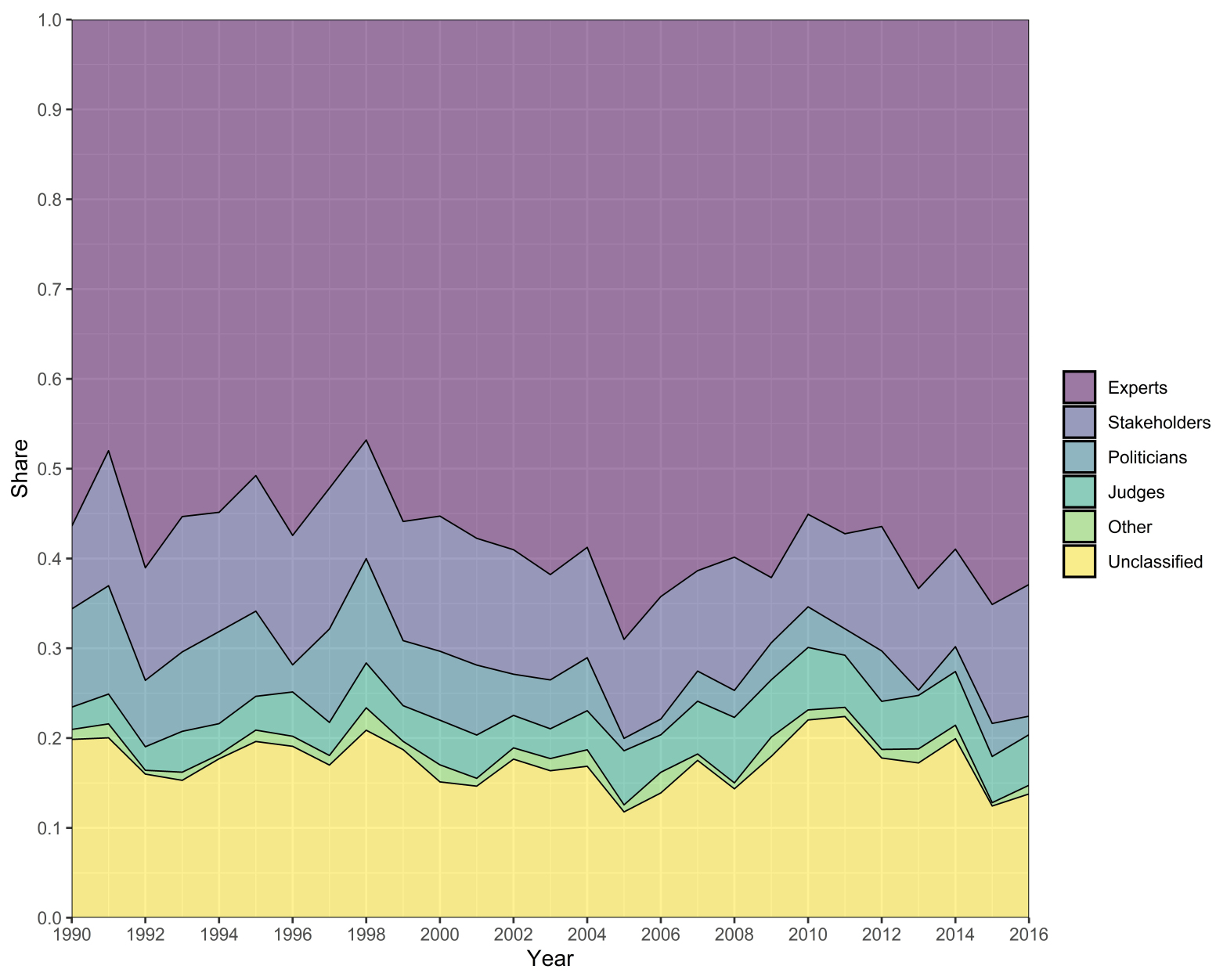


Figure 6.4: Shares of bureaucrats, interest groups, politicians, academics, and judges in new commissions and special investigator inquiries, 1990-2016

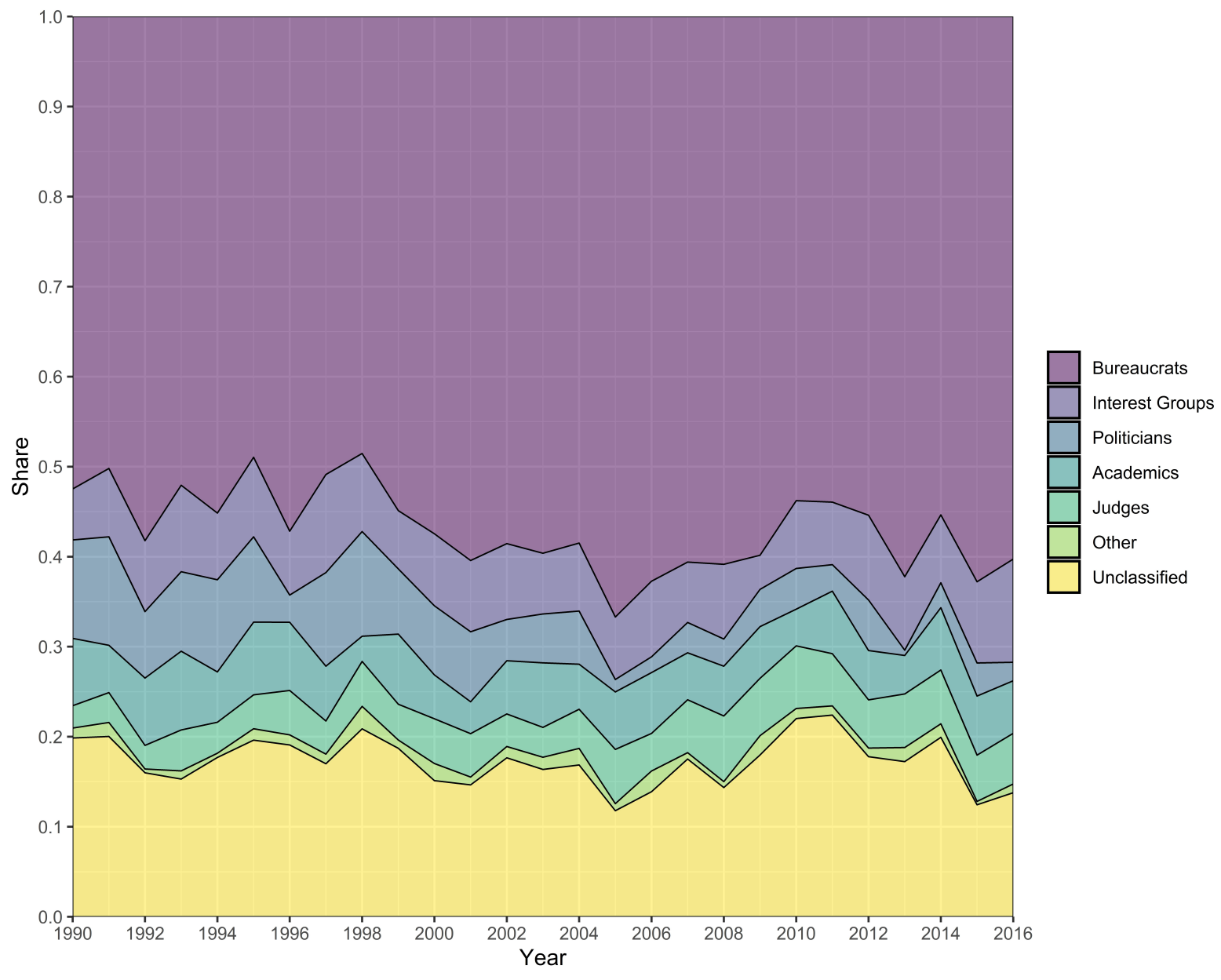


Table 6.5: Shares of experts, stakeholders, politicians, and judges in new commissions and special investigator inquiries, 1990-2016

\begin{tabular}{ccccccc}
\hline Year & Experts & Stakehold. & Polit. & Judges & Other & Unclass. \\
\hline 1990 & 0.52 & 0.11 & 0.11 & 0.03 & 0.01 & 0.21 \\
1991 & 0.47 & 0.15 & 0.11 & 0.03 & 0.01 & 0.23 \\
1992 & 0.59 & 0.11 & 0.06 & 0.05 & 0.01 & 0.15 \\
1993 & 0.56 & 0.13 & 0.08 & 0.04 & 0.01 & 0.16 \\
1994 & 0.53 & 0.13 & 0.10 & 0.04 & 0.00 & 0.19 \\
1995 & 0.50 & 0.14 & 0.09 & 0.06 & 0.02 & 0.18 \\
1996 & 0.56 & 0.13 & 0.04 & 0.04 & 0.02 & 0.19 \\
1997 & 0.53 & 0.14 & 0.09 & 0.03 & 0.01 & 0.18 \\
1998 & 0.47 & 0.13 & 0.11 & 0.05 & 0.02 & 0.20 \\
1999 & 0.58 & 0.12 & 0.06 & 0.03 & 0.01 & 0.18 \\
2000 & 0.56 & 0.14 & 0.07 & 0.07 & 0.02 & 0.13 \\
2001 & 0.60 & 0.12 & 0.08 & 0.05 & 0.01 & 0.13 \\
2002 & 0.60 & 0.12 & 0.04 & 0.03 & 0.01 & 0.17 \\
2003 & 0.57 & 0.10 & 0.06 & 0.04 & 0.01 & 0.20 \\
2004 & 0.60 & 0.11 & 0.05 & 0.04 & 0.02 & 0.16 \\
2005 & 0.70 & 0.10 & 0.01 & 0.05 & 0.01 & 0.12 \\
2006 & 0.64 & 0.12 & 0.02 & 0.05 & 0.02 & 0.13 \\
2007 & 0.60 & 0.11 & 0.03 & 0.05 & 0.01 & 0.17 \\
2008 & 0.58 & 0.17 & 0.03 & 0.06 & 0.01 & 0.14 \\
2009 & 0.59 & 0.07 & 0.05 & 0.07 & 0.02 & 0.18 \\
2010 & 0.52 & 0.09 & 0.05 & 0.08 & 0.01 & 0.22 \\
2011 & 0.55 & 0.11 & 0.02 & 0.08 & 0.01 & 0.21 \\
2012 & 0.54 & 0.14 & 0.05 & 0.07 & 0.01 & 0.17 \\
2013 & 0.61 & 0.10 & 0.01 & 0.05 & 0.01 & 0.19 \\
2014 & 0.55 & 0.10 & 0.03 & 0.07 & 0.01 & 0.21 \\
2015 & 0.63 & 0.11 & 0.05 & 0.05 & 0.00 & 0.14 \\
2016 & 0.62 & 0.13 & 0.02 & 0.06 & 0.01 & 0.14 \\
\hline & & & & & &
\end{tabular}


Table 6.6: Shares of bureaucrats, interest groups, politicians, academics, and judges in new appointed commissions and special investigator inquiries, 1990-2016

\begin{tabular}{cccccccc}
\hline Year & Bureau & Int. grp & Polit. & Acad. & Judges & Other & Unclass. \\
\hline 1990 & 0.50 & 0.06 & 0.11 & 0.08 & 0.03 & 0.01 & 0.21 \\
1991 & 0.50 & 0.06 & 0.11 & 0.05 & 0.03 & 0.01 & 0.23 \\
1992 & 0.54 & 0.06 & 0.06 & 0.09 & 0.05 & 0.01 & 0.15 \\
1993 & 0.51 & 0.08 & 0.08 & 0.09 & 0.04 & 0.01 & 0.16 \\
1994 & 0.54 & 0.06 & 0.10 & 0.06 & 0.04 & 0.00 & 0.19 \\
1995 & 0.49 & 0.08 & 0.09 & 0.07 & 0.06 & 0.02 & 0.18 \\
1996 & 0.55 & 0.07 & 0.04 & 0.07 & 0.04 & 0.02 & 0.19 \\
1997 & 0.51 & 0.09 & 0.09 & 0.06 & 0.03 & 0.01 & 0.18 \\
1998 & 0.47 & 0.09 & 0.11 & 0.04 & 0.05 & 0.02 & 0.20 \\
1999 & 0.55 & 0.06 & 0.06 & 0.09 & 0.03 & 0.01 & 0.18 \\
2000 & 0.55 & 0.07 & 0.07 & 0.08 & 0.07 & 0.02 & 0.13 \\
2001 & 0.62 & 0.07 & 0.08 & 0.03 & 0.05 & 0.01 & 0.13 \\
2002 & 0.58 & 0.07 & 0.04 & 0.07 & 0.03 & 0.01 & 0.17 \\
2003 & 0.54 & 0.06 & 0.06 & 0.07 & 0.04 & 0.01 & 0.20 \\
2004 & 0.58 & 0.07 & 0.05 & 0.06 & 0.04 & 0.02 & 0.16 \\
2005 & 0.65 & 0.06 & 0.01 & 0.10 & 0.05 & 0.01 & 0.12 \\
2006 & 0.60 & 0.07 & 0.02 & 0.09 & 0.05 & 0.02 & 0.13 \\
2007 & 0.58 & 0.06 & 0.03 & 0.07 & 0.05 & 0.01 & 0.17 \\
2008 & 0.62 & 0.08 & 0.03 & 0.05 & 0.06 & 0.01 & 0.14 \\
2009 & 0.57 & 0.03 & 0.05 & 0.06 & 0.07 & 0.02 & 0.18 \\
2010 & 0.51 & 0.06 & 0.05 & 0.03 & 0.08 & 0.01 & 0.22 \\
2011 & 0.53 & 0.06 & 0.02 & 0.06 & 0.08 & 0.01 & 0.21 \\
2012 & 0.54 & 0.09 & 0.05 & 0.05 & 0.07 & 0.01 & 0.17 \\
2013 & 0.59 & 0.07 & 0.01 & 0.05 & 0.05 & 0.01 & 0.19 \\
2014 & 0.52 & 0.07 & 0.03 & 0.06 & 0.07 & 0.01 & 0.21 \\
2015 & 0.59 & 0.08 & 0.05 & 0.07 & 0.05 & 0.00 & 0.14 \\
2016 & 0.60 & 0.10 & 0.02 & 0.05 & 0.06 & 0.01 & 0.14 \\
\hline & & & & & & & \\
\end{tabular}


I obtain a coefficient of -0.003 and a statistically significant $t$-statistic of $-6.21(p=0.000)$ for this trend.

The share of stakeholders, by contrast, does not have a statistically significant trend (coefficient $-0.001 ; t$-statistic $=-1.70 ; p=0.102)$. The share of interest groups also appears unchanged (coefficient $-0.0002 ;$-statistic $=0.40 ; p=0.690$ ). By contrast, the share of public servants has a negative trend (coefficient $-0.001 ; t$-statistic $=-3.31 ; p=0.003$ ). There are no statistically significant trends for the different subcategories for interest groups (labor unions, employers' unions, NGOs, professional organizations, and government interest groups) either. This is somewhat surprising, because previous research on the remiss procedure has revealed a decline in the share of member-benefit- and conflict-oriented interest organizations, while the level of public-benefit-oriented organizations has remained relatively stable (Lundberg, 2012). These results may reflect differences between the commissions and the remiss procedure, in the time period selected, or in the coding of interest groups. It is worth noting, however, that this same phenomenon is observed in Binderkrantz and Christiansen (2015). In their study comparing Danish advisory commissions from 1975 and 2010, Binderkrantz and Christiansen find that, despite substantial overall changes in membership composition, there was no significant change in interest group inclusion.

The share of experts has grown slightly, but the trend is not statistically significant at the 0.05 significance level. However, there has been a statistically significant increase in the share of bureaucrats (coefficient $0.003 ; t$-statistic $=2.82 ; p=0.009$ ). This change is largely driven by civil servants working for ministries and the central administration (coefficient $0.004 ; t$ statistic $=3.95 ; p=0.001)$. By contrast, the share of bureaucrats from government agencies does not display a significant trend (coefficient $0.001 ;$-statistic $=0.15 ; p=0.878$ ). Similarly, the trend for academics is not statistically significant (coefficient $-0.001 ; t$-statistic $=-1.97$; $p=0.060)$. In other words, there does not appear to be a trend toward expertization in terms of third-party experts, as documented in Norwegian and Danish commissions (Christensen and Hesstvedt, 2019). However, there is a statistically significant, though small, increase in the share of judges (coefficient $0.001 ; t$-statistic $=3.25 ; p=0.004$ ). 
In sum, the main changes in inquiry membership are the dramatic decline in the share of politicians and an increase in the share of civil servants from the ministries and central administration.

\subsubsection{Policy areas}

Table 6.7 shows the numbers and percentages of inquiries for different policy areas for each government. The most frequent policy areas are domestic commerce (11.4 percent), education and culture (11.2 percent), government operations (9.8 percent), law and crime (8.4 percent), and energy and environment (8.4 percent). There is an increase in the policy areas of immigration and citizenship and law and crime and a decrease in the policy areas of agriculture and technology. These changes reflect political and social developments since 1990 (the decrease in the share of GDP of agriculture, Sweden becoming a European Union (EU) member in 1995, the technological revolution of the 1990s, and increases in both immigration levels and crime). However, these shares of different policy areas are relatively stable across the time period under study. 
Table 6.7: Policy areas by government, Carlsson II-Löfven I cabinets (includes all policy inquiries appointed in 1990-2016)

\begin{tabular}{|c|c|c|c|c|c|c|c|c|c|c|c|c|c|c|c|c|c|c|c|c|}
\hline & \multicolumn{2}{|c|}{ Carl II } & \multicolumn{2}{|c|}{ Bildt } & \multicolumn{2}{|c|}{ Carl III } & \multicolumn{2}{|c|}{ Per I } & \multicolumn{2}{|c|}{ Per II } & \multicolumn{2}{|c|}{ Per III } & \multicolumn{2}{|c|}{ Rein I } & \multicolumn{2}{|c|}{ Rein II } & \multicolumn{2}{|c|}{ Löf I } & \multicolumn{2}{|c|}{ Total } \\
\hline & No. & $\%$ & No. & $\%$ & No. & $\%$ & No. & $\%$ & No. & $\%$ & No. & $\%$ & No. & $\%$ & No. & $\%$ & No. & $\%$ & No. & $\%$ \\
\hline Policy area & & & & & & & & & & & & & & & & & & & & \\
\hline Agriculture & 6 & 5.0 & 8 & 3.1 & 6 & 3.9 & 11 & 4.6 & 11 & 3.7 & 18 & 6.0 & 10 & 3.5 & 2 & 0.7 & 1 & 0.7 & 73 & 3.5 \\
\hline Civil rights & 4 & 3.3 & 2 & 0.8 & 2 & 1.3 & 9 & 3.8 & 8 & 2.7 & 17 & 5.7 & 6 & 2.1 & 14 & 4.8 & 3 & 2.0 & 65 & 3.1 \\
\hline Defense & 6 & 5.0 & 6 & 2.3 & 7 & 4.6 & 6 & 2.5 & 17 & 5.7 & 13 & 4.4 & 10 & 3.5 & 9 & 3.1 & 10 & 6.8 & 84 & 4.0 \\
\hline Dom. commerce & 22 & 18.2 & 25 & 9.7 & 17 & 11.2 & 27 & 11.3 & 27 & 9.1 & 35 & 11.7 & 21 & 7.4 & 45 & 15.5 & 20 & 13.5 & 239 & 11.4 \\
\hline Educ./culture & 11 & 9.1 & 31 & 12.0 & 20 & 13.2 & 26 & 10.9 & 27 & 9.1 & 34 & 11.4 & 37 & 13.0 & 30 & 10.3 & 17 & 11.5 & 233 & 11.2 \\
\hline Env./energy & 9 & 7.4 & 27 & 10.4 & 15 & 9.9 & 20 & 8.4 & 28 & 9.5 & 20 & 6.7 & 22 & 7.7 & 24 & 8.2 & 11 & 7.4 & 176 & 8.4 \\
\hline Foreign trade & 0 & 0.0 & 2 & 0.8 & 0 & 0.0 & 7 & 2.9 & 5 & 1.7 & 4 & 1.3 & 4 & 1.4 & 3 & 1.0 & 2 & 1.4 & 27 & 1.3 \\
\hline Govt ops & 12 & 9.9 & 29 & 11.2 & 11 & 7.2 & 22 & 9.2 & 39 & 13.2 & 26 & 8.7 & 23 & 8.1 & 30 & 10.3 & 12 & 8.1 & 204 & 9.8 \\
\hline Health & 3 & 2.5 & 20 & 7.7 & 4 & 2.6 & 12 & 5.0 & 16 & 5.4 & 15 & 5.0 & 21 & 7.4 & 18 & 6.2 & 7 & 4.7 & 116 & 5.6 \\
\hline Housing & 4 & 3.3 & 7 & 2.7 & 6 & 3.9 & 8 & 3.4 & 7 & 2.4 & 4 & 1.3 & 5 & 1.8 & 12 & 4.1 & 3 & 2.0 & 56 & 2.7 \\
\hline Immigration & 2 & 1.7 & 6 & 2.3 & 4 & 2.6 & 5 & 2.1 & 9 & 3.0 & 11 & 3.7 & 9 & 3.2 & 7 & 2.4 & 7 & 4.7 & 60 & 2.9 \\
\hline Intl affairs & 2 & 1.7 & 16 & 6.2 & 7 & 4.6 & 12 & 5.0 & 8 & 2.7 & 12 & 4.0 & 9 & 3.2 & 11 & 3.8 & 6 & 4.1 & 83 & 4.0 \\
\hline Labor & 5 & 4.1 & 19 & 7.3 & 10 & 6.6 & 17 & 7.1 & 13 & 4.4 & 20 & 6.7 & 14 & 4.9 & 15 & 5.2 & 12 & 8.1 & 125 & 6.0 \\
\hline Law/crime & 6 & 5.0 & 18 & 6.9 & 12 & 7.9 & 12 & 5.0 & 24 & 8.1 & 26 & 8.7 & 42 & 14.7 & 23 & 7.9 & 12 & 8.1 & 175 & 8.4 \\
\hline Macroecon. & 7 & 5.8 & 16 & 6.2 & 8 & 5.3 & 9 & 3.8 & 15 & 5.1 & 9 & 3.0 & 10 & 3.5 & 14 & 4.8 & 5 & 3.4 & 93 & 4.5 \\
\hline Soc. welfare & 8 & 6.6 & 6 & 2.3 & 9 & 5.9 & 13 & 5.5 & 16 & 5.4 & 23 & 7.7 & 17 & 6.0 & 18 & 6.2 & 11 & 7.4 & 121 & 5.8 \\
\hline Technology & 6 & 5.0 & 4 & 1.5 & 6 & 3.9 & 12 & 5.0 & 12 & 4.1 & 3 & 1.0 & 5 & 1.8 & 7 & 2.4 & 4 & 2.7 & 59 & 2.8 \\
\hline Transportation & 8 & 6.6 & 17 & 6.6 & 8 & 5.3 & 10 & 4.2 & 14 & 4.7 & 8 & 2.7 & 20 & 7.0 & 9 & 3.1 & 5 & 3.4 & 99 & 4.7 \\
\hline Total & 121 & 100.0 & 259 & 100.0 & 152 & 100.0 & 238 & 100.0 & 296 & 100.0 & 298 & 100.0 & 285 & 100.0 & 291 & 100.0 & 148 & 100.0 & 2,088 & 100.0 \\
\hline
\end{tabular}




\subsection{Theory: Factors Affecting the Government's Appointment Decision}

The trends in the data can be summarized as follows: throughout the sample period, there is a downward trend in the number of parliamentary commissions that are appointed and, as a consequence, a similar downward trend in the share of politicians as commission members. This decline is present with both left- and right-leaning governments and in governments that vary in their degree of parliamentary strength. At the same time, there is no corresponding drop in the inclusion of stakeholders, and although there is an increase in the use of special investigator inquiries, that increase appears to have peaked in the mid2000s. The policy areas, in broad terms, appear to be relatively stable, so it is unlikely that a shift in policy areas is the main driver of the change, although there could be shifts within the policy areas that are not apparent in the data.

In terms of the theory, there are several possible explanations of why governments would have less interest in appointing commissions with politicians but why there would not be a corresponding reduction in their willingness to involve stakeholders. I suggest five possibilities, each of which may contribute to the trend in various degrees.

One possibility is that the amount of valence gained from interest group inclusion has decreased but not vanished. From Theorem 1 and Subsection 4.5.4, the theory predicts that the shared gain from valence has to be at least as large as the government's private benefit to facilitate bargaining both within the commission and between the commission and the government. If stakeholder groups have become less powerful or more fragmented, they are less able to provide guarantees or assurances about the implementation of their policy proposals. This reduces the overall surplus from bargaining. As long as the implementation guarantees that stakeholders provide have not become too small, the government would still benefit from including stakeholders. Therefore, if stakeholders bring something but somewhat less to the table, the government would optimally choose to include them but not to broaden the commission to include politicians. In other words, changes in stakeholder power and in the composition of stakeholder groups provide an indirect reason for exclusion of politicians. 
A second possibility is that there have been ideological shifts in the party system. According to the theory, for a government to benefit from including politicians, it must be able to appoint politicians whose ideal points are both to the left and to the right of the government's. If the major parties all differ in their platforms from the government in the same direction, or if opponents on one side of the government are politically unacceptable as appointees, then the government would not benefit from having politicians on its commissions. Appointing politicians only to the left or only to the right of the government leads, according to Theorem 1, to all of the valence benefits being expropriated by commission members, with the government receiving nothing. Therefore, if the major parties have shifted ideologically in a way that does not provide acceptable appointees on both sides of the government, we would not expect to see politicians appointed to commissions. The emergence of the rightpopulist Sweden Democrats as a major political player after the 2010 general election may have added such an outlier to the political map.

The nature of the government itself can also lead to reduced politician involvement in commissions. Even if the government has viable appointees to both its left and its right, it may have a reduced benefit from including politicians. There are two reasons this may occur. A strong government always has less need for external support to implement policies, so the value of a broad political consensus would not be as large, at least for instrumental reasons, as it would be for a weak government. Even holding this benefit (called $K$ in the model) fixed, a strong government may have less need for including politicians. As shown in (4.13), an important benefit of including politicians is that they constrain the range of consensual proposals that the government would accept. If a government is strong, it does not need to rely on this indirect method of hoping the politicians will do its bidding. Instead, it can give more explicit instructions to the commission on what is and what is not within the commission's charge.

These three reasons for decreases in politician involvement are derived from the model and have testable empirical implications. It is also possible, however, that the explanation lies in the nature of the policy disagreements. In the theory presented here, all actors have policy differences that can be placed on a single left-right dimension. This may well continue to characterize the views of stakeholders. However, since the 1990s, there may have been a 
shift toward political parties having multidimensional ideologies. A conservative party, for example, may want fewer tariffs than both a left-wing and a right-wing party, because issues of economic conservatism or liberalism have become commingled with issues of nationalism versus globalism. If politicians come from parties with platforms scattered across multiple dimensions, then including politicians in a commission that involves bargaining leads to instability, for familiar reasons discussed in McKelvey (1976) and Shepsle (1979).

Although testing this hypothesis would require additional data, there is some suggestive evidence that the dimensionality of policy disagreements has increased. First, the current party system in Sweden includes eight parties, up from five before 1988, and is one of the most fragmented in Western Europe (Lindvall et al., 2020). In addition, there has been an increase in the dimensionality of party conflict. Historically, party competition in Sweden has been structured by the economic left-right dimension (Särlvik, 1966), and new dimensions (such as European integration) have eventually absorbed into the left-right dimension (Lindvall et al., 2020). In the last decade, however, immigration and multicultural values have added new dimensions to party conflict (Lindvall et al., 2020).

In addition to the above possible explanations, it is conceivable that the problem is not what it appears. The decline in appointing politicians may simply lag an earlier decline in the appointment of stakeholders. Recall from Chapter 5.2 that for most of the twentieth century, political power in Sweden was shared by a dual structure of a strong central government and highly organized interest groups. At the top of this hierarchy were several large organizations representing the interests of capital and labor: the Swedish Trade Union Confederation (LO), the Swedish Confederation of Professional Employees (TCO), the Swedish Confederation of Professional Associations (SACO), the Confederation of Swedish Enterprise, and the Swedish Federation of Business Owners (Anton, 1969). Within this dual structure, politicians and parties decided the overall policy goals in collaboration with leaders of main interest groups. The government then appointed commissions of inquiry, which included both interest group representatives from both sides of the aisle and politicians from all major parliamentary parties. These conducted policy research and negotiated agreement with the political actors. Interest groups were also represented on the boards of government agencies (Anton, 1969; Meijer, 1956, 346). This neocorporatist system started to weaken in 
the 1980s, which led to a drop in interest group participation in commissions of inquiry (see Johansson, 1992). Öberg et al. (2011) argues that the main reason for this decline is that the base of the exchange relationship between the government and interest groups had weakened and that interest groups were no longer controlling the resources, such as their ability to deliver the support of their membership, that made them attractive negotiation partners. On the other side of the coin, Europeanization and strained public budgets had weakened the governments' mandates and limited the number of policy concessions they could make. As a consequence, interest groups began to turn to political lobbying toward elected representatives in the parliament and the government instead of participating in corporatist arrangements (Rommetvedt et al., 2012; Petersson, 2016). There is debate over the extent of this decline, however (see Hermansson, Svensson and Öberg, 1997; Christiansen et al., 2010; Öberg et al., 2011; Binderkrantz and Christiansen, 2015, for some evidence that this decline is overstated or has occurred only in some limited respects). Nevertheless, the level of stakeholder involvement is perhaps already at a small level, and it is possible that there would be little point in decreasing their representation further.

\subsection{Consequences: No Decline in Latent Dissent but Less Dissent in Reports}

As Figure 6.5 and Table $6.8^{1}$ show, the presence and share of reservations and dissenting opinions have also declined. In 1990, 26 percent of inquiries had at least one reservation, and 44 percent had least one dissenting opinion. In 2018, the corresponding figures were 0 percent and 22 percent. Similarly, in 1990, the average share of reservations ${ }^{2}$ was 5 percent, and the average share of dissenting opinions was 11 percent. In 2018, the corresponding figures were 2 percent and 8 percent. All four trends are highly significant (coefficients -0.007 , $-0.007 ; t$-statistics $=-6.62,-5.97 ; p=0.000$ and 0.000 , for the presence of reservations and dissenting opinions, respectively, and coefficients $-0.001,-0.002 ; t$-statistics $=-6.15$,

\footnotetext{
${ }^{1}$ Both Figure 6.5 and Table 6.8 are based on the earlier sample of policy inquiry SOUs published in 1990-2018, which included final and intermediate inquiries. The years are SOU publication years, not new commission appointment years.

${ }^{2}$ Number of reservations divided by number of commission members, excluding secretaries, who are not allowed to dissent.
} 
$-7.24, p=0.000$ and 0.000 , for the shares of reservations and dissenting opinions, respectively).

Figure 6.5: Presence and share of reservations and special comments in inquiry reports, 1990-2018. Sample includes SOUs in 1990-2018 $(N=2,705)$

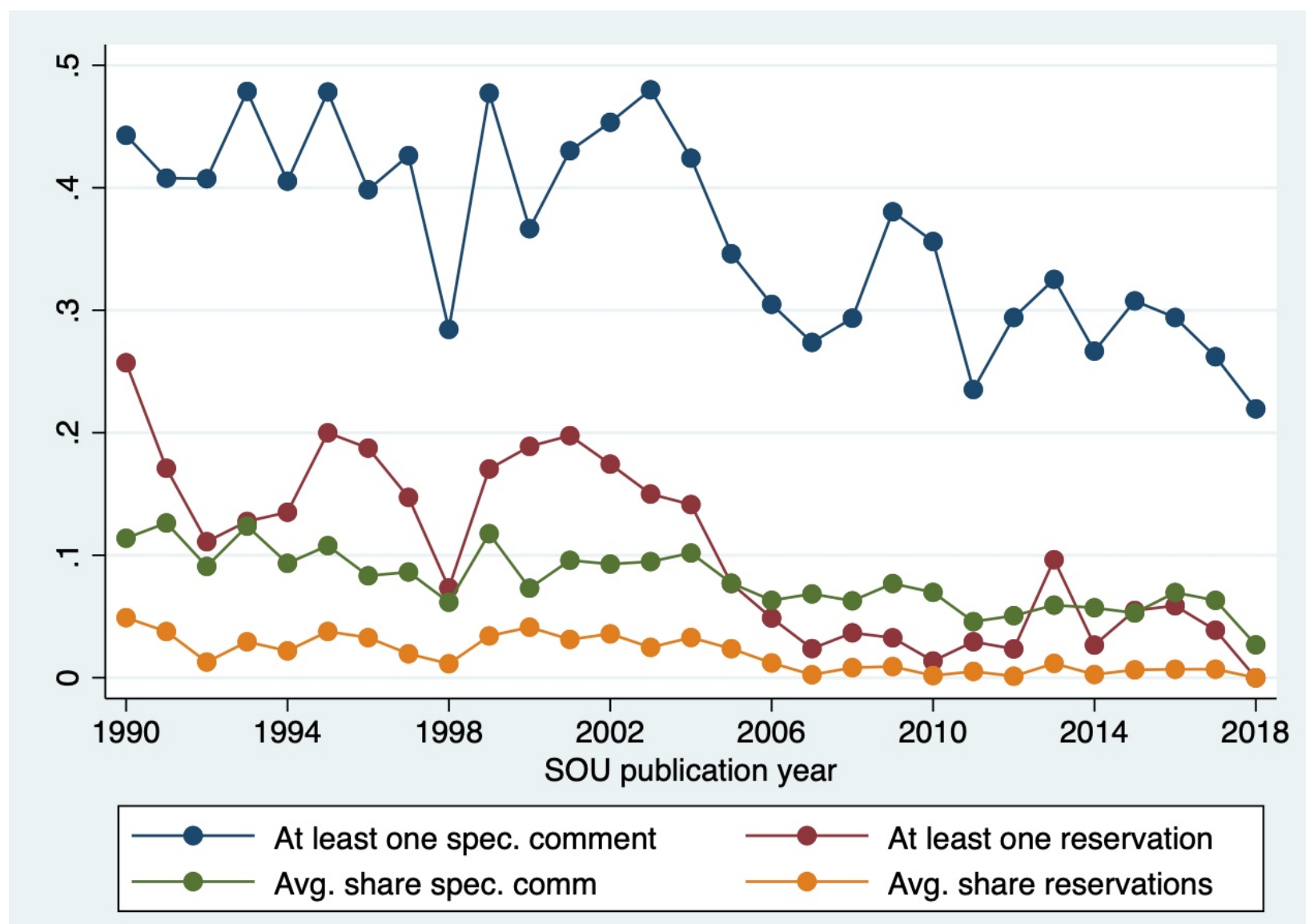

The decrease in dissent should not be taken as a sign of increased consensus among political actors, however, since both political polarization and fractionalization have increased in the past two decades (Lindvall et al., 2020). Instead, the decline is most likely due to the decreased shares of parliamentary commissions and politicians. As Table 6.9 shows, politicians are the most likely member type to express reservations and the third most likely member type to express dissenting opinions. Excluding them from public inquiries is likely to have a dampening effect on overall dissent. Reservations (two-thirds of which are written by politicians) are also more likely to cite ideological reasons for disagreement than dissent- 
Table 6.8: Presence and shares of reservations and dissenting opinions, 1990-2016

\begin{tabular}{|c|c|c|c|c|}
\hline $\begin{array}{l}\text { SOU } \\
\text { year }\end{array}$ & $\begin{array}{r}\text { Presence } \\
\text { reserv. }\end{array}$ & $\begin{array}{l}\text { Presence } \\
\text { diss. opin. }\end{array}$ & $\begin{array}{r}\text { Share of } \\
\text { reserv. }\end{array}$ & $\begin{array}{l}\text { Share of } \\
\text { diss. opin. }\end{array}$ \\
\hline 1990 & 0.26 & 0.44 & 0.05 & 0.11 \\
\hline 1991 & 0.17 & 0.41 & 0.04 & 0.13 \\
\hline 1992 & 0.11 & 0.41 & 0.01 & 0.09 \\
\hline 1993 & 0.13 & 0.48 & 0.03 & 0.12 \\
\hline 1994 & 0.14 & 0.41 & 0.02 & 0.09 \\
\hline 1995 & 0.20 & 0.48 & 0.04 & 0.11 \\
\hline 1996 & 0.19 & 0.40 & 0.03 & 0.08 \\
\hline 1997 & 0.15 & 0.43 & 0.02 & 0.09 \\
\hline 1998 & 0.07 & 0.28 & 0.01 & 0.06 \\
\hline 1999 & 0.17 & 0.48 & 0.03 & 0.12 \\
\hline 2000 & 0.19 & 0.37 & 0.04 & 0.07 \\
\hline 2001 & 0.20 & 0.43 & 0.03 & 0.10 \\
\hline 2002 & 0.17 & 0.45 & 0.04 & 0.09 \\
\hline 2003 & 0.15 & 0.48 & 0.02 & 0.09 \\
\hline 2004 & 0.14 & 0.42 & 0.03 & 0.10 \\
\hline 2005 & 0.08 & 0.35 & 0.02 & 0.08 \\
\hline 2006 & 0.05 & 0.30 & 0.01 & 0.06 \\
\hline 2007 & 0.02 & 0.27 & 0.00 & 0.07 \\
\hline 2008 & 0.04 & 0.29 & 0.01 & 0.06 \\
\hline 2009 & 0.03 & 0.38 & 0.01 & 0.08 \\
\hline 2010 & 0.01 & 0.36 & 0.00 & 0.07 \\
\hline 2011 & 0.03 & 0.24 & 0.01 & 0.05 \\
\hline 2012 & 0.02 & 0.29 & 0.00 & 0.05 \\
\hline 2013 & 0.10 & 0.33 & 0.01 & 0.06 \\
\hline 2014 & 0.03 & 0.27 & 0.00 & 0.06 \\
\hline 2015 & 0.05 & 0.31 & 0.01 & 0.05 \\
\hline 2016 & 0.06 & 0.29 & 0.01 & 0.07 \\
\hline 2017 & 0.04 & 0.26 & 0.01 & 0.06 \\
\hline 2018 & 0.00 & 0.22 & 0.00 & 0.03 \\
\hline Total & 0.10 & 0.36 & 0.02 & 0.08 \\
\hline
\end{tabular}


ing opinions Johansson (1992), so excluding politicians from commissions will also dampen ideological dissent.

Table 6.9: Nr reservations and dissenting opinions by member type

\begin{tabular}{lrr}
\hline Member type & Reserv. & Diss. opin. \\
\hline Academics & 22 & 143 \\
Civil servants & 30 & 714 \\
Interest groups & 22 & 755 \\
Judges & 14 & 59 \\
Other & 42 & 198 \\
Politicians & 634 & 529 \\
Public servants & 32 & 124 \\
Unclassified & 117 & 740 \\
Total & 913 & 3,262 \\
\hline Sample: Published SOU policy inquiry reports 1990-2018 $(\mathrm{N}=2,705)$
\end{tabular}

As Gosnell (1934) points out, reservations and dissenting opinions grow out of fundamental differences in outlook and should be expected in a properly functioning democracy. Therefore the exclusion of potential dissenting voices from the most important legislative preparation body is problematic. At the very least, it means that political conflicts are not resolved at the policy formulation stage of the legislative process but postponed to later stages of the process, when party positions have already hardened and there is less opportunity to build valence that can serve as a basis for compromise.

The 2016 welfare inquiry (Fi 2015:01), ${ }^{3}$ appointed by the Löfven I red-green cabinet (directive 2015:22), is a perfect example of the type of outcome that can happen when dissenting voices are excluded from the policy formulation process. The purpose of the inquiry was to recommend a new regulatory framework for public financing of privately performed health and welfare services, which would ensure that public funds were used only toward activities for which they were intended. Previous inquiries in the same policy area had almost invariably been prepared by a broadly representative commission. Instead, the government appointed a special investigator, Ilmar Reepalu, a municipal commissioner, to head the inquiry. He was assisted by 17 experts from various ministries and governmental agencies, 3 subject matter specialists from the Ministry of Finance, and 1 representative

\footnotetext{
${ }^{3}$ http://www.sou.gov.se/valfardsutredningen/,
} 
from the Swedish Association of Local Authorities and Regions (SALAR). The inquiry had two external reference groups representing the education and health care sectors. These did not participate in the decision-making or in drafting the report. In addition, the inquiry held meetings with various organizations and associations in the health care sector.

The inquiry published its interim report, Good Order in Welfare (SOU 2016:78), in November 2016 and its final report, Welfare Quality-Better Procurement and Follow-up (SOU 2017:38), in May 2017. Neither contained any dissenting opinions. The interim report concluded that private providers of public health care services had excessive profit margins and recommended a profit margin cap of 7 percent plus the current government interest rate. The special investigator argued that the large profit margins created perverse incentives in service provision and resulted in fewer resources being left available for service delivery. ${ }^{4}$

The interim report received immediate criticism from the opposition parties, policy researchers, governmental agencies, and the health care industry. The opposition parties accused the special investigator of having an ideological predisposition against privately provided health services. ${ }^{5}$ Others argued that the special investigator had failed to adequately assess the potential consequences of the profit margin cap and to ensure that the proposed framework was consistent with existing regulations. In a debate article published in Svenska Dagbladet, Anders Morin from the Confederation of Swedish Enterprise (Svenskt Näringsliv), an employers' organization representing 60,000 private companies with more than 1.6 million employees, argued that the new profit margin cap would bankrupt many, if not most, small for-profit businesses providing health and welfare services. ${ }^{6}$ This went against the government's explicit instructions that the new framework should ensure diversity and consumer choice in service delivery. In another article in Svenska Dagbladet, Håkan Tenelius from Vårdföretagarna (the Association of Private Care Providers), an association for 2,000 companies providing private care services in Sweden, went so far as to call the investigation "a fiasco."7

\footnotetext{
${ }^{4}$ https://www.sns.se/aktuellt/ilmar-reepalu-om-valfardsutredningen/, http://www.sou.gov . se/wp-content/uploads/2015/06/Presentation-presskonferens-161027-JL . pdf.

${ }^{5}$ https://www . aftonbladet.se/nyheter/samhalle/a/kn1dQ/alliansen-sagar-valfardsutredningen.

${ }^{6}$ https://www.svd.se/utredningens-forslag-slutet-for-valfardsbolagen/om/ vinster-i-valfarden- $7 \mathrm{GmE}$.

${ }^{7}$ https://www.svd.se/ny-kritikstorm-mot-valfardsutredningen-fiasko.
} 
Furthermore, in a November 2016 presentation of the inquiry's findings at the Centre for Business and Policy Studies (SNS), ${ }^{8}$ Per Strömberg, professor of financial economics, argued that the profit cap would mean losing the advantages of for-profit service delivery without increasing care quality. He also argued that the profit ceiling unfairly benefited larger for-profit providers and disadvantaged smaller ones. During the same presentation, Eva-Maj Mühlenbock, a partner in the Lindahl law firm, pointed out that the proposed cap was likely to be in conflict with existing Swedish and EU laws. Similar arguments were made independently by the Stockholm District Court and the National Audit Office, which argued that the proposed framework left room for different interpretations, which would create legal unpredictability and uncertainty for private service providers. ${ }^{9}$ The National Audit Office also pointed out that the state and municipal sector lacked capacity to take over services performed by the private sector should the new regulation result in companies exiting the market.

The rest of the proposed regulatory framework also met with resistance from the opposition parties. The Swedish Democrats disagreed with the proposal in general, while the center-right alliance of the Centre Party, the Moderates, the Christian Democrats, and the Liberals was prepared to agree with the general framework, but only if the requirement for the profit margin cap was dropped. ${ }^{10}$ Eventually, the government implemented a different policy, which incorporated some of the criticism received by the inquiry.

From the perspective of the theory, the Löfven I government chose an off-equilibrium strategy by not appointing a parliamentary commission. The policy issue was highly contentious and significant - changes to the regulatory framework would affect not only regional and municipal health care services but also ordinary Swedish citizens and the 4,500 health care businesses providing services through the existing framework. The Löfven I government was one of the weakest minority governments in post-World War II Swedish history, with only 37.9 percent of the popular vote and a 39.5 percent seat share, and was facing united opposition by the center-right parties (the Alliance). The inquiry had a large number of experts; these were all employed by ministries and governmental agencies. It did not include

\footnotetext{
${ }^{8}$ https://www.sns.se/aktuellt/ilmar-reepalu-om-valfardsutredningen/.

${ }^{9}$ https://www.svt.se/nyheter/ekonomi/riksrevisionen-sagar-valfardsutredningen.

${ }^{10}$ https://www . aftonbladet. se/nyheter/samhalle/a/kn1dQ/alliansen-sagar-valfardsutredningen.
} 
academics or politicians and included only one stakeholder from the SALAR. The special investigator (possibly) had strong ideological views of private provision of health care. From the perspective of the theory, the commission (although it did consult with organizations from the health and social sectors) failed. 


\subsection{Conclusions, Policy Implications, and Future Work}

Despite including a broad range of actors with different ideological preferences, advisory commissions have a surprisingly high rate of producing consensus recommendations. In this study, I argue that this fact can (at least partly) be explained by their institutional features and role in providing policy expertise. In particular, the fact that commissions are purely advisory, and do not make the final policy decision, means that the government considers the commission's recommendation but also evaluates its alternatives. By stating reservations or dissenting opinions, a member of a commission's minority can then try to steer the government away from the commission recommendation and toward an alternative or the status quo.

This (limited) ability of dissenters to influence the government incentivizes other commission members to moderate their demands and find a solution that is satisfactory to all parties. In other words, the ability to express dissent gives commission members a voice, even though it is not a veto.

To respond to the objections that potential dissenters voice, the commission's majority need to have something to offer. I argue that including stakeholders on the commission is the key to finding ways to make compromise policies more widely appealing. The specialized knowledge stakeholders bring to the table gives them the ability to increase valence

dimensions of their proposals, in a way that cannot easily be transferred to other potential policies.

These results suggest that ideologically diverse advisory commissions with experts and stakeholders are a good vehicle for obtaining informed consensus on policy under a fairly general set of conditions. This may explain their long persistence across different political systems and time periods. However, there are also likely to be preconditions which may be required for such a system to work. As discussed in Chapter 6, these may include a limited number of dimensions on which the policy conflict occurs, well-organized and centralized interest group structure, the absence of parties or governments with extreme political ide- 
ologies, and credible commitment from the government that consensus proposals have a reasonable chance of being implemented.

The theory also suggests that advisory commissions are most useful when there is policy uncertainty and therefore something new to learn. This is because, without increasing the valence of policy proposals, it is difficult to bridge ideological differences between the commission members. Therefore, advisory commissions are likely not particularly useful in situations where the commission is set up to negotiate over disagreements of a purely ideological nature, where it is not likely that additional information about the consequences of different policy options will bring the different parties together.

The above considerations point to several avenues for future research.

First, it would be useful to separate the importance of the two central forces that help advisory commissions build consensus. The purely advisory nature of the commissions studied here is central to giving commission members blackmail potential (in the terminology of Sartori, 2005). To the extent that commissions and other advisory bodies have decision making authority, the minority's blackmail potential is attenuated. However, those with specialized knowledge retain their coalitional potential, as discussed in the legislative committee model of Hirsch and Shotts (2012). An empirical comparison of inclusivity and consensus in legislative committees and in advisory commissions, after making suitable adjustments for selection issues, could help separate the roles of blackmail and coalitional potential.

Second, characterizing the range of of policy conflict and party polarization which are likely to produce high valence outcomes, and the level where polarization becomes too high to overcome, would be interesting questions to explore in future research. Exploring these questions would require a richer data set with more variation in the level of party polarization, and with more data about the relative policy preferences of the different political actors. In the absence of such data, an extension of the theory presented here, with more structure imposed on policy preferences and policy issues, could shed more light on appointment decisions.

Third, it may be fruitful to extend the current formal model, as presented in Chapter 4, to endogenize the proposal generating process and the commission's rule for selecting a proposal as its main recommendation. These extensions could provide insight into the choice 
of commission size, which is an important component of inclusivity. Additionally, making the commission's recommendation endogenous could potentially address whether there are important determinants of consensus within the commission, which might be preconditions for the commission to develop more broadly consensual policies.

Finally, a promising feature of advisory commissions to include in future work is the government's choice of the scope of the commission's work (that is, its terms of reference). Limiting the set of policies that the commission can study is a potential alternative to adding politicians to the commission, as both can serve the role of keeping politically infeasible proposals off the table. Understanding how the government chooses between these potential means of enforcement could provide further insight into the trends discussed in Chapter 6. 


\section{Appendix A Proofs}

Proof of Proposition 1. Immediate from substituting (4.8) into (4.2).

Proof of Theorem 1. Using (4.8) to substitute for $q$ in the second term of (4.12) gives

$$
\begin{aligned}
E\left[\left(q+\rho_{q} \tilde{\eta}+\tilde{\varepsilon}_{q}-g_{i}\right)^{2} \mid s, \tau\right] & =E\left[\left(\left(g_{G}-g_{i}\right)+\rho_{q}\left(\tilde{\eta}-\mu_{\eta \mid s}\right)+\left(\varepsilon_{q}-\mu_{\varepsilon_{q} \mid \tau}\right)\right)^{2} \mid s, \tau\right] \\
& =\left(g_{G}-g_{i}\right)^{2}+\rho_{q}^{2} h_{\eta \mid s}^{-1}+h_{\varepsilon_{q} \mid \tau}^{-1} \\
& =\left(g_{G}-g_{i}\right)^{2}-E U_{G}\left(\tilde{x}_{q} \mid s, \tau\right) .
\end{aligned}
$$

Rewriting the first in term of (4.12) gives

$$
\begin{aligned}
&-E\left[\left(r+\rho_{r} \tilde{\eta}+\tilde{\varepsilon}_{r}-g_{i}\right)^{2} \mid s, \tau\right]=-r^{2}-\rho_{r}^{2}\left(\mu_{\eta \mid s}^{2}+h_{\eta \mid s}^{-1}\right)-\mu_{\varepsilon_{r} \mid \tau}^{2}-h_{\varepsilon_{r} \mid \tau}^{-1} \\
&-2 r \rho_{r} \mu \eta\left|s-2 r \mu_{\varepsilon_{r} \mid \tau}-2 \rho_{r} \mu_{\eta \mid s} \mu \varepsilon_{r}\right| \tau \\
& \underbrace{-g_{i}^{2}+2 g_{i}\left(r+\rho_{r} \mu_{\eta \mid s}+\mu_{\varepsilon_{r} \mid \tau}\right)}_{\text {Only portion that depends on } g_{i}} \\
&=E U_{G}\left(\tilde{x}_{r} \mid s, \tau\right)-\alpha K+g_{i}^{2}-g_{G}^{2}-2\left(g_{i}-g_{G}\right)\left(r+\rho_{r} \mu_{\eta \mid s}+\mu_{\varepsilon_{r} \mid \tau}\right) .
\end{aligned}
$$

Now substitute (A.1) and (A.2) into (4.12) to solve for $\Delta_{i}\left(\tilde{x}_{r}\right)$ in terms of $\Delta_{G}\left(\tilde{x}_{r}\right)$ :

$$
\begin{aligned}
\Delta_{i}\left(\tilde{x}_{r}\right) & =E U_{G}\left(\tilde{x}_{r} \mid s, \tau\right)-E U_{G}\left(\tilde{x}_{q} \mid s, \tau\right)-\alpha K+\left(g_{G}-g_{i}\right)^{2}+g_{i}^{2}-g_{G}^{2} \\
& -2\left(g_{i}-g_{G}\right)\left(r+\rho_{r} \mu_{\eta \mid s}+\mu_{\varepsilon_{r} \mid \tau}\right) \\
& =\Delta_{G}\left(\tilde{x}_{r}\right)-\alpha K+2\left(g_{i}-g_{G}\right)\left(g_{G}-r-\rho_{r} \mu_{\eta \mid s}-\mu_{\varepsilon_{r} \mid \tau}\right) .
\end{aligned}
$$

If the government gets its outside option, then $\Delta_{G}\left(\tilde{x}_{r}\right)=\alpha K$, then

$$
\Delta_{G}\left(\tilde{x}_{r}\right) \geq 0 \Rightarrow 2\left(g_{i}-g_{G}\right)\left(g_{G}-r-\rho_{r} \mu_{\eta \mid s}-\mu_{\varepsilon_{r} \mid \tau}\right) \geq 0 .
$$

If $g_{G}-r=\rho_{r} \mu_{\eta \mid s}-\mu_{\varepsilon_{r} \mid \tau}$, then $r$ statisfies (4.8), that is, is the government's outside option. But in that case, the government's payoff from adopting $\tilde{x}_{r}$ is $\alpha K>0$, contradicting the assumption that $G$ 's individual rationality constraint binds. If $g_{G}-r>\rho_{r} \mu_{\eta \mid s}-\mu_{\varepsilon_{r} \mid \tau}$, then $\Delta_{G}\left(\tilde{x}_{r}\right) \geq 0$ if and only if $g_{i} \geq g_{G}$, so commission members support the recommendation if 
and only if they are to the right of the government. If $g_{G}-r \leq \rho_{r} \mu_{\eta \mid s}-\mu_{\varepsilon_{r} \mid \tau}$, then $\Delta_{G}\left(\tilde{x}_{r}\right) \geq 0$ if and only if $g_{i} \leq g_{G}$, so commission members support the recommendation if and only if they are to the left of the government. 


\section{Appendix B Description of Data and Codebook}

The data set consists of two Stata .dta files. T he fi rst fil e (membership 1990to2018) contains information about members of Swedish policy inquiries whose reports were published in the Government Official Reports (Statens offentliga utredningar, or SOU) series in 19902018. The second file (master1990to2018) c ontains information a bout all i nquiries for the same time period, including the ones excluded from the membership file. The files can be linked by using the SOU year and SOU number as unique identifiers.

\section{B.1 Membership Data File}

This file c ontains i nformation a bout $\mathrm{m}$ embers of $\mathrm{S}$ wedish $\mathrm{p}$ olicy i nquiries w hose SOU reports were published in 1990-2018. The data exclude permanent commissions and inquiries that did not publish a SOU report or did not make a policy recommendation. The unit of analysis is an individual member.

\section{B.1.1 Population}

\section{Inclusion criteria}

(i) Inquiries that published a report in the Government Official Reports (Statens offentliga utredningar, or SOU) document series in 1990-2018 and made a policy recommendation.

\section{Exclusion criteria}

(i) Inquiries whose total membership (excluding secretaries) is less than three.

(ii) Inquiries that did not include a policy recommendation in their report. 
(iii) Additional volumes, appendices, background materials, and so on.

(iv) Special inquiries investigating historical events, political scandals, or large-scale accidents.

(v) Permanent commissions of inquiry producing periodic reports on nuclear security, long-term economic trends, and so on.

(vi) Other special commissions (e.g., a commission appointed to provide a new official translation of the Bible).

\section{B.1.2 Members}

\section{Inclusion criteria}

(i) People with the following roles: chairperson/vice chair (ordförande/vice ordförande), special investigator (särskild utredare), member (ledamot), subject specialist (sakkunnig), expert (expert), secretary (sekretarare). (Note: A few inquiries were headed by a coordinator (samordnare) or a chief negotiator (förhandlingsman). These were coded as special investigators.)

(ii) Members of parliamentary or other reference groups (referensgrupp), expert groups (expertgrupp), and working groups (arbetsgrupp).

(iii) Members who are initially appointed and members who are appointed later.

(iv) If the same member serves in several roles throughout an inquiry's mandate period, only the final role is included.

\section{Exclusion criteria}

(i) Members who were explicitly replaced by another during the inquiry or members in the same membership category and with the same title or affiliation and who were appointed on the same day.

(ii) Clerical support staff. 
(iii) Experts who do not have an assigned role or who do not belong to external reference groups (referensgrupp, expertgrupp, arbetsgrupp).

\section{B.1.3 Variables}

Table B.1: Commission and inquiry-level variables

\begin{tabular}{ll}
\hline Variable & Description \\
\hline Commission-level variables & \\
comm_code & Commission code (e.g., K 1999:1) \\
comm_year & Year the commission was appointed \\
department & Appointing ministry (see separate table) \\
comm_name & Commission name \\
dir_date (YYYY-MM-DD) & Date of the government directive \\
\hline Inquiry-level variables & \\
sou_year & Year the inquiry report (SOU) was published \\
sou_nr & Numeric identifier of the report \\
dir_nr & Directive numbers in chronological order \\
sou_name & Title of the report \\
sou_date (YYYY-MM-DD) & Date the inquiry was completed \\
eupolicy & $1=$ An EU directive applies to the policy issue \\
info_source & Data source used \\
\hline
\end{tabular}

Table B.2: Member-level variables

\begin{tabular}{lll}
\hline Variable & Subcategory & Explanation \\
\hline first & & First and middle names \\
sex & & Last name \\
role & Sex $(\mathrm{M} / \mathrm{F})$ \\
& Ordförande & Chairperson \\
& Vice ordförande & Vice chair \\
Särskild utredare & Special investigator \\
Ledamot & Commissioner \\
Sakkunnig & Subject matter specialist \\
Expert & Expert \\
Sekreterare & Secretary \\
& Other & Leftover category for member roles \\
& not in above categories \\
& Referensgrupp & Reference group attached to the inquiry
\end{tabular}




\begin{tabular}{|c|c|c|}
\hline & $\begin{array}{l}\text { Parlamentarisk } \\
\text { referensgrupp }\end{array}$ & Group of MPs attached to the inquiry \\
\hline career & & Occupational title \\
\hline employer & & Employer/affiliation \\
\hline \multirow[t]{9}{*}{ party } & $s$ & Social Democrats \\
\hline & $m$ & Moderate Party \\
\hline & $c$ & Centre Party \\
\hline & $m p$ & Green Party \\
\hline & $v$ & Left Party \\
\hline & $f p$ & Liberals \\
\hline & $k d$ & Christian Democrats \\
\hline & nyd & New Democracy \\
\hline & $s d$ & Sweden Democrats \\
\hline classification_main & Member type & See coding rules \\
\hline classification_sub & Member subtype & See coding rules \\
\hline reser & & No. of reservations by the member \\
\hline yttr & & No. of special comments by the member \\
\hline
\end{tabular}

\section{B.1.4 Codebook}

Commission code (comm_code): Each commission has a unique identifier, consisting of a one- or two-letter abbreviation of the appointing ministry, the year the commission was appointed, and the commission code (e.g., S 1997:24). The year does not denote a calendar year but the year when the current year's parliamentary session began. Thus "2011" refers to the 2011-2012 session. There are a few exceptions to these rules. In some cases, the commission code was not found and a similar unique identifier w as c reated to i dentify the commission.

Commission year (comm_year): Taken from the commission code.

Commission name (comm_name): Many commissions are known by several names. In cases of discrepancy, I generally used the name in the SOU report.

Table B.3: Ministries

\begin{tabular}{lll}
\hline Name & Abbr & Areas of responsibility \\
\hline Ministry of Labor & A & Issues related to labor
\end{tabular}




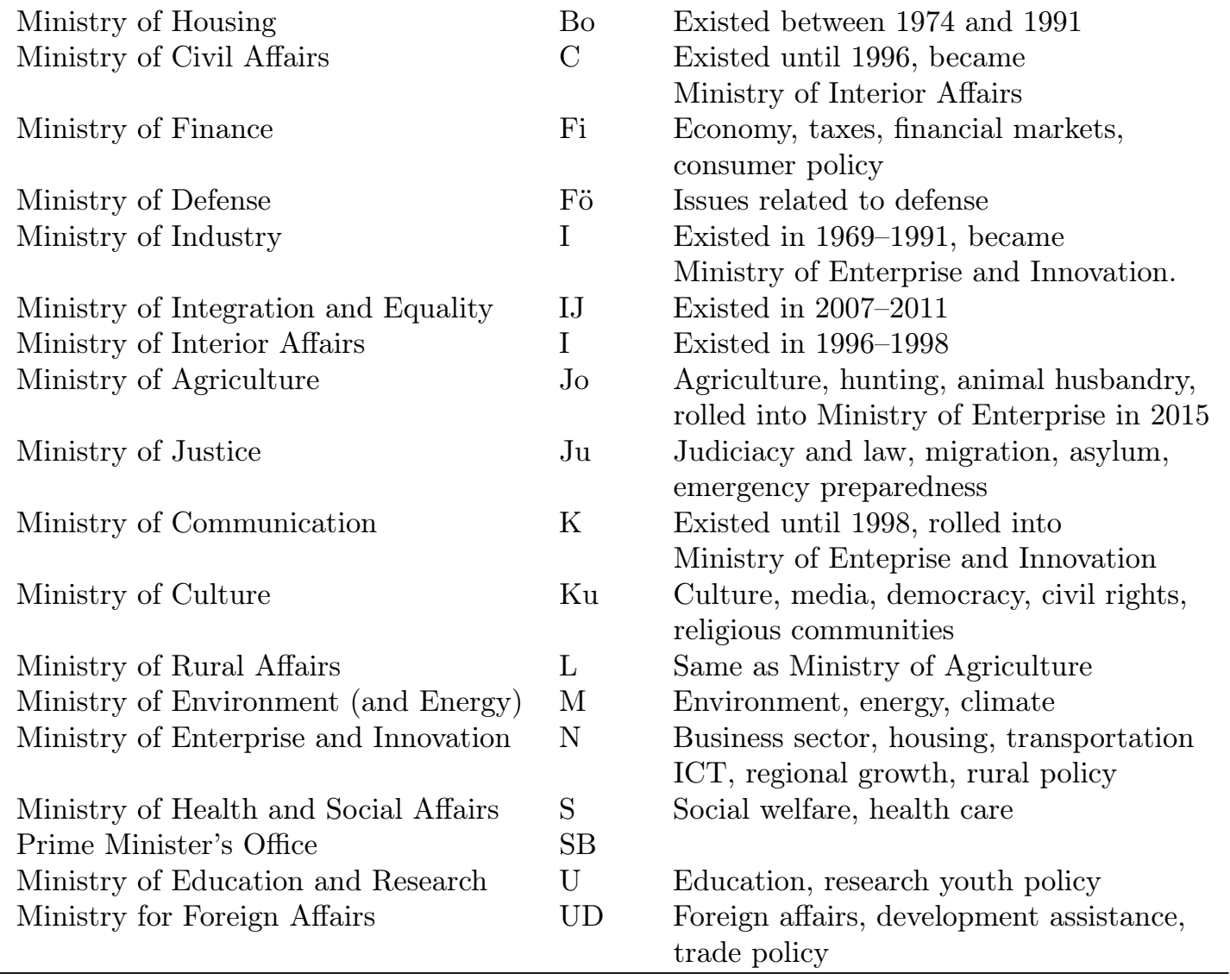

\section{Directive date}

(i) Date of the original committee directive (kommittékdirektiv).

(ii) For multi-inquiry commissions, the relevant date of appointment for a subsequent report is defined either by (1) the original appointment date or (2) a new directive date or the date of an additional directive (tillläggsdirektiv). In case it is not clear which date should be used, the date mentioned in the $\mathrm{I}=$ introduction of the SOU is used.

(iii) If only month and year are specified, the date is coded as the first of the month. 


\section{Directive number}

(i) All directive numbers pertaining to the inquiry are listed in chronological order, separated by commas.

(ii) EU directives mentioned in the text and pertaining to the inquiry are listed after regular directive numbers.

\section{Employer/affiliation}

(i) Employer/affiliation: The organization or employer with which the member is affiliated, established based on information in the report or scraped data.

(ii) If an affiliation is not provided in either source, it may be established based on additional sources.

(iii) Affiliation is coded as affiliation at the time of the member's appointment.

Table B.4: Membership classification

\begin{tabular}{lll} 
Main category & Subcategory & Description \\
\hline Academics & Professors & Professors \\
& Adjuncts & Academic adjuncts \\
& Docents & \\
& Lecturers & \\
& PhDs./licenciates & people with a doctoral/licenciate degree \\
& & (unless in another category) \\
& Prof. emer. & Retired professors \\
& Researchers & People with a title "Researcher" \\
\hline Civil servants & Ministries & Employed by a ministry \\
& Agencies & Employed by an agency/bureau \\
& Research agencies & Employed by a research agency \\
& Public prosecutors & \\
& and attorney general & \\
& Ministry attorneys & \\
& County governors & Attorneys in ministries or agencies \\
& Other & Landshövdinger \\
\hline Public servants & Local public servants & \\
& Regional public servants & Local/municipal public sector employees \\
& Schools & Regional public sector employees \\
& University admins & Teachers, rectors \\
Medical personnel & University rectors or administrators \\
State enterprise employees & Doctors, nurses, psychologists \\
Riksbanken & \\
\end{tabular}




\begin{tabular}{|c|c|c|}
\hline & $\begin{array}{l}\text { Military } \\
\text { Ombudsman } \\
\text { Other }\end{array}$ & $\begin{array}{l}\text { Military personnel } \\
\text { Ombudsmen at public agencies }\end{array}$ \\
\hline \multirow[t]{6}{*}{ Interest groups } & Labor unions & Labor unions and organizations \\
\hline & Employers associations & Employer or industry associations \\
\hline & NGOs & $\begin{array}{l}\text { NGOs, religious organizations } \\
\text { (incl. Church of Sweden) }\end{array}$ \\
\hline & Professional organizations & Organizations representing professions/trades \\
\hline & Government interest groups & $\begin{array}{l}\text { Organizations representing municipalities } \\
\text { and regional governments }\end{array}$ \\
\hline & Other & Other or unidentified interest groups \\
\hline \multirow[t]{10}{*}{ Politicians } & Parlamentarians & Present and previous MPs \\
\hline & State secretaries & \\
\hline & Ministers & Cabinet ministers \\
\hline & Mayors & \\
\hline & Regional mayors & \\
\hline & Regional politicians & \\
\hline & Local politicians & \\
\hline & Deputy representatives to & \\
\hline & $\begin{array}{l}\text { the Riksdag } \\
\text { Party secretaries }\end{array}$ & \\
\hline & EU politicians & \\
\hline Judges & Judges & \\
\hline \multirow[t]{7}{*}{ Other } & Private sector employees & \\
\hline & Consultants & \\
\hline & Attorneys employed by private firms & \\
\hline & Accountants and auditors & \\
\hline & Journalists and writers & \\
\hline & Arts and culture & Artists, theater directors, etc. \\
\hline & Other & \\
\hline Unclassified & & Could not be classified \\
\hline
\end{tabular}

\section{B.2 Inquiry Data File}

This file contains information about all inquiries in 1990-2018, including ones excluded from the membership file. The exception are inquiries that did not publish a SOU report. The unit of analysis is an individual inquiry. The files can be linked using the SOU year and SOU number. The unit of analysis is an individual inquiry (SOU). More detailed information about coding policy areas can be found at the Comparative Agendas Project website, http://www.comparativeagendas.net/datasets_codebooks. 


\section{B.2.1 Population; inclusion and exclusion criteria}

All inquiries that published their reports between 1990 and 2018, including ones excluded from the membership file.

\section{B.2.2 Variables}

Table B.5: Inquiry-, commission-, and government-level variables

\begin{tabular}{ll}
\hline Variable & Description \\
\hline Inquiry-level variables & Year the inquiry was completed \\
sou_year & Numeric identifier of the report (SOU) \\
sou_nr & Title of the report \\
sou_name_M & Policy area (see separate table) \\
policy_area & Type of inquiry \\
\hline type_comm & Inquiry with a policy recommendation \\
Policy inquiry & A report/anthology (rapport/antologi) \\
Report & An appendix to another inquiry report \\
Appendix & Inquiry report is missing from all archives \\
Missing & Inquiries about scandals, accidents, etc. \\
Special inquiry & Inquiries not fitting the above categories \\
Other & \\
\hline Commission-level variables & Commission code (e.g. K 1999:1) \\
\hline comm_code & Year appointed \\
comm_year & Ministry appointing the commission \\
department & Commission name \\
comm_name & Date of directive \\
dir_date (YYYY-MM-DD) & \\
\hline Government-level variables & \\
\hline gvt_start date (YYYY-MM-DD) & Start date of appointing government \\
gvt_end date (YYYY-MM-DD) & End date of appointing government \\
gvt_name & Name of appointing government \\
gvt_parties & Government parties \\
rile_pol & Political polarization (Dalton, 2008) \\
gov_sup & \\
\hline &
\end{tabular}

Table B.6: Policy areas

\begin{tabular}{lll}
\hline Variable & CAP classification & Description \\
\hline agriculture & Agriculture & Agriculture, food, animal welfare, fisheries \\
civil & Civil rights & Civil rights \\
crime & Law and crime & Law and crime, courts, police
\end{tabular}




\begin{tabular}{|c|c|c|}
\hline defense & Defense & Issues related to the military and civil defense \\
\hline economy & Macroeconomics & $\begin{array}{l}\text { Domestic economic policy, budget, interest rates, } \\
\text { unemployment, tax code, industrial policy }\end{array}$ \\
\hline domestic & Domestic commerce & $\begin{array}{l}\text { Banking, finance, insurance, business, } \\
\text { tourism, sports regulation }\end{array}$ \\
\hline education & $\begin{array}{l}\text { Education } \\
\text { Culture }\end{array}$ & $\begin{array}{l}\text { Issues related to education } \\
\text { Issues related to culture }\end{array}$ \\
\hline environment & $\begin{array}{l}\text { Energy } \\
\text { Environment }\end{array}$ & $\begin{array}{l}\text { Energy, gas and oil } \\
\text { Environment, pollution, waste disposal, drinking water }\end{array}$ \\
\hline & Public lands & Public lands, national parks, forests, water \\
\hline foreign & Foreign trade & Foreign trade, tariffs, exports, exchange rate \\
\hline gov_ops & Government operations & $\begin{array}{l}\text { Government operations, bureaucracy } \\
\text { intergovernmental relations, census }\end{array}$ \\
\hline health & Health care & Health care/insurance, drugs/alcohol/tobacco \\
\hline housing & Housing & Housing policy, development, special populations \\
\hline immigration & Immigration & Immigration, refugees, citizenship \\
\hline international & International affairs & International affairs, foreign aid, terrorism \\
\hline labor & Labor & Labor, employment and pensions \\
\hline technology & Technology and media & Science, technology, media \\
\hline transportation & Transportation & Mass transit, highways, maritime issues \\
\hline welfare & Social welfare & Social welfare, childcare, volunteer associations \\
\hline
\end{tabular}




\section{Bibliography}

Aldrich, John H., James E. Alt and Arthur Lupia. 2008. The EITM Approach: Origins and Interpretations. In Oxford Handb. Polit. Methodol. Oxford: Oxford University Press.

Anton, Thomas J. 1969. "Policy-Making and Political Culture in Sweden." Scan. Polit. Stud. 4(A4):88-102.

Armingeon, Klaus, Virginia Wenger, Fiona Wiedemeier, Christian Isler, Laura Knöpfel, David Weisstanner and Sarah Engler. 2019. Comparative Political Data Set 1960-2017. Data set.

Arrow, Kenneth. 1951. Social Choice and Individual Values. Yale University Press: New Haven.

Arrow, Kenneth J. 1950. "A Difficulty in the Concept of Social Welfare." J. Polit. Econ. 58(4):328-346.

Austen-Smith, David and William H. Riker. 1987. "Asymmetric Information and the Coherence of Legislation." Am. Polit. Sci. Rev. 81(3):897-918.

Baron, David P. and John a. Ferejohn. 1989. "Bargaining in Legislatures." Am. Polit. Sci. Rev. 83(4):1181-1206.

Barro, R. 1973. "The Control of Politicians: An Economic Model." Public Choice 14:19-42.

Battaglini, Marco, Ernest K Lai and Joseph Tao-yi Wang. 2019. "The Informational Theory of Legislative Committees: An Experimental Analysis." Am. Polit. Sci. Rev. 113(1):55-76.

Binderkrantz, Anne Skorkjær and Peter Munk Christiansen. 2015. "From Classic to Modern Corporatism. Interest Group Representation in Danish Public Committees in 1975 and 2010." J. Eur. Public Policy 22(7):1022-1039.

Blom-Hansen, Jens. 2000. "Still Corporatism in Scandinavia? A Survey of Recent Empirical Findings." Scan. Polit. Stud. 23(2):157-181.

Bulmer, Martin. 1981. "Applied Social Research? The Use and Non-Use of Empirical Social Inquiry by British and American Governmental Commissions." J. Public Policy 1(3):353380.

Bulmer, Martin. 1983. "Introduction: Commissions as Instruments for Policy Research." Am. Behav. Sci. 26(5):559-567.

Cameron, A. Colin and Douglas L. Miller. 2011. "A Practitioner's Guide to Cluster-Robust Inference." J. Hum. Resour. 50(2):317-372. 
Cartwright, T.J. 1975. Royal Commissions and Departmental Commissions in Britain. Hodder and Stoughton.

Christensen, Johan and Cathrine Holst. 2017. "Advisory commissions, academic expertise and democratic legitimacy: The case of Norway." Sci. Public Policy 44(6):821-833.

Christensen, Johan and Stine Hesstvedt. 2019. "Expertisation or Greater Representation? Evidence from Norwegian Advisory Commissions." Eur. Polit. Soc. 20(1):83-100.

Christiansen, Peter Munk. 1999. "From Corporatism to Lobbyism?" Scan. Polit. Stud. 22(3).

Christiansen, Peter Munk, Asbjørn Sonne Asbjørrn Sonne Asbjørn Sonne Nørgaard, Hilmar Rommetwedt, Torsten Svensson, Gunnar Thesen, PerOla Ola Öberg, Hilmar Rommetvedt, Torsten Svensson, Gunnar Thesen and PerOla Ola Öberg. 2010. "Varieties of Democracy: Interest Groups and Corporatist Committees in Scandinavian Policy Making." Voluntas $21(1): 22-40$.

Clokie, H. and J. Robinson. 1937. Royal Commissions of Inquiry: The Significance of Investigations in British Politics. Stanford: Stanford University Press.

Cooper, David J. and John H. Kagel. 2005. "Are Two Heads Better than One? Team versus Individual Play in Signaling Games." Am. Econ. Rev. 95(3):477-509.

Craft, Jonathan and Michael Howlett. 2013. "The Dual Dynamics of Policy Advisory Systems: The Impact of Externalization and Politicization on Policy Advice." Policy Soc. 32(3):187-197.

Crawford, Vincent and Joel Sobel. 1982. "Strategic Information Transmission." Econometrica $50(6): 1431-1451$.

Dahlström, Carl, Erik Lundberg and Kira Pronin. 2019. "SNS Research Brief 59. The Swedish Commissions of Inquiry 1990-2016.".

Dahlström, Carl, Erik Lundberg and Kira Pronin. 2020. "No More Compromise? Swedish Commissions of Inquiry 1990-2016.".

Dalton, Russell J. 2008. "The Quantity and the Quality of Party Systems: Party System Polarization, Its Measurement, and Its Consequences." Comp. Polit. Stud. 41(7):899-920.

Diermeier, D. and K. Krehbiel. 2003. "Institutionalism as a Methodology." J. Theor. Polit. $15(2): 123-144$.

Donnison, David. 1968. "Committees and Committeemen." New Soc. 11(290):558 - 561.

Downs, Anthony. 1957. An Economic Theory of Democracy. New York: Harper and Routledge. 
Epstein, David F. and Sharyn O'Halloran. 1994. "Administrative Procedures, Information, and Agency Discretion." Am. J. ofPolitical Sci. 38(3):697-722.

Farson, Stuart and Mark Phythian, eds. 2010. Commissions of Inquiry and National Security: Comparative Approaches. Praeger.

Ferejohn, John. 1986. "Incumbent Performance and Electoral Control." Public Choice 50:525.

Fung, Archon. 2013. The Principle of Affected Interests: An Interpretation and Defense. In Represent. Elections Beyond, ed. Jack H. Nagel and Rogers M. Smith. Philadelphia: University of Pennsylvania Press.

Gilligan, Thomas W. and Keith Krehbiel. 1987. "Collective Decisionmaking and Standing Committees: An Informational Rationale for Restrictive Amendment Procedures." J. Law, Econ. Organ. 3(2):287 - 335 .

Gilligan, Thomas W. and Keith Krehbiel. 1989. "Asymmetric Information and Legislative Rules with a Heterogeneous Committee." Am. J. Pol. Sci. 33:459-490.

Gilligan, Thomas W. and Keith Krehbiel. 1990. "Organization of Informative Committees by a Rational Legislature." Polit. Sci. 34(2):531-564.

Giuliani, Marco. 2016. "Patterns of Democracy Reconsidered: The Ambiguous Relationship between Corporatism and Consensualism." Eur. J. Polit. Res. 55(1):22-42.

Goodin, Robert E. 2007. "Enfranchising All Affected Interests, and Its Alternative." Philos. Public Aff. 36(1):40-68.

Gosnell, Harold F. 1934. "British Royal Commissions of Inquiry." Polit. Sci. Q. 49(1):84-118.

Granato, Jim, Melody Lo and M. C.S. Wong. 2010. "A Framework for Unifying Formal and Empirical Analysis." Am. J. Pol. Sci. 54(3):783-797.

Gross, Donald A. and Lee Sigelman. 1984. "Comparing Party Systems: A Multidimensional Approach." Comp. Polit. 16(4):463-479.

Hammond, Thomas H. and Jack H. Knott. 1996. "Who Controls the Bureaucracy?: Presidential Power, Congressional Dominance, Legal Constraints, and Bureaucratic Autonomy in a Model of Multi-Institutional Policy-Making." J. Law, Econ. Organ. 12(1):119-166.

Hedborg, Anna. 1998. Ds 1998:57 Kommittéerna och bofinken. Får en kommitté se ut hur som helst. Technical report.

Hermansson, Jörgen. 1993. Politik som intressekamp. Stockholm: Norstedts.

Hermansson, Jörgen, Torsten Svensson and PerOla Öberg. 1997. "Vad blev det av den svenska korporativismen?" Politica 29:365-384. 
Hesslén, Gunnar. 1927. Det svenska kommittéväsendet intill år 1905: dess uppkomst, ställning och betydelse. Uppsala.

Hesstvedt, Stine and Peter Munk Christiansen. 2020. The Politics of Policy Inquiry: How Political Factors Affect Appointments of Policy Inquiry Commissions in Norway and Denmark, 1971-2017. Working paper.

Hirsch, Alexander V. and Kenneth W. Shotts. 2012. "Policy-Specific Information and Informal Agenda Power." Am. J. Pol. Sci. 56(1):67-83.

Hogwood, Brian W. and B. Guy Peters. 1985. The Pathology of Public Policy. Oxford University Press, USA.

Inwood, Gregory J. and Carolyn M. Johns. 2018. "13 Commissions of Inquiry and Policy Change: A Comparative Analysis." Can. Public Adm. 59(3):382-404.

Inwood, Gregory J. and Carolyn M. Johns, eds. 2014. Commissions of Inquiry and Policy Change: A Comparative Analysis. University of Toronto Press.

Johansson, F. 1979. Offentliga utredningars genomslag i politiska beslut. Report 1979:12. Technical report Institute of Political Science: University of Gothenburg.

Johansson, Jan. 1992. Det statliga kommittéväsendet: kunnskap, kontroll, konsensus PhD thesis University of Stockholm.

Kiewiet, D. Roderick and Mathew D. McCubbins. 1991. The Logic of Delegation. Chicago: University of Chicago Press.

Krehbiel, Keith. 1991. Information and Legislative Organization. University of Michigan Press.

Lewin, Leif. 1998. "Majoritarian and Consensus Democracy: The Swedish Experience." Scan. Polit. Stud. 21(3):195-206.

Lindvall, Johannes and Bo Rothstein. 2006. "Sweden: The Fall of the Strong State." Scan. Polit. Stud. 29(1):47-63.

Lindvall, Johannes, Hanna Bäck, Carl Dahlström, Elin Naurin and Jan Teorell. 2017. Samverkan och strid $i$ den parlamentariska demokratin. Stockholm: SNS Förlag.

Lindvall, Johannes, Hanna Bäck, Carl Dahlström, Elin Naurin and Jan Teorell. 2020. "Sweden's Parliamentary Democracy at 100." Parliam. Aff. 73(3).

Lindvall, Johannes and Joakim Sebring. 2005. "Policy Reform and the Decline of Corporatism in Sweden." West Eur. Polit. 28(5):1057-1074.

Lockwood, Thomas. 1967. "A History of Royal Commissions." Osgoode Hall Law J. 5(2):172209. 
Londregan, John. 2000. Legislative Institutions and Ideology in Chile. Cambridge University Press: Cambridge.

Lundberg, Erik. 2012. "Changing Balance: The Participation and Role of Voluntary Organisations in the Swedish Policy Process." Scan. Polit. Stud. 35(4):347-371.

Marier, Patrik. 2009. "The Power of Institutionalized Learning: The Uses and Practices of Commissions to Generate Policy Change." J. Eur. Public Policy 16(8):1204-1223.

Martin, Cathie Jo. 2013. Conditions for Successful Negotiation: Lessons from Europe. In Negot. Agreem. Polit., ed. Jane Mansbridge, Cathie Jo Martin, Sarah Binder, Frances Lee, Nolan Mccarty, John Odell, Dustin Tingley and Mark Warren. American Political Science Association Task Force Report chapter 1, pp. 121-143.

McEachern, William. 1987. "Federal Advisory Commissions in an Economic Model of Representative Democracy." Public Choice 54(1):41-62.

McKelvey, Richard D. 1976. "Intransitivities in Multidimensional Voting Models and Some Implications for Agenda Control." J. Econ. Theory 12(3):472-482.

Meijer, Hans. 1956. Kommittépolitik och kommittéarbete : det statliga kommittéväsendets utvecklingslinjer 1905-1954 samt nuvarande funktion och arbetsformer. Gleerup.

Meijer, Hans. 1969. "Bureaucracy and Policy Formulation in Sweden." Scan. Polit. Stud. 4:103-116.

Milgrom, Paul R and John Roberts. 1986. "Relying on the Information of Interested Parties." RAND J. Econ. 17(1):18-32.

Mitnick, Barry M. 1992. The Theory of Agency and Organizational Analysis. In Ethics Agency Theory An Introd., ed. Norman M. Bowie and R. Edward Freeman. New York: Oxford University Press pp. 75-96.

Mylovanov, Tymofiy. 2008. "Veto-Based Delegation." J. Econ. Theory 138(1):297-307.

Niskanen, William A. 1971. Bureaucracy and Representative Government. Transaction Publishers.

Öberg, PerOla. 2002. "Does Administrative Corporatism Promote Trust and Deliberation?" Gov. An Int. J. Policy Adm. 15(4):455-475.

Öberg, PerOla. 2016. Interest Organizations in the Policy Process: Interest Advocacy and Policy Advice. In Oxford Handb. Swedish Polit., ed. Jon Pierre. Oxford: Oxford University Press pp. 663-678.

Öberg, PerOla, Peter Munk Christiansen, Asbjørn Sonne Nørgaard, Hilmar Rommetvedt, Gunnar Thesen, Torsten Svensson, Peter Munk Christiansen, Asbjørn Sonne Nørgaard, 
Hilmar Rommetvedt and Gunnar Thesen. 2011. "Disrupted Exchange and Declining Corporatism: Government Authority and Interest Group Capability in Scandinavia." Gov. Oppos. 46(3):365-391.

Peachment, Alan, ed. 2006. The Years of Scandal: Commissions of Inquiry in Western Australia, 1991-2004. University of Western Australia Press.

Peters, B. Guy. 1996. Political Institutions, Old and New. In A New Handb. Polit. Sci., ed. Robert E. Goodin and Hans-Dieter Klingemann. Oxford University Press Inc., New York chapter 7, pp. 180-205.

Peters, B. Guy. 2001. The Politics of Bureaucracy. 5th ed. Rutledge.

Petersson, Olof. 2016. "Rational Politics: Commissions of Inquiry and the Referral System in Sweden." Oxford Handb. Swedish Polit. pp. 1-18.

Prasser, Gavin Scott. 2003. A Study of Commonwealth Public Inquiries PhD thesis Griffith University (School of Politics and Public Policy).

Prasser, Scott. 2014. Royal Commissions and Public Inquiries: Practice and Potential. In $R$. Comm. Public Inq. Pract. Potential, ed. Scott Prasser and Helen Tracey. Connor Court Publishing pp. 1-4.

Premfors, Rune. 1983. "Governmental Commissions in Sweden." Am. Behav. Sci. 26(5):623642.

Raudenbush, S.W. and A.S. Bryk. 2001. Hierarchical Linear Models: Applications and Data Analysis Methods. 2nd ed. ed. Thousand Oaks, CA: Sage Publications.

Rommetvedt, H., G. Thesen, P. M. Christiansen and A. S. Norgaard. 2012. "Coping with Corporatism in Decline and the Revival of Parliament: Interest Group Lobbyism in Denmark and Norway, 1980-2005." Comp. Polit. Stud. 46(4):457-485.

Rothstein, Bo and Jonas Bergström. 1999. Korporatismens fall och den svenska modellens kris. SNS Förlag, Stockholm.

Rowe, Mike and Laura Mcallister. 2006. "The Roles of Commissions of Inquiry in the Policy Process." Public Policy Adm. 21(4):99-115.

Rustow, Dankwart A. 1955. Politics of Compromise. Princeton, NJ: Princeton University Press.

Salter, L. 2003. The Complex Relationship between Inquiries and Public Controversy. In Comm. Inq. Praise or Reappraise?, ed. A. Manson and D. Mullan. Toronto: Irwin Law pp. 185-209.

Särlvik, B. 1966. "Political Stability and Change in the Swedish Electorate." Scan. Polit. Stud. 1:188-222. 
Sartori, Giovanni. 2005. Parties and Party Systems: A Framework for Analysis (Reprint of 1976 edition). ECPR press.

Shapiro, Ian. 2003. The State of Democratic Theory. Princeton, NJ: Princeton University Press.

Shepsle, Kenneth A. 1979. "Institutional Arrangements and Equilibrium in Multidimensional Voting Models." Am. J. Pol. Sci. 23(1):27-59.

Shepsle, Kenneth A. and Barry P. Weingast. 1987. "The Institutional Foundations of Committee." Am. Polit. Sci. Rev. 81(1):85-104.

Sheriff, Peta E. 1983. "State Theory, Social Science, and Governmental Commissions." Am. Behav. Sci. 26(5):669-680.

Siaroff, A. 1999. "Corporatism in 24 Industrial Democracies: Meaning and Measurement." Eur. J. Polit. Res. J. Polit. Res. 36:175-205.

Stigler, G.J. 1963. The Intellectual and the Marketplace and Other Essays. New York: The Free Press of Glencoe.

Stokes, Donald E. 1963. "Spatial Models of Party Competition." Am. Polit. Sci. Rev. $57(2): 368-377$.

Sulitzeanu-Kenan, R. 2006. "If They Get It Right: An Experimental Test of the Effects of the Appointment and Reports of UK Public Inquiries." Public Adm. 84:623-653.

Sulitzeanu-Kenan, R. 2010. "Reflection in the Shadow of Blame: When Do Politicians Appoint Commissions of Inquiry?" Br. J. Polit. Sci. 40(3):613-634.

Sulitzeanu-Kenan, Raanan and Yifat Holzman-Gazit. 2016. "Form and Content: Institutional Preferences and Public Opinion in a Crisis Inquiry." Adm. Soc. 48(1):3-30.

Tama, Jordan. 2014. "Crises, Commissions, and Reform: The Impact of Blue-Ribbon Panels." Polit. Res. Q. 67(1):152-164.

Tama, Jordan. 2016. "Independent Commissions as Settings for Civil-Military Deliberation: The Case of Women in the Military." Armed Forces Soc. 42(2):407-426.

Tingsten, Herbert. 1940. "Problem i svensk demokrati I: Vår parlamentarism." Tiden $32(1): 25-32$.

Tsebelis, George. 1995. "Decision Making in Political Systems: Veto Players in Presidentialism, Parliamentarism, Multicameralism and Multipartyism." Br. J. Polit. Sci. 25(3):289325.

Tsebelis, George. 1999. "Veto Players and Law Production in Parliamentary Democracies: An Empirical Analysis." Am. Polit. Sci. Rev. 93(3):591-608. 
Tsebelis, George. 2002. Veto Players: How Political Institutions Work. Princeton, NJ: Princeton University Press.

Volkens, Andrea, Werner Krause, Pola Lehmann, Theres Matthieß, Nicolas Merz, Sven Regel and Bernhard Weßels. 2019. "The Manifesto Data Collection. Manifesto Project (MRG/CMP/MARPOR). Version 2019b.".

URL: https://doi.org/10.25522/manifesto.mpds.2019b

Warren, Mark E and Jane Mansbridge. 2013. Deliberative Negotiation. In Negot. Agreem. Am. Polit. American Political Science Association Task Force Report pp. 86-120.

Waterman, Richard W and Kenneth J Meier. 1998. "Principal-Agent Models: An Expansion?" J. Public Adm. 8(2):173-202.

Wicksell, Knut. 1896. Finanztheoretische Untersuchungen (Investigations in the Theory of Public Finance). Jena: Gustav Fischer Verlag.

Zetterberg, Kent. 1990. Det statliga kommittéväsendet. In Att styra riket. Stockholm: Allmänna förlaget. 